2016-09

\title{
Brain health: time matters in multiple sclerosis
}

Giovannoni, G

http://hdl.handle.net/10026.1/5548

10.1016/j.msard.2016.07.003

Multiple Sclerosis and Related Disorders

Elsevier BV

All content in PEARL is protected by copyright law. Author manuscripts are made available in accordance with publisher policies. Please cite only the published version using the details provided on the item record or document. In the absence of an open licence (e.g. Creative Commons), permissions for further reuse of content should be sought from the publisher or author. 


\section{Brain health: time matters in multiple sclerosis}

Gavin Giovannoni, ${ }^{a}$ Helmut Butzkueven, ${ }^{b}$ Suhayl Dhib-Jalbut, ${ }^{c}$ Jeremy Hobart, ${ }^{d}$ Gisela Kobelt, ${ }^{e}$ George Pepper, ${ }^{\dagger}$ Maria Pia Sormani,, 9 Christoph Thalheim ${ }^{\mathrm{h}}$ Anthony Traboulsee, ${ }^{,}$Timothy Vollmer

\section{[MSARD ask for an email address as part of the affiliation. Please check that this is the address you would like to provide.]}

aQueen Mary University London, Blizard Institute, Barts and The London School of Medicine and Dentistry, London, UK. g.giovannoni@qmul.ac.uk

bMelbourne Brain Centre, Royal Melbourne Hospital, University of Melbourne, Parkville, Australia. butz@unimelb.edu.au

'Department of Neurology, RUTGERS-Robert Wood Johnson Medical School, New Brunswick, NJ, USA. jalbutsu@rwjms.rutgers.edu

dPlymouth University Peninsula Schools of Medicine and Dentistry, Plymouth, UK. jeremy.hobart@plymouth.ac.uk

eEuropean Health Economics, Mulhouse, France. kobelt.gisele@wanadoo.fr

fShift.ms, Leeds, UK. george@shift.ms

9Biostatistics Unit, University of Genoa, Genoa, Italy. mariapia.sormani@unige.it

hPatient Advocate in Multiple Sclerosis, Brussels, Belgium. christoph.thalheim@emsp.org

'Department of Medicine, University of British Columbia, Vancouver, BC, Canada. t.traboulsee@ubc.ca

iDepartment of Neurology, University of Colorado Denver, Aurora, CO, USA.

Timothy.Vollmer@ucdenver.edu

Corresponding author: Gavin Giovannoni, g.giovannoni@qmul.ac.uk 
This is an author's draft of an accepted article submitted and

published in Multiple Sclerosis and Related Disorders

DOI : http://www.sciencedirect.com/science/article/pii/S221103481630102X

\section{Abstract}

\section{Introduction}

We present international consensus recommendations for improving diagnosis, management and treatment access in multiple sclerosis (MS). Our vision is that these will be used widely among those committed to creating a better future for people with MS and their families.

\section{Methods}

Structured discussions and literature searches conducted in 2015 examined the personal and economic impact of MS, current practice in diagnosis, treatment and management, definitions of disease activity and barriers to accessing disease-modifying therapies (DMTs).

\section{Results}

Delays often occur before a person with symptoms suggestive of MS sees a neurologist. Campaigns to raise awareness of MS are needed, as are initiatives to improve access to MS healthcare professionals and services.

We recommend a clear treatment goal: to maximize neurological reserve, cognitive function and physical function by reducing disease activity. Treatment should start early, with DMT and lifestyle measures. All parameters that predict relapses and disability progression should be included in the definition of disease activity and monitored regularly when practical. On suboptimal control of disease activity, switching to a DMT with a different mechanism of action should be considered. A shared decision-making process that embodies dialogue and considers all appropriate DMTs should be implemented. Monitoring data should be recorded formally in registries to generate real-world evidence.

In many jurisdictions, access to DMTs is limited. To improve treatment access the relevant bodies should consider all costs to all parties when conducting economic evaluations and encourage the continuing investigation, development and use of cost-effective therapeutic strategies and alternative financing models.

\section{Conclusions}

The consensus findings of an international author group recommend a therapeutic strategy based on proactive monitoring and shared decision-making in MS. Early diagnosis and improved treatment access are also key components. 


\section{Abbreviations}

\begin{tabular}{|c|c|}
\hline AAN & American Academy of Neurology \\
\hline ABN & Association of British Neurologists \\
\hline AUD & Australian dollars \\
\hline CIS & clinically isolated syndrome \\
\hline CNS & central nervous system \\
\hline DMT & disease-modifying therapy \\
\hline EDSS & Kurtzke Expanded Disability Status Scale \\
\hline EMA & European Medicines Agency (the European regulatory authority) \\
\hline EUReMS & European Register for Multiple Sclerosis \\
\hline FDA & Food and Drug Administration (the US regulatory authority) \\
\hline GP & general practitoner (family or primary care physician) \\
\hline HTA & health technology assessment \\
\hline MoA & mechanism of action \\
\hline MRI & magnetic resonance imaging \\
\hline MS & multiple sclerosis \\
\hline NEDA & no evidence of disease activity \\
\hline NRSPMS & non-relapsing secondary progressive multiple sclerosis \\
\hline PPMS & primary progressive multiple sclerosis \\
\hline QALY & quality-adjusted life year \\
\hline RICT & randomized controlled trial \\
\hline RIS & radiologically isolated syndrome \\
\hline RRMS & relapsing-remitting multiple sclerosis \\
\hline RSPMS & relapsing secondary progressive multiple sclerosis \\
\hline RWE & real-world evidence \\
\hline SPMS & secondary progressive multiple sclerosis \\
\hline US\$ & US dollars \\
\hline$€$ & euros \\
\hline
\end{tabular}

In this report, the term established DMTs refers to disease-modifying therapies approved for relapsing forms of MS during the 1990s, and to reformulations and generic versions of these substances.

In this report, the term newer DMTs refers to disease-modifying therapies approved for relapsing forms of MS after the 1990s that have different mechanisms of action from established DMTs; some newer DMTs have an evidence base supporting efficacy superior to that of an established DMT, which may include head-to-head clinical trials or real-world evidence. 
This is an author's draft of an accepted article submitted and published in Multiple Sclerosis and Related Disorders

DOI : http://www.sciencedirect.com/science/article/pii/S221103481630102X

\section{Graphical abstract}

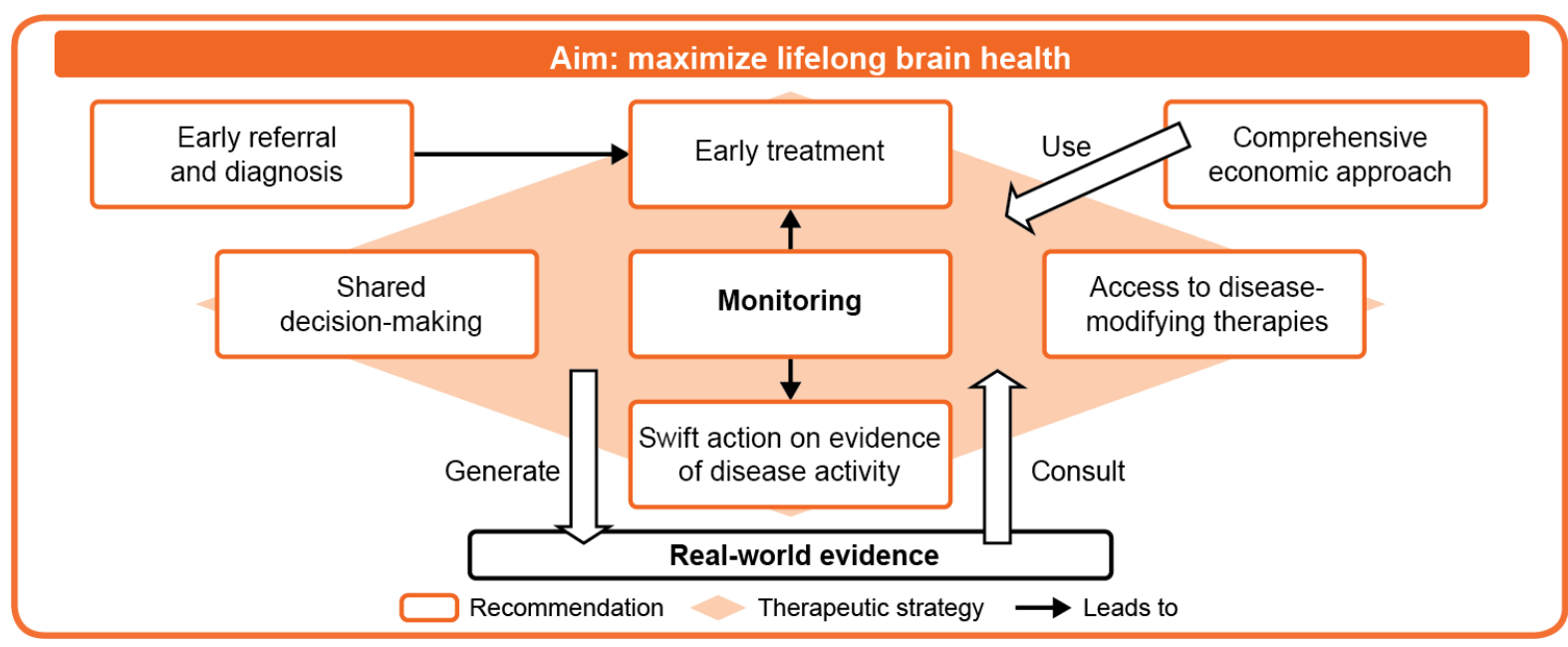

\section{Keywords}

multiple sclerosis

consensus statement

treatment strategy

disease activity

disease-modifying therapy (DMT)

magnetic resonance imaging (MRI)

\section{Highlights}

- Consensus recommendations on MS diagnosis, management and treatment are presented.

- Neurological reserve, a component of brain health, can compensate for CNS damage.

- We propose a therapeutic strategy that aims to maximize lifelong brain health.

- Proactive monitoring, shared decision-making and improved treatment access are key.

- Early referral, diagnosis and treatment initiation are also of crucial importance. 


\section{Disclosures [authors - please check your disclosures]}

G Giovannoni has received consulting fees from AbbVie, Bayer HealthCare, Biogen, Canbex Therapeutics, Five Prime Therapeutics, Genzyme-Sanofi, GlaxoSmithKline, GW Pharma, Merck, Merck Serono, Novartis, Oxford PharmaGenesis, Protein Discovery Laboratories, Roche, Synthon, Teva Neuroscience and UCB; and has received grant/research support from Bayer HealthCare, Biogen, Genzyme-Sanofi, Merck, Merck Serono and Novartis.

$\mathrm{H}$ Butzkueven has received consulting fees from Biogen, Genzyme, Merck, Novartis, and Oxford PharmaGenesis; and has received grant/research support from Biogen, Genzyme, Merck and Novartis.

S Dhib-Jalbut has received consulting fees from Bayer, Genentech, Genzyme, Oxford PharmaGenesis, Serono and Teva; and has received grant/research support from Biogen and Teva Pharmaceuticals.

$\mathrm{J}$ Hobart has received consulting fees, honoraria, support to attend meetings or research support from Acorda, Asubio, Bayer Schering, Biogen Idec, Genzyme, Merck Serono, Novartis, Teva, Oxford PharmaGenesis and F. Hoffmann-La Roche.

G Kobelt has received consulting fees from Biogen, Merck Serono, Novartis, Oxford PharmaGenesis, Sanofi Genzyme and Teva.

G Pepper has received consulting fees from Biogen, Novartis, Oxford PharmaGenesis and Teva.

MP Sormani has received consulting fees from Biogen, Genzyme, Merck Serono, Oxford PharmaGenesis, Teva, Novartis, Roche and Vertex; and has received grant/research support from Biogen and Merck Serono.

C Thalheim has acted as a speaker and adviser on non-product-specific subjects for Almirall, Bayer, Biogen, GSK, Novartis, Roche, Synthon and Teva; and has received consulting fees from Oxford PharmaGenesis.

A Traboulsee has received consulting fees from Biogen, Genzyme, Roche, Oxford PharmaGenesis and Teva; and has received grant/research support as a PI on clinical trials with Biogen, Chugai, Genzyme and Roche.

T Vollmer has received consulting fees from AbbVie, Acorda, Biogen Idec, Consortium of MS Centers, DeltaQuest, Genentech, Novartis, Novartis Canada, Novartis Japan, Oxford PharmaGenesis, Roche, Teva and Teva Canada; and has received grant/research support from Biogen Idec, EMD Serono, Genzyme, NIH, Novartis, Ono, Roche, Rocky Mountain MS Center and Teva. 


\section{Preface}

This report presents an expert, evidence-based position for policy recommendations aimed at improving outcomes for people with multiple sclerosis (MS). It summarizes the evidence and consensus findings from the structured discussions of a global author group, comprising clinicians, researchers, specialist nurses, health economists and representatives from patient groups, all with expertise and experience in the area of MS.

In summarizing the available data, this report:

- demonstrates the personal and economic impact of MS (Section 1)

- examines the reasons behind delays in diagnosis (Section 2)

- presents the evidence base for a therapeutic strategy that aims to maximize lifelong brain health, centred around a more urgent approach to management, which involves:

- early intervention with therapies most likely to provide optimal benefit and safety for each person with MS on an individualized basis (Section 3)

- regular monitoring of disease activity and safety parameters (Section 4)

- $\quad$ switching therapy based on evidence of disease activity (Section 5)

- provides guidance on how to improve access to treatment in order to create the optimal environment for this therapeutic strategy (Section 6).

Our vision is that the report and its recommendations will be used widely among those committed to creating a better future for people with MS and their families. Healthcare professionals, patient groups, healthcare authorities, health technology assessors, insurance companies, payers, regulatory authorities, government bodies, pharmaceutical companies and other relevant stakeholders who influence care quality can affect these outcomes; all have a responsibility to strive towards the highest possible standards of care. 
This is an author's draft of an accepted article submitted and

published in Multiple Sclerosis and Related Disorders

DOI : http://www.sciencedirect.com/science/article/pii/S221103481630102X

\section{Executive summary}

Multiple sclerosis (MS) is an incurable chronic disease in which the body's own immune system destroys tissue in the brain and spinal cord. It is the leading cause of non-traumatic disability among young and middle-aged adults in many developed countries, and it affects 2.3 million people worldwide (Multiple Sclerosis International Federation, 2013a). Although there is no cure for MS, therapies exist that can alter the disease course by reducing disease activity and slowing down the accumulation of disability. This report recommends specific actions that aim to achieve the best possible outcome for every person with MS (Appendix A).

A therapeutic strategy that offers the best chance of preserving brain and spinal cord tissue early in the disease course needs to be widely accepted - and urgently adopted (Figure A.1). Even in the early stages of MS, cognition, emotional well-being, quality of life, day-to-day activities and ability to work can be markedly affected by the damage occurring in the brain and spinal cord. As the disease progresses, increasing disability - such as difficulties in walking - imposes a heavy burden on people with MS and on their families. It also leads to substantial economic losses for society, owing to diminished working capacity.

Significant delays often occur before a person with symptoms suggestive of MS sees a neurologist for diagnosis and treatment. This is despite diagnosis being 10 times more rapid now than in the 1980s (Marrie et al., 2005) and substantial evidence that early treatment is more effective than later treatment. Campaigns to raise awareness of MS among the general public and among clinicians who make referrals are urgently needed, as they have the potential to improve outcomes by enabling earlier diagnosis. Initiatives to improve access to specialist MS healthcare professionals and specialized diagnostic procedures are also needed.

Early intervention is vital. Appropriate lifestyle interventions, treatment with a therapy that can reduce disease activity and consideration of rapid switching to another therapy if monitoring reveals a suboptimal response are crucial elements of the strategy. Involving people with MS proactively in decision-making and in managing their disease is also key to the successful management of MS. Healthcare professionals should encourage those in their care to play a fully informed, shared role in treatment decisions and to live a 'brain-healthy' lifestyle.

Regular monitoring of disease activity and recording this information formally are the cornerstone of the strategy recommended by the authors. The results of clinical examinations and brain scans will enable personalized treatment for every person with MS and will generate longterm real-world evidence that can be used by regulatory bodies, health technology assessors, payers and clinicians for evaluating therapeutic strategies.

Offering the full range of therapies that can reduce disease activity improves the chance of finding the best option for each person with MS. The number of effective therapies continues to grow, providing increasing scope to tailor treatment to individual needs. In many jurisdictions, however, access to therapies is limited by licensing stipulations, prescribing guidelines or reimbursement decisions; these typically lag behind the most recent clinical trial data and real-world evidence. We therefore call on regulatory bodies, healthcare authorities, insurance companies, health technology assessors and payers to improve access to therapies, so that personalized treatment can be optimized. We also recommend that the relevant bodies consider all costs to all parties when conducting economic evaluations and that they encourage the continuing investigation, development and use of cost-effective therapeutic strategies and alternative financing models.

Major public policy changes are needed in order to translate recent advances in the diagnosis and treatment of MS into improved outcomes. Enabling and promoting widespread adoption of the therapeutic strategy for MS recommended in this report has the potential to minimize disease activity 
This is an author's draft of an accepted article submitted and published in Multiple Sclerosis and Related Disorders

DOI : http://www.sciencedirect.com/science/article/pii/S221103481630102X

and maximize lifelong brain health for those with the disease. It is time to make a real difference to the lives of people with MS and their families - and to avoid many of the long-term economic and personal costs that result from unnecessary irreversible disability. 


\section{Endorsements}

The organizations listed below endorse the recommendations made in this report.

- Accelerated Cure Project for Multiple Sclerosis

- ACTRIMS (Americas Committee for Treatment and Research in Multiple Sclerosis)

- BCTRIMS (Brazilian Committee for Treatment and Research in Multiple Sclerosis)

- Consortium of Multiple Sclerosis Centers

- Czech MS Society (Unie ROSKA)

- ECTRIMS (European Committee for Treatment and Research in Multiple Sclerosis)

- European Brain Council

- European Multiple Sclerosis Platform

- International Organization of Multiple Sclerosis Nurses

- International Society of Neuroimmunology

- LACTRIMS (Latin-American Committee for Treatment and Research in Multiple Sclerosis)

- MENACTRIMS (Middle East North Africa Committee for Treatment and Research in Multiple Sclerosis)

- MexCTRIMS (Mexican Committee for Treatment and Research in Multiple Sclerosis)

- Multiple Sclerosis Australia

- Multiple Sclerosis International Federation

- Multiple Sclerosis Ireland

- Multiple Sclerosis Research Australia

- Multiple Sclerosis Society

- Multiple Sclerosis Society of Canada

- Multiple Sclerosis Society of Norway (Multippel Sklerose Forbundet)

- Multiple Sclerosis Trust

- National Multiple Sclerosis Society

- PACTRIMS (Pan-Asian Committee for Treatment and Research in Multiple Sclerosis)

- RUCTRIMS (Russian Committee for Treatment and Research in Multiple Sclerosis)

- SFSEP (Société Francophone de la Sclérose en Plaques)

- Shift.ms 


\section{Raise awareness of the global burden of multiple sclerosis}

\section{Key points}

- In multiple sclerosis (MS), tissue in the brain, spinal cord and optic nerve is destroyed by the body's own immune system, often leading to physical disability and cognitive impairment.

- MS typically affects young adults in the prime of life. For many, bouts of symptoms (relapses), disability progression, fatigue and cognitive impairment markedly reduce their quality of life and ability to work or study.

- As disability worsens, personal and economic costs soar. Most of this additional burden falls on people with MS and on family members, many of whom become lifelong caregivers.

- Early and appropriate treatment can markedly reduce disease activity and accumulation of disability, but there is currently no cure for MS.

\subsection{Multiple sclerosis affects young adults worldwide}

MS is a progressive neurodegenerative disease that typically affects young adults in the prime of life, causing irreversible physical and mental disability. It is the leading cause of non-traumatic disability among young and middle-aged people in many developed countries (Multiple Sclerosis International Federation, 2013a). MS is the most common cause of wheelchair use among those aged 18-64 years (Kaye et al., 2000), and the third most common cause of paralysis (after stroke and spinal cord injury) across all age groups (Cahill et al., 2009) in the USA. The disease thus negatively affects the lives of people with MS and their families, and leads to large, long-term health and economic burdens.

Globally, the estimated number of people with MS has increased from 2.1 million in 2008 (World Health Organization, 2008) to 2.3 million in 2013 (Multiple Sclerosis International Federation, 2013a). Better reporting and diagnosis (Multiple Sclerosis International Federation, 2013a) and improved survival (Marrie et al., 2010b) may have contributed to this change, although the disease has been shown to be on the increase in a UK population (Hirst et al., 2009). MS is found worldwide but it becomes more common with increasing distance from the equator, particularly in the northern hemisphere (Simpson et al., 2011). It is most prevalent in North America, Europe, Australia, New Zealand (Multiple Sclerosis International Federation, 2013a), other countries with Caucasian populations (Multiple Sclerosis International Federation, 2013i) and Iran (Etemadifar et al., 2013). The causes of MS are unclear, but risk is partially determined by a complex interaction between genetic (Robertson et al., 1996; Carton et al., 1997; Willer et al., 2003; De Jager et al., 2009) and environmental (Martyn et al., 1993; Levin et al., 2005; Handunnetthi et al., 2010; Levin et al., 2010; Solomon and Whitham, 2010; Handel et al., 2011; Simpson et al., 2011; Torkildsen et al., 2012; Disanto et al., 2013; Berg-Hansen et al., 2014; Breuer et al., 2014; Fiddes et al., 2014; Spelman et al., 2014; Torkildsen et al., 2014; Marsh-Wakefield and Byrne, 2015) factors.

Typically, MS is diagnosed in young, active people in their 20s or 30s (Compston and Coles, 2002), and about two-thirds of those affected are women (Multiple Sclerosis International Federation, 2013a). MS therefore affects people with the potential for many decades of employment ahead of them, who also may be making decisions about starting and raising families. 


\subsection{Multiple sclerosis is progressive and irreversible}

\subsubsection{Brain tissue is damaged and brain volume is lost}

In MS, the immune system mistakenly attacks and damages tissue in the brain, spinal cord and optic nerve, collectively known as the central nervous system (CNS). This results in lesions (areas of acute injury) that can be seen in a brain scan or post-mortem examination, as well as diffuse damage that is more difficult to observe (Filippi and Rocca, 2005). Although repair mechanisms operate in the CNS, repair is often incomplete, some nerve tissue is irreversibly destroyed and the brain begins to atrophy (decrease in volume) more rapidly than in people unaffected by MS (Trapp et al., 1999; De Stefano et al., 2001; Kuhlmann et al., 2002; Schirmer et al., 2009; De Stefano et al., 2010; Sbardella et al., 2013).

In healthy adults, a small amount of brain atrophy occurs with ageing - in the region of $0.1-0.5 \%$ per year (De Stefano et al., 2016). However, in many people with untreated MS the brain typically atrophies at a much higher rate, at about 0.5-1.35\% per year (Figure 1) (De Stefano et al., 2014a; De Stefano et al., 2016). Accelerated brain atrophy starts early, often before a diagnosis of MS (Figure 2a), and proceeds throughout the course of the disease if left untreated (De Stefano et al., 2010). The goal of treating MS should be to prevent damage to the brain and spinal cord that leads to accelerated atrophy.

\subsubsection{Symptom burden worsens as damage to the brain accumulates}

The brain appears to have an inbuilt neurological reserve - a finite capacity to retain function by remodelling itself to compensate for loss of nerve cells, loss of nerve fibres and atrophy. It does this partly by rerouting signals via undamaged areas or adapting undamaged areas to take on new functions (Rocca et al., 2003; Rocca and Filippi, 2007). This ability is present in addition to the mechanisms that exist to repair physical damage to the CNS. Neurological reserve and repair mechanisms explain why MS-related brain damage may go undetected during the early phase of the disease - and therefore why MS may be undiagnosed and untreated for a long time. There is evidence that cognitive impairment is present in a significant proportion of people before the clinical symptoms of MS appear - sometimes years before (Sinay et al., 2015). It is therefore important to diagnose MS as early as possible (Section 2), before neurological reserve is exhausted and the progressive stage of the disease begins (Figure $\mathbf{2 b}$ ).

Usually, damage to the CNS is first detected when clinical symptoms appear. Symptoms may take the form of an attack (known as a relapse, or bout), when a lesion develops in a location that noticeably disrupts nerve function, although most lesions ( 90\%) do not directly lead to relapses (Figure 2c, 2d) (Barkhof et al., 1992; Kappos et al., 1999). Clinically evident progression of symptoms can also occur from the onset if neurological reserve is exhausted before a relapse occurs; however, progressive disease most often manifests after a period of relapses and remissions. Occasionally, lesions are detected before any clinical symptoms appear, on a brain scan (Okuda et al., 2009) that is conducted for another purpose (for example, headaches).

The range of symptoms experienced by a person with MS (Figure 3) (Compston and Coles, 2008; Giovannoni et al., 2012) can depend on the locations of lesions in the CNS. The most common clinical symptoms reported when first visiting a healthcare professional are sensory ( $40 \%$ of people with MS; numbness, tingling, burning pain), motor (39\% of people with MS; weakness, stiffness, clumsiness, difficulty with walking), visual (30\%) and fatigue (30\%; a feeling of lacking physical or mental energy that interferes with usual or desired activities) (Multiple Sclerosis International Federation, 2013a). 
This is an author's draft of an accepted article submitted and

published in Multiple Sclerosis and Related Disorders

DOI : http://www.sciencedirect.com/science/article/pii/S221103481630102X

\section{First-person account (Mayo Clinic, 2010)}

The fine motor coordination in my left hand was affected, at times my speech was slurred, and the stiffness in my legs made walking extremely tiring and difficult ... . I had gone from a very healthy and physically active person to a very handicapped one. My whole life had changed.

With permission from Mayo Clinic

\section{First-person account (Borreani et al., 2014)}

I always need help ... . That really kills me. I've stopped going out because l'm afraid of doing it in my pants ... . I'm always scared of sudden incontinence and creating a stink.

\subsubsection{Multiple sclerosis typically involves relapses and progression}

People with brain lesions who have not yet had any clinical symptoms are said to have radiologically isolated syndrome (RIS) (Figure 2d, 2e). About one-third of people with RIS will go on to experience at least one attack of clinical symptoms within 5 years (Okuda et al., 2014). An initial attack of symptoms is known as a clinically isolated syndrome (CIS) (Figure 2d, 2e) (Miller et al., 2005). Many people (approximately $30-70 \%$ ) with CIS will develop MS, even though they may not initially meet the full diagnostic criteria for the disease (Miller et al., 2005).

About $80-90 \%$ of people with MS will initially have the relapsing-remitting form of the disease (RRMS) (Figure 2d, 2e) (Compston and Coles, 2008; Koch et al., 2010). People with RRMS experience acute (sudden) attacks of symptoms (relapses). Usually, a relapse develops over a few days, before the symptoms plateau and ease off (remit) over the following few weeks or months (Leary et al., 2005); during this time CNS repair mechanisms operate and neurological reserve is 'used up' to remodel and compensate for the damage (Rocca et al., 2003; Rocca and Filippi, 2007). Although complete physical recovery from a relapse often occurs (most likely early on) (Berkovich, 2013), relapses can also be associated with a sustained increase in disability (Lublin et al., 2003; Cutter et al., 2013). Incomplete recovery from relapses contributes to stepwise disability progression (Leary et al., 2005; Berkovich, 2013).

If and when neurological reserve and repair mechanisms are exhausted, and can no longer compensate for damage, a stage of progressive disability begins, called secondary progressive MS (SPMS) (Schwartz et al., 2013). In SPMS, disability progressively worsens (with or without relapses) (Compston and Coles, 2008; Weiner, 2009; Lublin et al., 2014), especially the ability to walk (Confavreux et al., 2000). Typically, there is an 'overlap' phase during which relapses still occur (relapsing SPMS, RSPMS), followed by progression with no relapses (non-relapsing SPMS, NRSPMS) (Figure 2d, 2e). If RRMS is left untreated, 50-60\% of people develop SPMS within 15-20 years and it takes only 14 years on average for people to become unable to walk for 100 metres unaided (Scalfari et al., 2014). In addition, about $10-15 \%$ of people with MS have a progressive disease course from the outset, with a gradual progression of clinical symptoms in the absence of relapses (known as primary progressive MS; PPMS) (Miller and Leary, 2007).

\subsubsection{Appropriate drug treatment can reduce disease activity}

The key therapeutic strategy in MS should be to minimize relapses, lesions and brain atrophy at all stages of the disease. This is especially important in early disease, when it is possible to reduce the number of new lesions and amount of brain inflammation, both of which lead to atrophy. This approach aims to maximize brain health, productivity and quality of life. 
This is an author's draft of an accepted article submitted and published in Multiple Sclerosis and Related Disorders

DOI : http://www.sciencedirect.com/science/article/pii/S221103481630102X

A number of disease-modifying therapies (DMTs) have been approved in various jurisdictions for treating CIS and relapsing forms of MS. These drugs can directly affect the disease course by reducing relapses, slowing disability progression, reducing the number of new lesions and slowing the rate of brain atrophy (Sections 3-5). To date, no DMTs have been approved for PPMS, and the only DMT to have been approved in a small number of jurisdictions for NRSPMS has since been removed from the market in the USA. Relapsing forms of MS are therefore the main focus of the DMT-related sections of this report.

\subsection{Multiple sclerosis affects all areas of life}

\subsubsection{Quality of life decreases as the disease advances}

Disability in MS is typically measured using the Kurtzke Expanded Disability Status Scale (EDSS), which allocates increasing numerical values to greater levels of physical disability $(0.0$, normal neurological functioning; 10.0, death) (Kurtzke, 1983). However many factors that affect quality of life, such as mental health, vitality (Naci et al., 2010), cognitive impairment (Zwibel and Smrtka, 2011) and fatigue (Khan et al., 2014), are either not included or are poorly measured by the EDSS. Even in the early stages of MS, cognitive impairment may result in a lower quality of life (Glanz et al., 2010), have a negative impact upon day-to-day activities (Rao et al., 1991; Kalmar et al., 2008) and lead to a reduced ability to work (Rao et al., 1991; Benedict et al., 2005). Persistent or sporadic fatigue also leads to a lower quality of life (Khan et al., 2014) (see first-person account below) and affects about $75 \%$ of all people with MS (Lerdal et al., 2007).

\section{First-person account (Multiple Sclerosis Society UK, 2015)}

What a silly word 'fatigue' is. It sounds like 'I need to have a quick sit-down on this sofa'. In reality it's more like 'I can hardly move and my brain has shut down on me, I feel like l've just had a heavy bout of flu'.

It's hard to predict when fatigue will strike. Sometimes I have to cancel meeting up with friends, or cut short a very happy outing when my energy slumps. I have to build in rest days to avoid a crash-andburn episode of fatigue. These make my diary seem fuller than it really is. 'No I can't meet on Wednesday, it's got to be a rest day'. I am lucky to have friends who are understanding of fatigue.

With permission from the Multiple Sclerosis Society

When making decisions about how healthcare resources should be allocated, it is necessary to compare how different diseases affect health-related quality of life. In the cost-effectiveness analyses that drive such decisions, a person's perspective on their state of health is measured using utility, a value between 1 (full health) and 0 (death). A number of studies have shown that people with MS report a lower utility than the general population, even early in the disease when physical disability is minimal, and that they experience a rapid decrease in utility with increasing disability (Figure 4) (Kobelt et al., 2006b; Orme et al., 2007; Kobelt et al., 2009; Naci et al., 2010; Zwibel and Smrtka, 2011).

Although advancing age can be expected to lead to a decrease in utility, people with MS in the 1829-year age group already rate their own health status lower than those aged 80 years or older in the general population do. Also, when individuals in the same age group are compared, the average utility is about $0.2-0.3$ points lower for people with MS compared with the general population (Figure 5) (Kobelt and Kasteng, 2009). 
This is an author's draft of an accepted article submitted and

published in Multiple Sclerosis and Related Disorders

DOI : http://www.sciencedirect.com/science/article/pii/S221103481630102X

\section{First-person account (Ploughman et al., 2012)}

My mother is 20 years older than I am and I can't keep up with her. I do feel that I've been cheated. I have been made an old woman before my time.

Many studies have shown that the worsening of symptoms that results from disability progression markedly affects day-to-day living and quality of life (Lobentanz et al., 2004; Kobelt et al., 2006a; Kobelt et al., 2006c; Miller and Dishon, 2006; Naci et al., 2010). The symptoms that emerge during relapses last for weeks to months and also lead to restricted mobility (Parkin et al., 2000), a temporary worsening of pain (Parkin et al., 2000), an increased risk of symptoms of depression (Moore et al., 2012), a lower quality of life and reduced function (Naci et al., 2010; Oleen-Burkey et al., 2012); these are on top of the significant symptom burden that may already have accumulated.

\subsubsection{Multiple sclerosis often results in unemployment}

Unemployment levels among people with MS are higher than those in the general population, even at low levels of physical disability (Figure 6) (Kobelt et al., 2006b; Kobelt et al., 2009; Eurostat, 2015). This suggests that the ability to work is affected early on; the most likely reasons for this are problems such as cognitive decline, fatigue, depression and anxiety, which are not fully captured by the EDSS. This observation is supported by real-world evidence (evidence obtained from outside the clinical trial setting), which indicates that cognitive impairment (Julian et al., 2008; Ruet et al., 2013) and fatigue, as well as problems with hand function and mobility (Julian et al., 2008), are associated with an increased likelihood of becoming unemployed. As physical disability progresses, the proportion of people with MS who are unemployed rises markedly (Figure 6) (Kobelt et al., 2006b; Kobelt et al., 2009; Eurostat, 2015). Case studies have shown, however, that the chances of people with MS remaining in the workforce can be improved by using approaches that focus on ability (rather than on disability), such as adapting working environments, working hours and job roles (Swiss Multiple Sclerosis Society, 2011). Indeed, a Europe-wide campaign focusing on supporting sustainable employment was launched in March 2015 by the European Multiple Sclerosis Platform (European Multiple Sclerosis Platform, 2015a).

\section{First-person account (Ploughman et al., 2012)}

One of the things that I found difficult was losing friendship because you are no longer in the workforce. It becomes a pretty lonely thing.

\subsubsection{Being a caregiver can be a lifetime commitment}

Despite the devastating impact of the disease, the life expectancy of people with MS is reduced by only 5-10 years (Bronnum-Hansen et al., 2006; Grytten Torkildsen et al., 2008; Kaufman et al., 2014; Marrie et al., 2015); this indicates that many individuals live a long time with substantial disability. As a result, nearly one-third of people with MS need care, about $80 \%$ of which is provided 'informally' by unpaid caregivers such as relatives (Hillman, 2013). As the disease progresses, the need for care gradually increases. A typical informal caregiver spends more than 4 hours per day on caring activities over many years, which is both physically and emotionally draining (Hillman, 2013). Thus, the personal costs of disability progression fall not just on people with MS but also on their families. 
This is an author's draft of an accepted article submitted and

published in Multiple Sclerosis and Related Disorders

DOI : http://www.sciencedirect.com/science/article/pii/S221103481630102X

\section{Caregiver account (Borreani et al., 2014)}

My old life has vanished. It's just me, my husband, and his disease. That's all. The disease stands between me and my husband. I used to work, now my life is dedicated to him. This is all very depressing and I don't know how long I can go on.

\subsection{Costs of multiple sclerosis soar as the disease progresses}

The total costs of MS to society include direct medical and non-medical costs, and indirect costs (Figure 7). In Europe, the overall annual cost of MS to society has been estimated at $€ 15.5$ billion. This represents an average annual cost of $€ 37000$ per person with MS (Kobelt and Kasteng, 2009), comparable with averages of $\$ 52000$ (€39000) in the USA (Kobelt et al., 2006a) and AUD 49000 $(€ 33000)$ in Australia (Palmer et al., 2013). (For ease of comparison, all monetary values in this section have been adjusted to 2010 values using the Consumer Price Index.)

This annual cost per person is greater than that for other long-term conditions such as asthma (Braman, 2006), chronic obstructive pulmonary disease (a collection of chronic lung problems) (Chapman et al., 2006; Miravitlles et al., 2013) and diabetes (American Diabetes Association, 2013). It is also greater than the annual cost per person of most other brain disorders considered by the European Brain Council in a series of economic cost estimates (Olesen et al., 2012), apart from the neuromuscular condition Guillain-Barré syndrome (which costs approximately $€ 54000$ per person (Olesen et al., 2012), about $80 \%$ of whom do not have persistent neurological problems (Walling and Dickson, 2013) - unlike in MS where accumulated disability is mostly irreversible) (Olesen et al., 2012).

As a person with MS becomes more disabled, total societal costs (detailed in Figure 7) increase significantly. In Europe, the mean annual cost per person with MS has been estimated at $€ 23000$ for EDSS score $0.0-3.5$, rising as disability increases to $€ 46000$ for EDSS score $4.0-6.5$ and $€ 77000$ for EDSS score 7.0-9.5 (Kobelt and Kasteng, 2009). Indirect costs (productivity losses associated with sick leave, incapacity to work and early retirement) - and especially informal care costs - increase dramatically with increasing disability (Figure 8) (Kobelt et al., 2006b). This additional cost burden falls largely outside of the healthcare and social care systems, and a lot of it is borne by people with MS and their families. Medicines (pharmaceuticals) comprise a relatively low proportion of total societal costs, especially at greater levels of disability (Figure 8) (Kobelt et al., 2006b).

Relapses also lead to additional costs, only about half of which are borne by the healthcare system (for example, inpatient, outpatient and professional care, consultations, tests and medicines) (Johansson et al., 2012; Karampampa et al., 2012b; Karampampa et al., 2012c; Karampampa et al., 2012d; Karampampa et al., 2012e). The cost per relapse was estimated at $€ 3400-9600$ in a series of recent European studies in people with RRMS and EDSS scores less than 5.0 (Johansson et al., 2012; Karampampa et al., 2012a; Karampampa et al., 2012b; Karampampa et al., 2012c; Karampampa et al., 2012d; Karampampa et al., 2012e; Karampampa et al., 2013; Karabudak et al., $2015)$ and at $\$ 10100(€ 7600)$ in members of a US patient support group with RRMS (Oleen-Burkey et al., 2012).

These data show that the bulk of the additional costs of disability progression and roughly half of the costs of relapses fall outside the healthcare and social care systems. However, in many countries these significant societal costs are not considered when treatments for MS are being assessed (Section 6.1).

The following sections of this report outline a therapeutic strategy that has the potential to improve outcomes for people with relapsing forms of MS by reducing relapses and disability progression. It 
This is an author's draft of an accepted article submitted and published in Multiple Sclerosis and Related Disorders

DOI : http://www.sciencedirect.com/science/article/pii/S221103481630102X

could also lead to lower formal and informal care costs and indirect costs, which escalate at higher levels of disability. 
This is an author's draft of an accepted article submitted and published in Multiple Sclerosis and Related Disorders

DOI : http://www.sciencedirect.com/science/article/pii/S221103481630102X

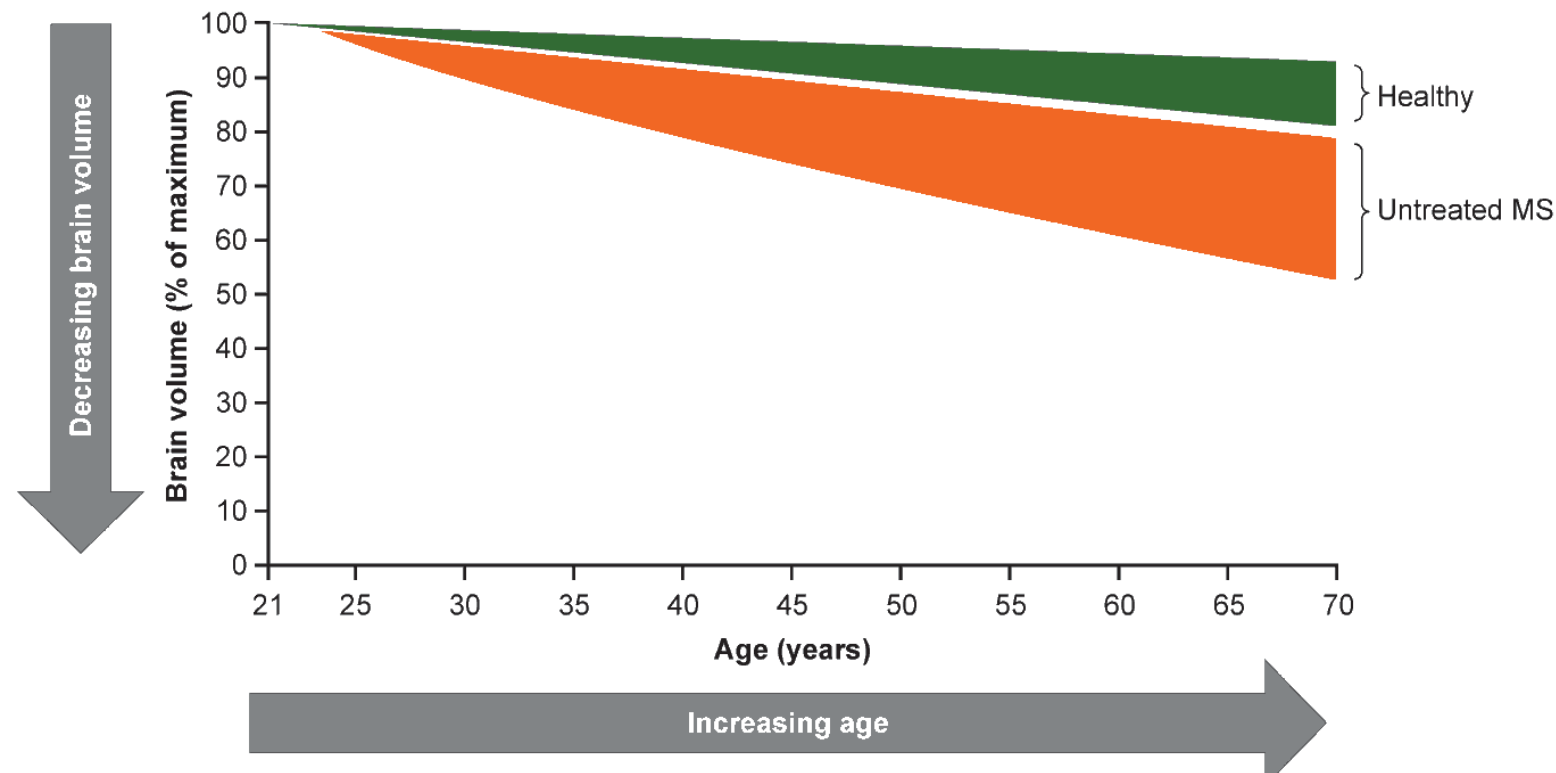

Figure 1. Brain atrophy in many people with MS is faster than usual and proceeds throughout the disease course. This example illustrates how brain atrophy may be accelerated in a person with untreated MS (De Stefano et al., 2014a), with disease onset at 25 years of age, compared with a healthy individual (De Stefano et al., 2016).

Reproduced with permission from Oxford PharmaGenesis Ltd. @ 2015 Oxford PharmaGenesis Ltd. 
a
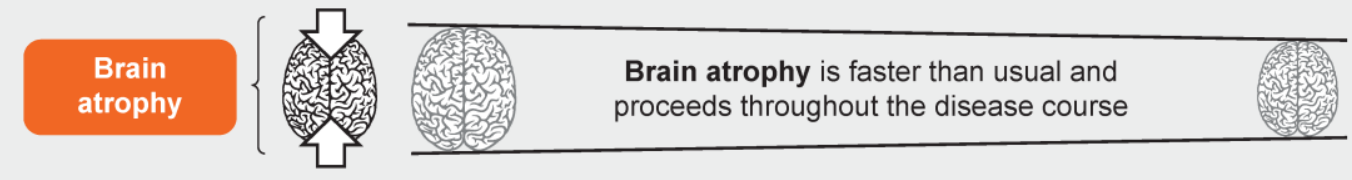

b

Neurological reserve

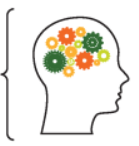

Progressive disease starts when neurological reserve is exhausted

C

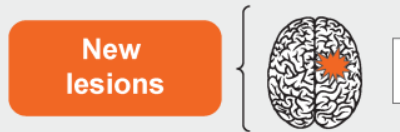

d

Clinical symptoms

e

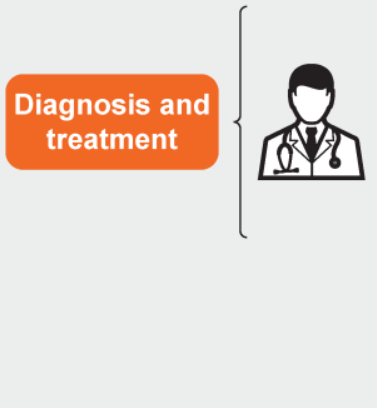

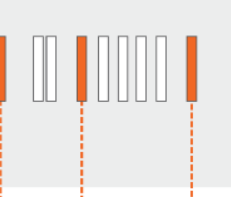

New lesions appear, some lead to relapses

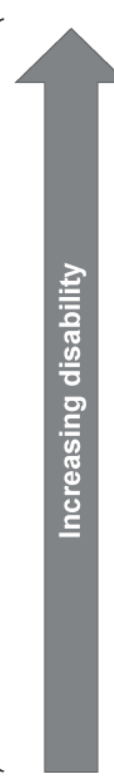

|

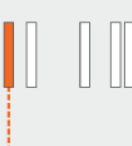

elapses are

acute attacks of symptoms

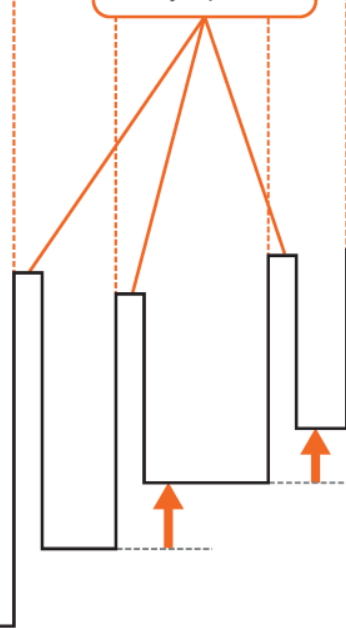

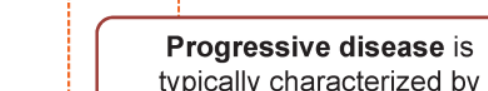
typically characterized by losing the ability to walk

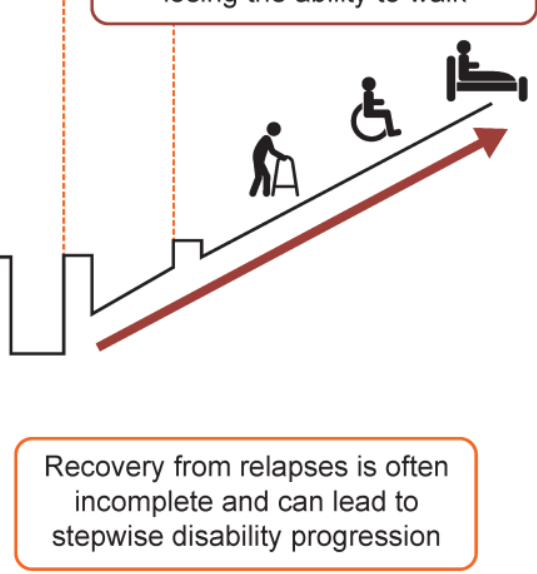

Figure 2. The damage caused by MS typically leads to relapses followed by progressive disease. a. The brains of people with MS shrink (atrophy) more rapidly than usual as a result of damage caused by the disease. $\mathbf{b}$. The brain can use its neurological reserve to compensate for damage by remodelling itself. However, when neurological reserve is used up, the clinical symptoms of the disease may progress. c. MS causes lesions - acute areas of damage to the brain and spinal cord that accumulate over time. If a lesion noticeably disrupts nerve function, it leads to a relapse (an attack of clinical symptoms). d. A typical MS disease course involves relapses, followed by progressive disease. e. A person with MS may have a variety of diagnoses over time (see text for details), but disease-modifying therapies are effective only in the early stages when relapses are still 
This is an author's draft of an accepted article submitted and published in Multiple Sclerosis and Related Disorders

DOI $:$ http://www.sciencedirect.com/science/article/pii/S221103481630102X

present.

CIS, clinically isolated syndrome; NRSPMS, non-relapsing secondary progressive multiple sclerosis; RIS, radiologically isolated syndrome; RRMS, relapsing-remitting multiple sclerosis; RSPMS, relapsing secondary progressive multiple sclerosis.

Reproduced with permission from Oxford PharmaGenesis Ltd. @ 2015 Oxford PharmaGenesis Ltd. 
This is an author's draft of an accepted article submitted and published in Multiple Sclerosis and Related Disorders DOI : http://www.sciencedirect.com/science/article/pii/S221103481630102X

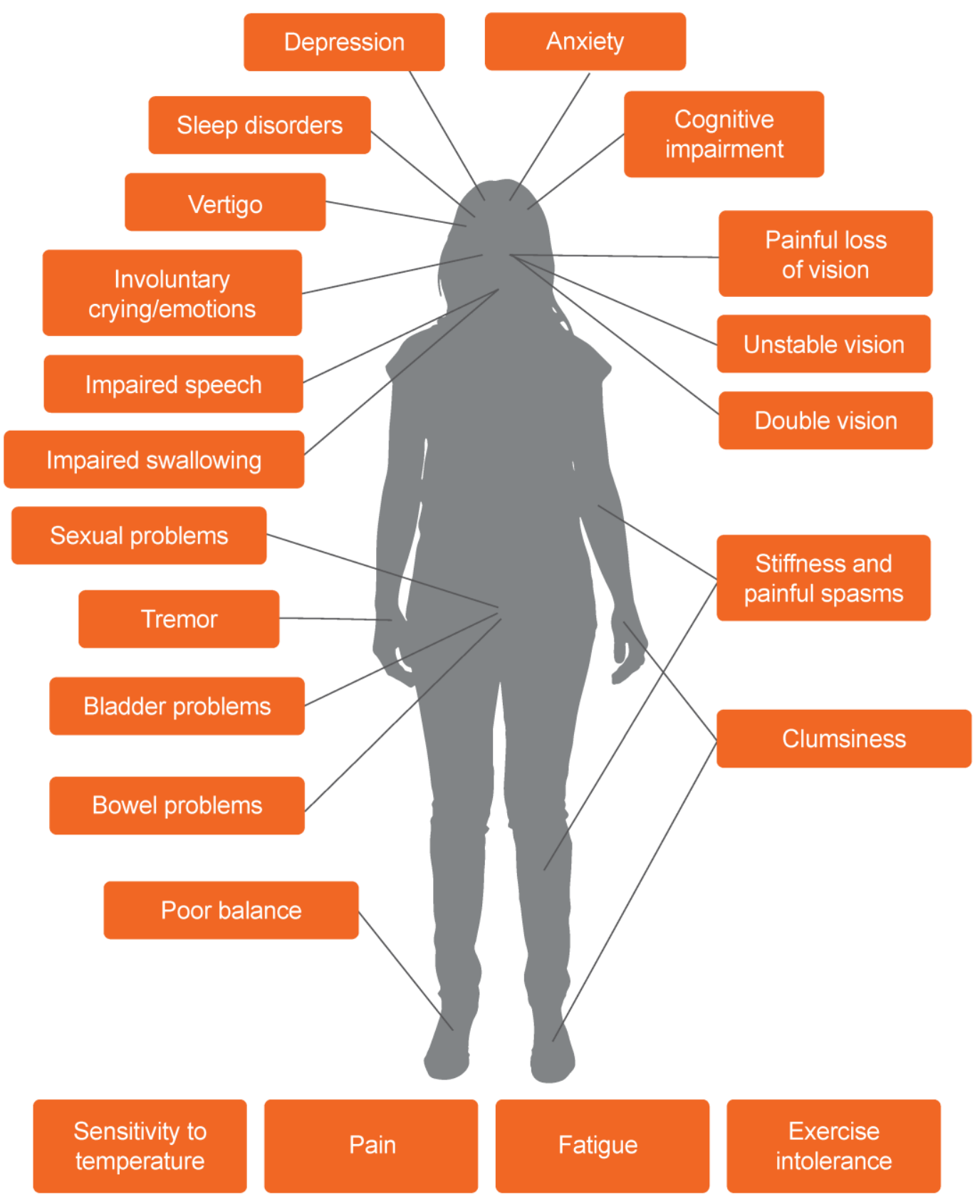

Figure 3. The symptoms of MS(Compston and Coles, 2008; Giovannoni et al., 2012) are distressing and exhausting.

Reproduced with permission from Oxford PharmaGenesis Ltd. @ 2015 Oxford PharmaGenesis Ltd. 
This is an author's draft of an accepted article submitted and published in Multiple Sclerosis and Related Disorders

DOI : http://www.sciencedirect.com/science/article/pii/S221103481630102X

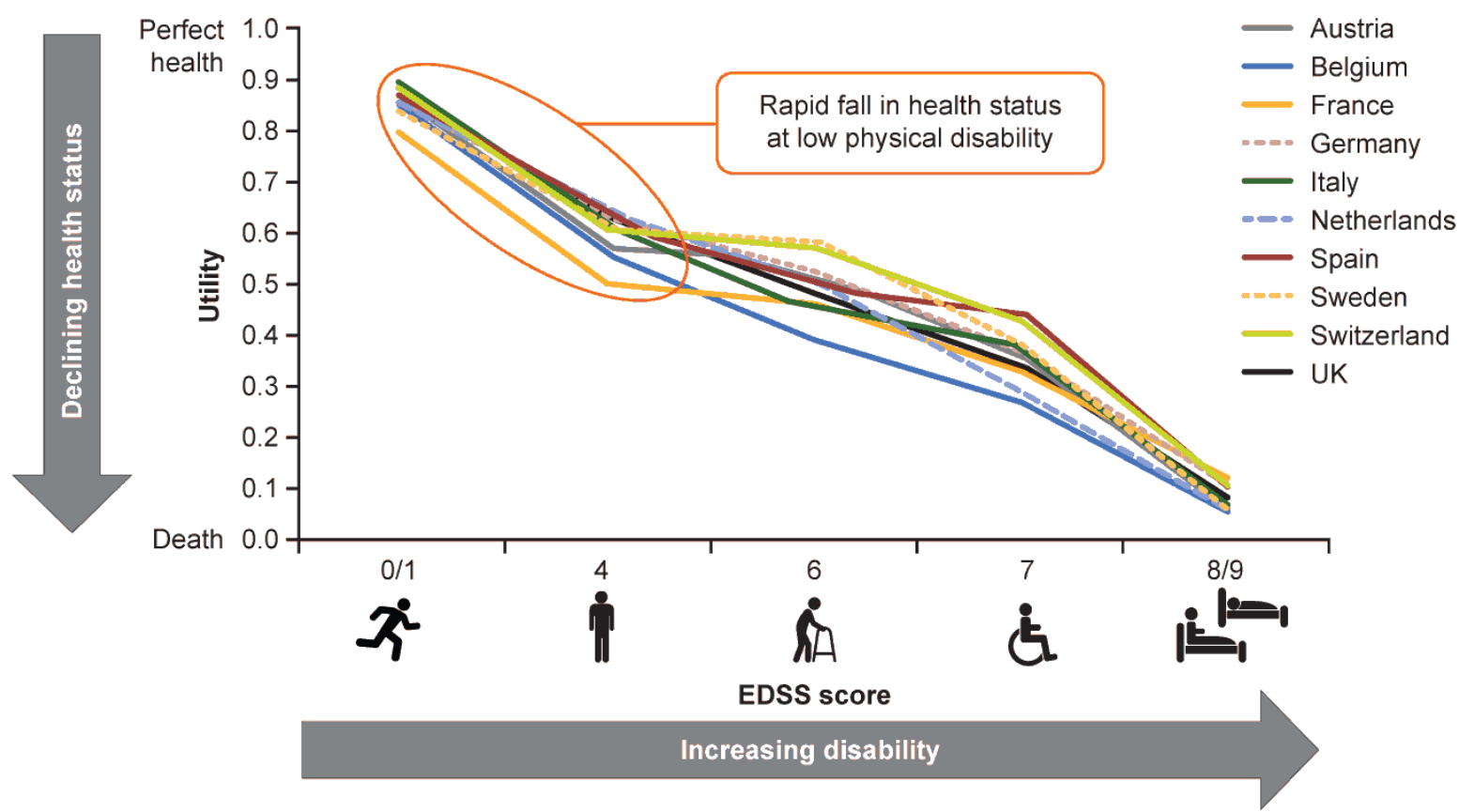

Figure 4. People with MS report a rapid decline in health status (utility) even early in the disease course; this continues to worsen with increasing disability (Kobelt et al., 2006b; Kobelt et al., 2009). EDSS, Kurtzke Expanded Disability Status Scale.

Reproduced and adapted from J Neurol Neurosurg Psychiatry, Kobelt G, Berg J, Lindgren P et al. 77, 918-26, () 2006 with permission from BMJ Publishing Group Ltd. 
This is an author's draft of an accepted article submitted and published in Multiple Sclerosis and Related Disorders

DOI : http://www.sciencedirect.com/science/article/pii/S221103481630102X

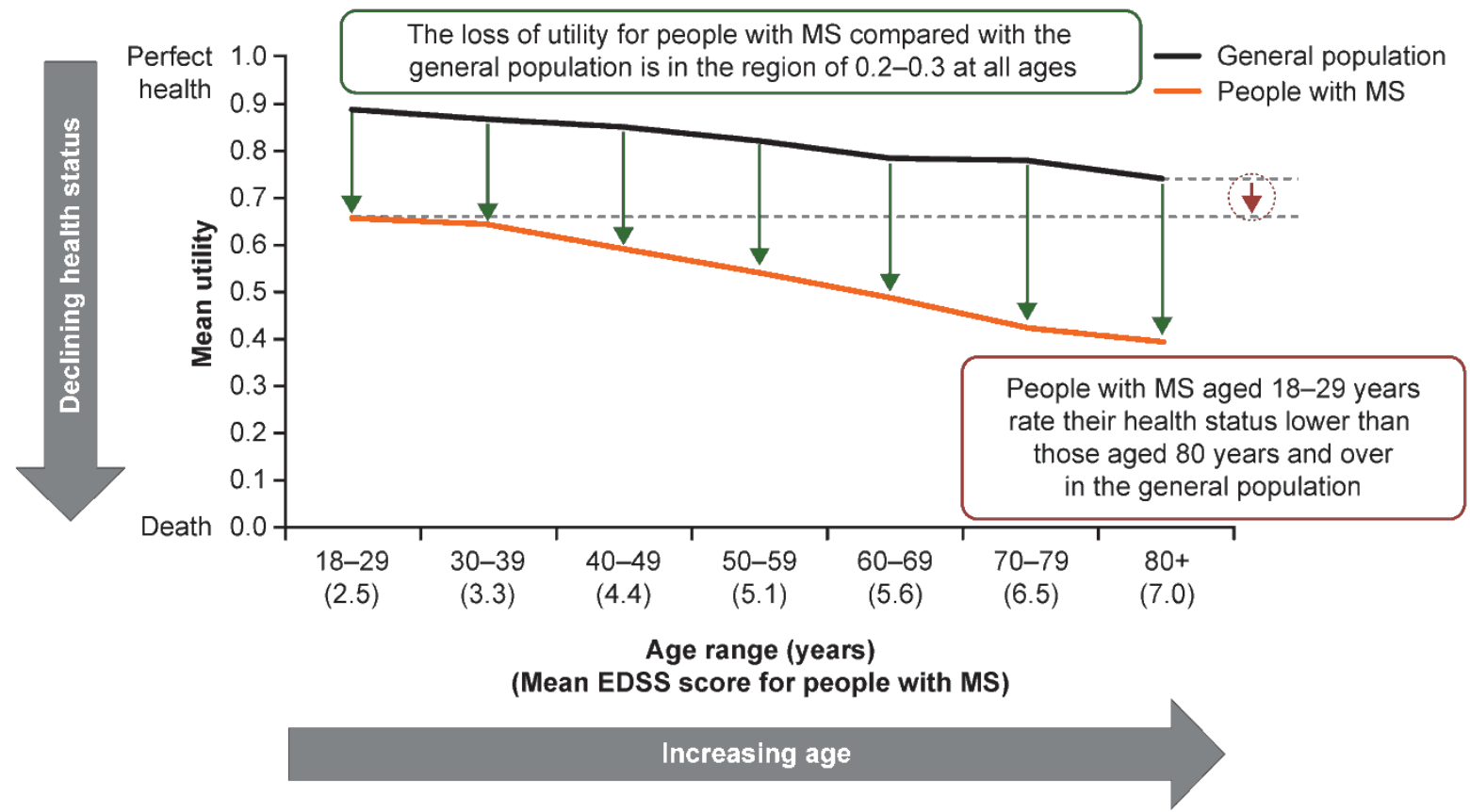

Figure 5. People with MS report a lower average health status (mean utility) than those of a similar age in the general population (Kobelt and Kasteng, 2009).

EDSS, Kurtzke Expanded Disability Status Scale.

Reproduced and adapted with permission from Gisela Kobelt from Kobelt G, Kasteng F. Access to innovative treatments in multiple sclerosis in Europe. The European Federation of Pharmaceutical Industry Associations (EFPIA) 2009 (Kobelt and Kasteng, 2009). ( ) Gisela Kobelt 2009. 


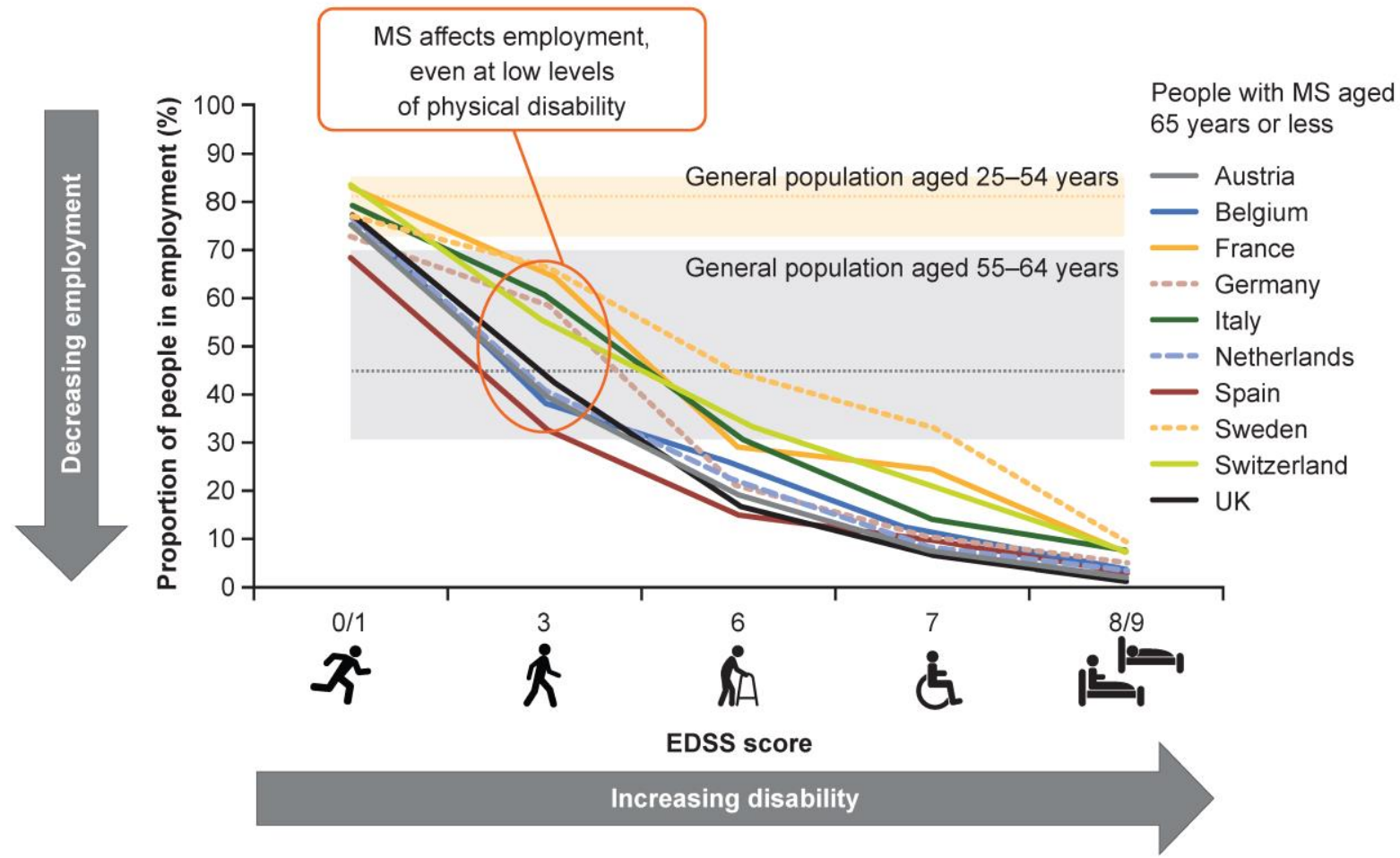

Figure 6. The proportion of people with MS who are in employment is greatly reduced even at low levels of physical disability, and decreases markedly as disability increases (Kobelt et al., 2006b; Kobelt et al., 2009; Eurostat, 2015).

EDSS, Kurtzke Expanded Disability Status Scale. The range (shaded areas) and median (dotted lines) of the proportion of the general population in employment are shown for the age groups stated for the countries listed. It should be noted that, in many of these countries, people retire at less than 65 years of age.

Reproduced and adapted from J Neurol Neurosurg Psychiatry, Kobelt G, Berg J, Lindgren P et al. 77, 918-26, ( 2006 with permission from BMJ Publishing Group Ltd. 


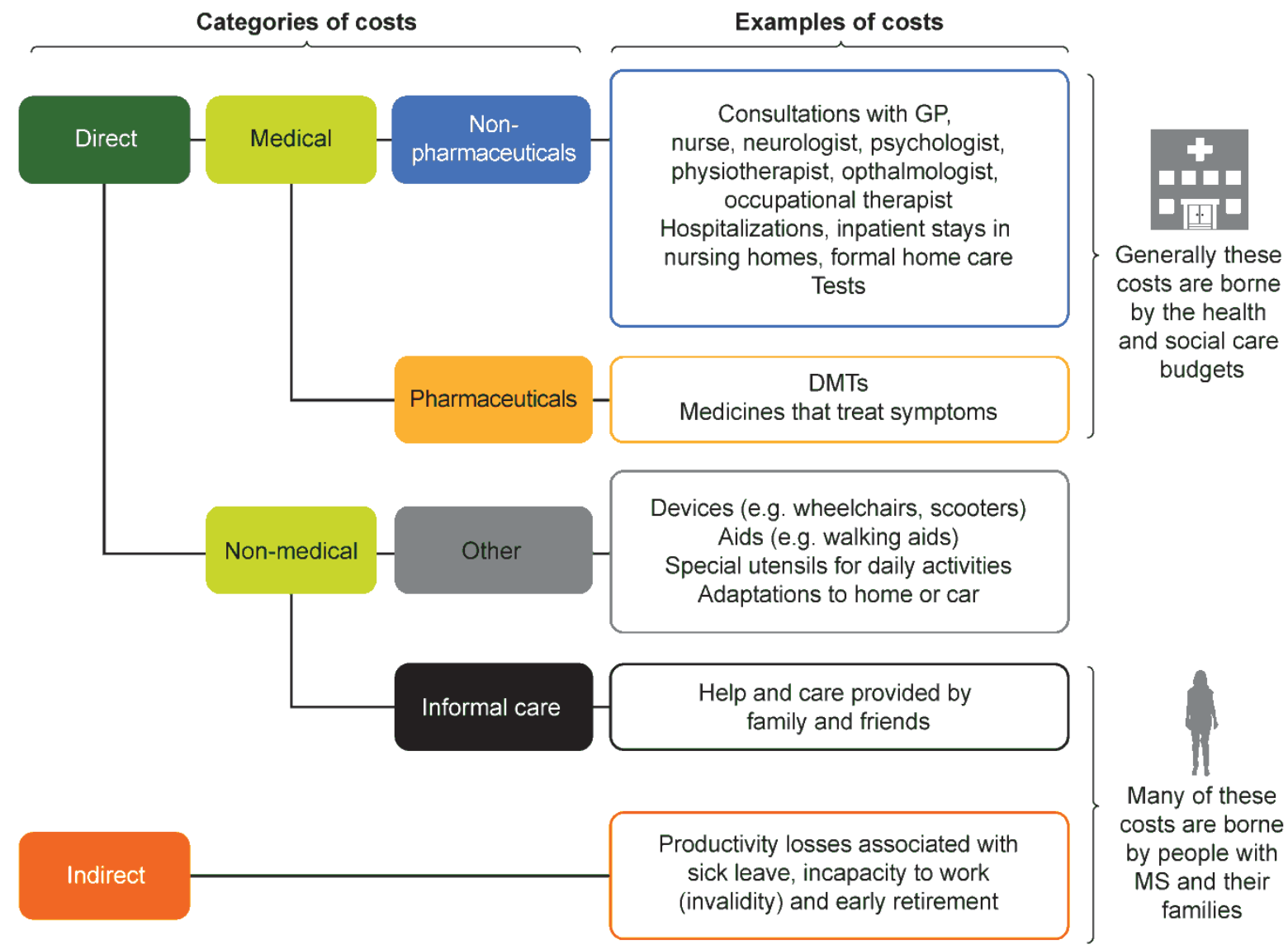

Figure 7. The total societal costs of MS are borne mainly by health and social care services, people with MS and their families.

DMT, disease-modifying therapy; GP, general practitioner (family or primary care physician).

Reproduced with permission from Oxford PharmaGenesis Ltd. @ 2015 Oxford PharmaGenesis Ltd. 
a UK
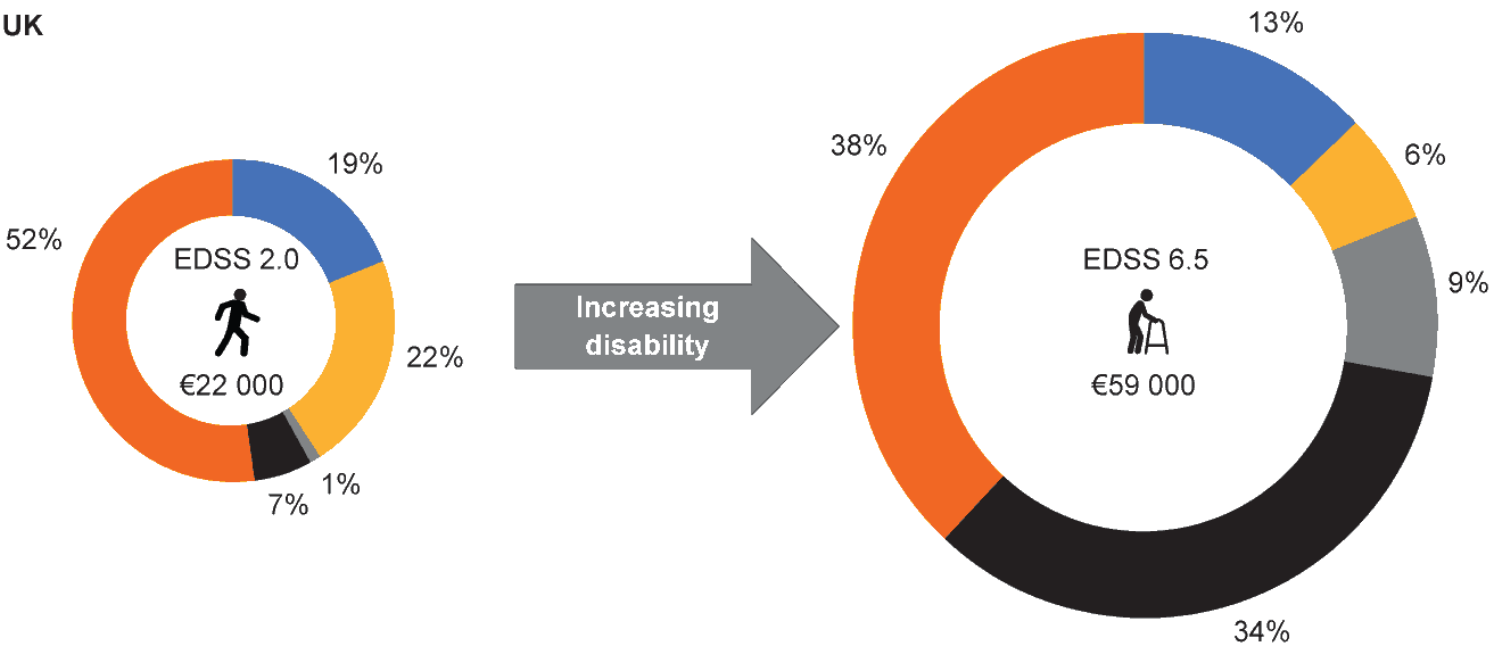

b Germany
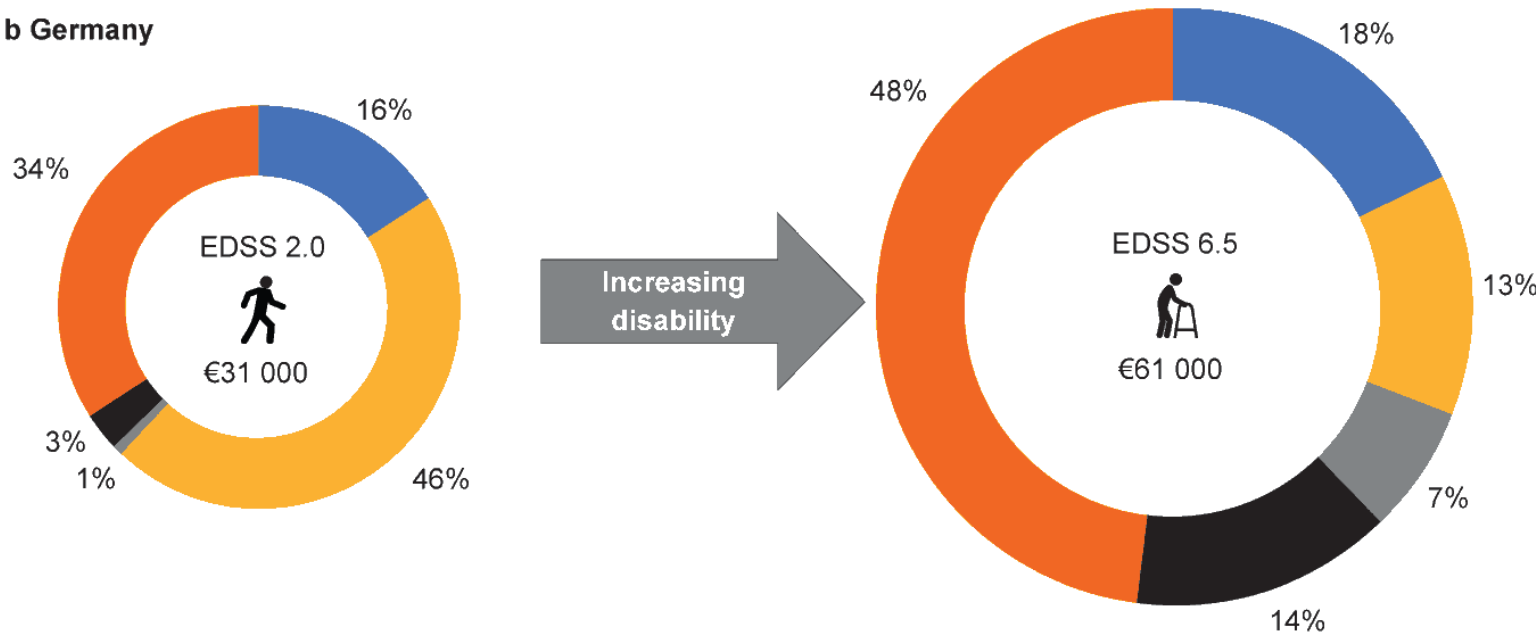

Medical, non-pharmaceuticals

Medical, pharmaceuticals

Non-medical, other

Non-medical, informal care

Indirect

Figure 8. As disability progresses, informal care (black) and indirect costs (dark orange) increase dramatically and greatly exceed the cost of pharmaceuticals (medicines; light orange) (Kobelt et al., 2006b).

Average annual costs per person with MS $\mathbf{a}$ in the UK and $\mathbf{b}$ in Germany at EDSS scores 2.0 and 6.5, converted to 2010 euros. Examples of items in each cost category can be found in Figure 7. Percentages have been independently rounded.

EDSS, Kurtzke Expanded Disability Status Scale.

Reproduced with permission from Oxford PharmaGenesis Ltd. @ 2015 Oxford PharmaGenesis Ltd. 


\section{Speed up referral and diagnosis}

\section{Key points}

- The earlier that MS can be diagnosed, the sooner treatment can be initiated.

- Ideally, people with suspected MS should be referred for diagnosis to a neurologist with a special interest, and expertise, in MS and an experienced team and facilities at their disposal. Such specialists are best placed to diagnose, treat and manage MS.

- It is currently possible to diagnose MS earlier than ever before - 10 times more rapidly than in the 1980s - by using evidence from magnetic resonance imaging (MRI) brain scans in conjunction with clinical assessments.

- However, significant delays can still occur between noticing the first symptoms and receiving a diagnosis. Such delays could be reduced by improving awareness of MS among the general public and healthcare professionals who make referrals and by improving access to specialist MS healthcare professionals and diagnostic equipment.

\subsection{Time is critical to preserving brain volume and physical function}

As discussed in Section 1.2.1, many people with CIS (Zivadinov et al., 2006) and early MS already experience brain atrophy more rapidly than the general population (Figure 1) (De Stefano et al., 2010). This loss of brain tissue is often subclinical (not accompanied by clinical symptoms), owing to repair mechanisms in the CNS and neurological reserve that enable the brain to reorganize itself and reroute pathways to avoid damaged areas, even when repair is incomplete (Rocca et al., 2003; Rocca and Filippi, 2007). If the brain were not so flexible, clinical symptoms of MS would become apparent sooner; this remarkable ability to compensate means that ongoing damage may go unrecognized until neurological reserve has deteriorated significantly.

In the absence of a cure for MS, the aim of starting treatment with a DMT should be to reduce subclinical disease activity, preserve brain volume and slow or prevent disability progression (Gold et al., 2010; Damal et al., 2013). Early diagnosis means that early DMT initiation can be accompanied by other appropriate steps to preserve brain tissue and optimize brain health (for example, exercise, smoking cessation, weight loss and control of comorbidities [other diseases present alongside MS] such as high blood pressure). This approach maximizes the chances of altering the disease course before further relapses or disability progression occur (Section 3).

\subsection{Early referral to a neurologist is essential}

Generally, a person experiencing symptoms compatible with early MS will go initially to their family doctor or primary care physician or to a hospital. From there, they should be referred urgently to a neurologist - a doctor who specializes in diseases of the nervous system.

Neurology is a wide-ranging discipline that has grown in complexity over the years, resulting in subspecialization. For example, a world-leading neurology department of a large hospital may offer specialist clinics in the areas of epilepsy, headache, motor neurone disease, movement disorders (such as Parkinson's disease), peripheral nerve disorders, and MS (sometimes combined with other autoimmune disorders under the term 'neuroimmunology') (Barts Health NHS Trust, 2015).

\subsubsection{Referral to an MS neurologist is desirable}

MS is a complex disease, and neurologists who specialize in MS (MS neurologists) (Scolding et al., 2015), together with their multidisciplinary teams (Table 1), are best placed to provide routine 
This is an author's draft of an accepted article submitted and published in Multiple Sclerosis and Related Disorders

DOI : http://www.sciencedirect.com/science/article/pii/S221103481630102X

diagnosis and an integrated approach to specialist care and management (Biogen Idec Inc., 15 August 2014; Genzyme Corporation, 17 October 2014; De Broe et al., 2001; While et al., 2009; Mynors et al., 2012; Adamec et al., 2013; MS Society, 2013; Multiple Sclerosis International Federation, 2013a; Novartis Pharma GmbH, Revised 24 July 2014; Biogen Idec Inc., Revised: 3 December 2014; Genzyme Corporation, Revised: 14 November 2014; Biogen Idec Ltd., Revised: 18 December 2014; Revised: 23 December 2014; Genzyme Therapeutics Ltd, Revised: 25 March 2014; Sanofi-aventis Groupe, Revised: 28 November 2014; Novartis Pharmaceuticals Corporation, Revised: 30 April 2014). MS neurologists have broad experience of the long-term management of MS and the fast pace of changes in understanding of the disease, diagnostic criteria, treatment options and monitoring processes.

However, access to MS healthcare professionals, specialist teams and diagnostic facilities varies widely across the globe. There are about 120 times more MRI scanners and neurologists per capita in high-income countries than in low-income countries - and the numbers per capita vary considerably even within high-income countries - according to a 2013 survey (Multiple Sclerosis International Federation, 2013a). In addition, the existence of multidisciplinary hospital-based teams was reported by respondents from 36 of the 52 countries for which the survey question was completed (Multiple Sclerosis International Federation, 2013a). These data indicate that the existence of specialist personnel or facilities does not necessarily imply that they are readily accessible in practice.

\section{First person account(Colhoun et al., 2015)}

My MS nurse is my lifeline. Without her I would be lost. She gives me as much or as little as I request.

Modern technology can be used to address some of the inequalities in access to diagnostic services and ongoing specialist care for people with MS, as indicated by a number of pilot studies in the field of telemedicine (remote diagnosis, treatment or ongoing management using telecommunications technology) (Table 2) (Finkelstein et al., 2008; Kane et al., 2008; Luccichenti et al., 2010; Zissman et al., 2012; Ortiz-Gutierrez et al., 2013; Wood et al., 2013; Turner et al., 2014; Khan et al., 2015). Although telemedicine has proved to be extremely useful for servicing remote populations, it does not solve the problem of a low density of services per capita.

Technology can also provide greater access to specialist training for MS healthcare professionals. For example, 2379 nurses from 30 countries across the globe (Winslow, 2015) have registered for the MS Nurse Professional course, led by the European Multiple Sclerosis Platform in collaboration with the International Organization of Multiple Sclerosis Nurses and Rehabilitation in MS (European Multiple Sclerosis Platform, 2015b), in the 2 years to March 2015.

\subsection{Delays in the referral pathway are common}

Delays between the onset of symptoms and MS diagnosis can occur at two key points. Delays between the onset of symptoms and an initial consultation with a healthcare professional are common (Fernandez et al., 2010; Adamec et al., 2013) and can last more than 1 year (Fernandez et al., 2010). This indicates the need to raise awareness of the symptoms of MS among the general population (Fernandez et al., 2010).

Further delays may then occur before eventual diagnosis by a specialist healthcare professional (neurologist or MS neurologist). In addition to waiting lists that inevitably occur when the numbers of neurologists per capita are low, such delays can also result from non-availability of diagnostic tools such as MRI scanners and lumbar puncture, from administrative issues (for example, long waiting lists for neurology services after referral) (Kelly et al., 2011) and from lack of awareness among family or primary care physicians (Figure 9) (Fernandez et al., 2010; Kelly et al., 2011; Adamec et al., 2013). 
This is an author's draft of an accepted article submitted and

published in Multiple Sclerosis and Related Disorders

DOI : http://www.sciencedirect.com/science/article/pii/S221103481630102X

There is evidence of a relationship between delays in referral to an MS neurologist and disability level at the time of the first visit: the longer the delay, the greater the initial disability level at that time (Kingwell et al., 2010). The effects of delays between diagnosis and treatment initiation are described in Section 3.

\section{First-person account(Jarvis, 2012)}

I started getting a lot of pain in my legs and lower back. Along with the pain, I was getting weird nerve sensations in my legs and my legs felt as though they were getting weaker and weaker. This continued from 2003 to this day. I saw orthopaedic specialists on nine occasions and they put the problems down to the sciatic nerve. In $2010 \ldots$... I registered with a new doctor ... . He told me he was referring me to a neurosurgeon [ $\mathrm{sic}$ ] to get this checked out properly. In early 2011 , I was sent for full body MRI scans and lumbar punctures ... finally ... [in] February 2012, I was diagnosed with primary progressive MS ... . I have fought for 9 years to try and work out what was going on in my legs.

\subsection{Magnetic resonance imaging evidence assists early diagnosis}

Symptoms similar to those of MS appear in many other conditions. Therefore when making a diagnosis, clear differentiation between these other conditions and MS is crucial. Being diagnosed with a chronic, unpredictable, progressive incurable disease such as MS has huge personal implications, including reduced employability, increased anxiety and mental distress, and years of taking medicines (Rolak and Fleming, 2007).

\subsubsection{Early diagnostic criteria required two or more acute clinical relapses}

Historically, it was difficult to diagnose MS because lesions in the CNS could only be observed directly on autopsy. The early diagnostic criteria for MS (the Schumacher(Schumacher et al., 1965) and Poser(Poser et al., 1983) criteria, published in 1965 and 1983, respectively) therefore relied on directly observable events: a diagnosis of clinically definite MS required at least two acute clinical relapses. The Poser criteria also incorporated evidence from electrical measurements of brain activity when certain nerves are stimulated ('evoked potentials') and lumbar puncture to help to support the clinical diagnosis (Poser et al., 1983).

\subsubsection{Evidence from brain scans now allows faster and more accurate diagnosis}

With the advent of MRI it became possible to classify lesion patterns in the CNS that are suggestive of MS. As understanding of MRI improved, the McDonald diagnostic criteria were introduced in 2001 (McDonald et al., 2001) and further refined in 2005 (Polman et al., 2005; Swanton et al., 2007) and 2010 (Polman et al., 2011). The McDonald criteria allow a diagnosis of MS to be made in a person who has had just one relapse, by incorporating evidence from MRI scans. The criteria recognize that diagnostic certainty can be increased when lesions are observed in typical locations and when they can be shown to have appeared over a period of time (rather than all at once) (Montalban et al., 2010).

As a result of incorporation of MRI evidence into the diagnostic criteria, people with MS can have their condition diagnosed more rapidly than was previously possible and in a more sensitive and consistent way (Zipoli et al., 2003). The number of people whose MS is accurately diagnosed within 1 year of their first relapse more than doubles (Dalton et al., 2002) or triples (Tintore et al., 2003) using the original McDonald criteria compared with the Poser criteria. In addition, a diagnosis can be established from the earliest MRI scans in about one in five people who have experienced a single relapse using the 2010 McDonald criteria (Runia et al., 2013). It should be noted, however, that the McDonald criteria are not always used consistently in clinical practice (Hawkes and Giovannoni, 2010). 
This is an author's draft of an accepted article submitted and

published in Multiple Sclerosis and Related Disorders

DOI : http://www.sciencedirect.com/science/article/pii/S221103481630102X

\subsubsection{Greater diagnostic certainty enables earlier treatment}

The McDonald criteria are now widely accepted and used to establish a diagnosis of MS. Of the 105 countries for which data were provided in a 2013 global survey, a version of the McDonald criteria was reported as being used in 92\% (Multiple Sclerosis International Federation, 2013g). Real-world evidence from the USA shows that the average delay from symptom onset to diagnosis has fallen 10fold, from 7.2 years in 1980-1984 to 0.63 years in 2000-2004 (Table 3) (Marrie et al., 2005). In the same time period, the proportion of people who had moderate or severe disability (as opposed to mild disability) on their initial visit to a healthcare professional fell from over $50 \%$ to about $25 \%$ (Marrie et al., 2005). Early diagnosis means that early treatment is possible - which will improve the long-term prognosis for people with MS by reducing subsequent damage to the CNS and preventing further unnecessary clinical relapses or disability progression (Section $\mathbf{3}$ ).

The evolution and subsequent implementation of MS diagnostic criteria is an excellent example of the use of an evidence base to improve clinical practice and outcomes for people with MS. Despite clear diagnostic evidence, however, the prescribing guidelines for MS issued by national healthcare authorities in some countries still require a person to experience two clinical relapses, and in some cases disabling relapses, before a DMT can be initiated (Section 3.3.1). This means that further irreversible damage to the CNS can occur, both during the time spent waiting for a second relapse and as a result of the relapse itself.

\subsection{Recommendations}

Delays in the diagnosis of MS should be minimized as these can result in irreversible disability progression.

- Educate the general public to take prompt action if early symptoms of MS develop, by visiting a healthcare professional. Awareness campaigns that highlight the typical initial symptoms, the negative impact of delaying treatment and the personal and societal costs of the disease would support this.

- Educate family and primary care physicians about the importance of promptly referring people with suspected MS to a neurologist, and ultimately to a specialist clinic, to speed up diagnosis and treatment initiation.

- Recommend that general neurologists refer people suspected of having the disease to specialist MS neurologists.

- Improve access to specialist care for MS: make diagnostic and monitoring procedures more widely accessible, increase the numbers of healthcare professionals who specialize in the management of MS, and ensure that these specialists provide prompt diagnostic and support services for people with suspected MS and those who have been newly diagnosed with the disease.

- Adopt the latest accepted diagnostic criteria, in order to diagnose MS as early as possible. 
This is an author's draft of an accepted article submitted and

published in Multiple Sclerosis and Related Disorders

DOI : http://www.sciencedirect.com/science/article/pii/S221103481630102X

\begin{tabular}{|c|c|}
\hline Specialist aspect & Description \\
\hline $\begin{array}{l}\text { MS neurologists have access to } \\
\text { specialist equipment and personnel }\end{array}$ & $\begin{array}{l}\text { MS neurologists have direct access to specialist diagnostic and } \\
\text { monitoring equipment (for example, MRI scanners) and often } \\
\text { work with experienced and MS-specialized staff, including } \\
\text { nurses, physiotherapists, psychologists and others }\end{array}$ \\
\hline $\begin{array}{l}\text { MS neurologists have knowledge } \\
\text { of rapidly evolving treatment } \\
\text { options }\end{array}$ & $\begin{array}{l}\text { MS neurologists have in-depth knowledge of the latest } \\
\text { techniques and treatment options. In the last } 5 \text { years alone, five } \\
\text { new DMTs were approved for use in the USA (Biogen Idec Inc., } \\
15 \text { August 2014; Genzyme Corporation, } 17 \text { October 2014; } \\
\text { Biogen Idec Inc., Revised: } 3 \text { December } 2014 \text {; Genzyme } \\
\text { Corporation, Revised: } 14 \text { November } 2014 \text {; Novartis } \\
\text { Pharmaceuticals Corporation, Revised: } 30 \text { April 2014) and } \\
\text { Europe (Novartis Pharma GmbH, Revised } 24 \text { July 2014; Biogen } \\
\text { ldec Ltd., Revised: } 18 \text { December } 2014 \text {; Revised: } 23 \text { December } \\
\text { 2014; Genzyme Therapeutics Ltd, Revised: } 25 \text { March 2014; } \\
\text { Sanofi-aventis Groupe, Revised: } 28 \text { November } 2014 \text { ); the } \\
\text { situation is similar in other geographical regions }\end{array}$ \\
\hline $\begin{array}{l}\text { MS specialist nurses can } \\
\text { implement programmes and } \\
\text { support people with MS }\end{array}$ & $\begin{array}{l}\text { MS specialist nurses are the key staff members in many MS } \\
\text { clinical services. Their varied roles include implementation of } \\
\text { DMT safety and effectiveness monitoring programmes, support } \\
\text { and counselling, case management, symptom screening and } \\
\text { management, and provision of education about MS disease and } \\
\text { DMTs. There is evidence that MS specialist nurses are highly } \\
\text { valued by people with MS (Colhoun et al., 2015), can provide } \\
\text { emotional support (While et al., 2009) and can improve their } \\
\text { knowledge, confidence and ability to cope (De Broe et al., 2001) }\end{array}$ \\
\hline $\begin{array}{l}\text { Involving MS specialist nurses can } \\
\text { save money }\end{array}$ & $\begin{array}{l}\text { The potential for economic savings has been illustrated in a } \\
\text { number of case studies when MS specialist nurses were } \\
\text { involved in ongoing care, through reduced numbers of hospital } \\
\text { admissions and neurologist appointments (Mynors et al., 2012) }\end{array}$ \\
\hline $\begin{array}{l}\text { Specialist clinics enable rapid } \\
\text { diagnosis }\end{array}$ & $\begin{array}{l}\text { Diagnosis of MS and CIS was more rapid at a specialist clinic } \\
\text { compared with non-specialist options for those suspected of } \\
\text { having demyelinating diseases (that is, diseases in which the } \\
\text { sheath surrounding the nerves is damaged) (Adamec et al., } \\
\text { 2013) }\end{array}$ \\
\hline $\begin{array}{l}\text { Access to MS healthcare } \\
\text { professionals increases the } \\
\text { likelihood of people with MS taking } \\
\text { a DMT }\end{array}$ & $\begin{array}{l}\text { People with MS were more than twice as likely to be taking a } \\
\text { DMT if they had access to an MS neurologist or specialist nurse, } \\
\text { according to a } 2013 \text { UK survey. In Northern Ireland, a region } \\
\text { where people with MS are invited to see a neurologist or MS } \\
\text { specialist nurse for a twice-yearly review (unlike in the rest of the } \\
\text { UK), } 70 \% \text { more people with MS eligible to receive a DMT were } \\
\text { taking one compared with the national average (MS Society, } \\
2013 \text { ) }\end{array}$ \\
\hline $\begin{array}{l}\text { A multidisciplinary team offers an } \\
\text { integrated approach to care where } \\
\text { different aspects of the disease are } \\
\text { managed by specialists }\end{array}$ & $\begin{array}{l}\text { Team members may include: MS neurologist, MS specialist } \\
\text { nurse, physiotherapist, ophthalmologist, pharmacist, clinical } \\
\text { psychologist, psychiatrist, occupational therapist, speech } \\
\text { therapist, pain management specialist, chiropodist/podiatrist, } \\
\text { urologist, continence advisor, social worker, dietician (Multiple } \\
\text { Sclerosis International Federation, 2013a) }\end{array}$ \\
\hline
\end{tabular}

Table 1. Neurologists with a special interest in MS (described above as MS neurologists) and their multidisciplinary teams have extensive experience, knowledge and facilities at their disposal.

$\mathrm{CIS}$, clinically isolated syndrome; DMT, disease-modifying therapy; MRI, magnetic resonance imaging. 


\begin{tabular}{|l|l|}
\hline Type of telemedicine resource & Outcome \\
\hline $\begin{array}{l}\text { Analysis of lesions on MRI scans } \\
\text { using software that runs in a web } \\
\text { browser }\end{array}$ & $\begin{array}{l}\text { Similar results to those obtained using conventional software } \\
\text { (Luccichenti et al., 2010) }\end{array}$ \\
\hline Remote assessment of disability & $\begin{array}{l}\text { Clinically valid information and similar total EDSS scores } \\
\text { compared with 'in-person assessments' using a } \\
\text { videoconference link (Kane et al., 2008) or low-cost webcam } \\
\text { (Wood et al., 2013) }\end{array}$ \\
\hline $\begin{array}{l}\text { Home-based rehabilitation } \\
\text { programmes }\end{array}$ & $\begin{array}{l}\text { Improvements in function, such as walking, balance (Finkelstein } \\
\text { et al., 2008) and postural control (Ortiz-Gutierrez et al., 2013) } \\
\text { Low-level evidence for reduction in impairments (such as fatigue, } \\
\text { pain and insomnia) and improvement in functional activities and } \\
\text { participation, based on a systematic review of nine randomized } \\
\text { controlled trials (Khan et al., 2015) }\end{array}$ \\
\hline $\begin{array}{l}\text { Brief telecounselling sessions and } \\
\text { home monitoring }\end{array}$ & $\begin{array}{l}\text { Better adherence to medication than that found for people } \\
\text { who did not receive these services (Turner et al., 2014) }\end{array}$ \\
\hline Home monitoring & $\begin{array}{l}\text { Less severe symptoms than in those who did not receive the } \\
\text { service; additionally, two-thirds of those in the telecare home- } \\
\text { monitoring group had a decrease in medical costs of at } \\
\text { least 35\% (Zissman et al., 2012) }\end{array}$ \\
\hline
\end{tabular}

Table 2. Telemedicine can help to improve access to diagnostic services and ongoing specialist care by extending services to remote populations, as indicated by the results of several pilot studies.

EDSS, Kurtzke Expanded Disability Status Scale; MRI, magnetic resonance imaging. 
This is an author's draft of an accepted article submitted and published in Multiple Sclerosis and Related Disorders

DOI : http://www.sciencedirect.com/science/article/pii/S221103481630102X

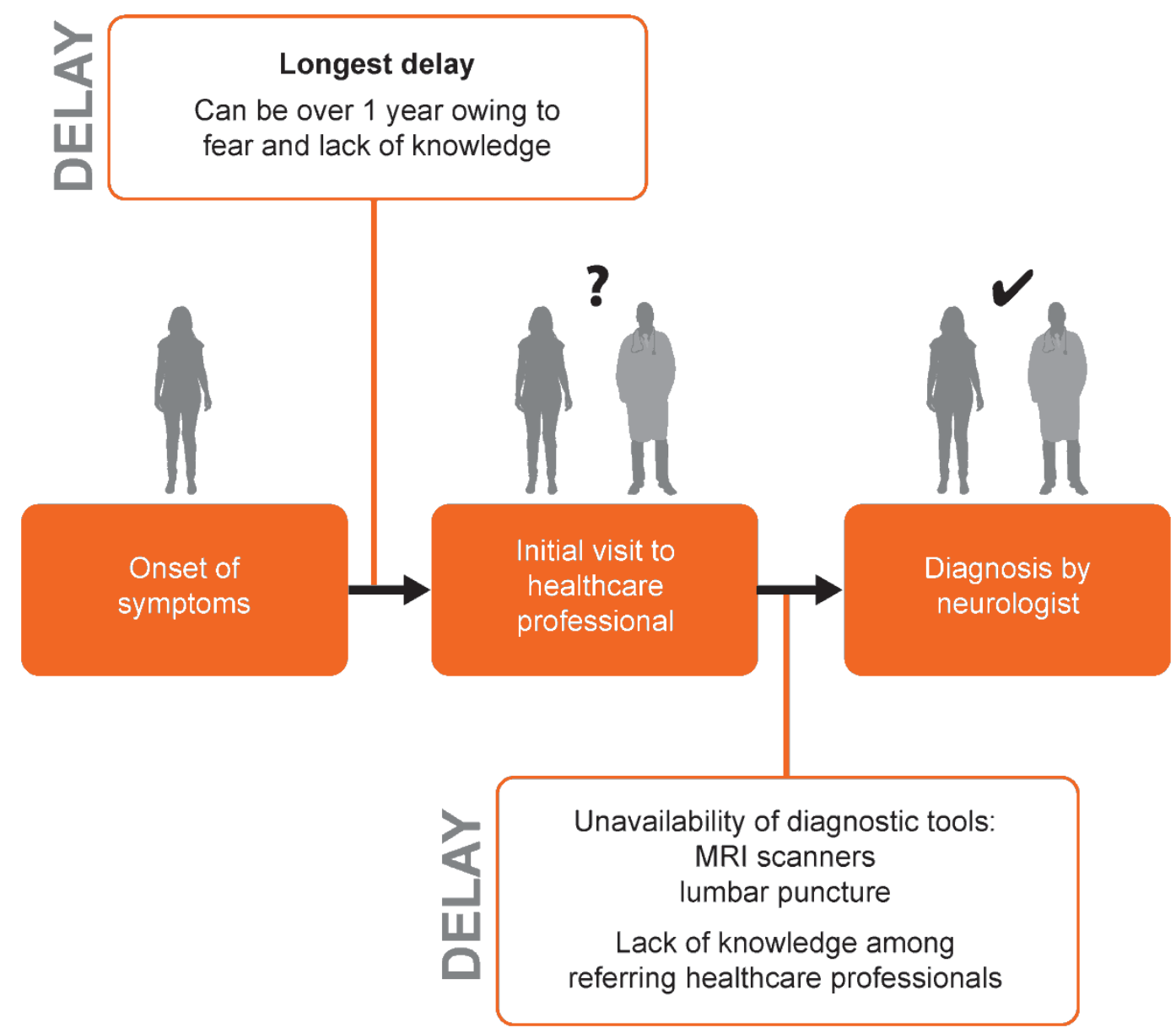

Figure 9. Delays between the initial onset of MS symptoms and diagnosis are common (Fernandez et al., 2010; Kelly et al., 2011; Adamec et al., 2013) and can last more than 2 years (Fernandez et al., 2010).

$\mathrm{MRI}$, magnetic resonance imaging.

Reproduced with permission from Oxford PharmaGenesis Ltd. @ 2015 Oxford PharmaGenesis Ltd. 
This is an author's draft of an accepted article submitted and published in Multiple Sclerosis and Related Disorders

DOI : http://www.sciencedirect.com/science/article/pii/S221103481630102X

\begin{tabular}{|l|l|}
\hline $\begin{array}{l}\text { Onset of } \\
\text { symptoms }\end{array}$ & $\begin{array}{l}\text { Mean (SD) delay (years) } \\
\text { from onset of symptoms } \\
\text { to diagnosis }\end{array}$ \\
\hline $1980-1984$ & $7.2(5.7)$ \\
\hline $1985-1989$ & $5.3(4.4)$ \\
\hline $1990-1994$ & $3.7(3.2)$ \\
\hline $1995-1999$ & $1.8(1.7)$ \\
\hline $2000-2004$ & $0.63(0.8)$ \\
\hline
\end{tabular}

Table 3. There has been a 10-fold decrease in the delay between the onset of MS symptoms and diagnosis since 1980 in the USA (Marrie et al., 2005).

$\mathrm{SD}$, standard deviation. 


\section{Intervene early to maximize lifelong brain health}

\section{Key points}

- The goal of treating MS should be to preserve brain tissue and maximize lifelong brain health by reducing disease activity.

- There is a lot of evidence to support the therapeutic strategy of early intervention with a DMT. This should accompany measures to encourage a 'brain-healthy' lifestyle as part of a comprehensive approach to treatment.

- However, initiating treatment with a DMT is often delayed and subject to restrictions in licensing, prescribing guidelines and reimbursement policies.

- Treatment options are rapidly evolving and many DMTs are now available. They are not all equally effective in all people with MS, and they have a variety of side-effect profiles.

- The choice to initiate treatment should be an informed, shared decision between the person with MS and their clinician, and should consider all appropriate DMTs. The disease course, values, needs, limitations and lifestyle of the person with MS should all be assessed in parallel with the potential benefits and risks of specific DMTs.

\subsection{Intervention should aim to maximize brain health and physical function}

\subsubsection{Early intervention is key}

MS causes irreversible damage to the brain and spinal cord. Although repair mechanisms and remodelling of the CNS can partially compensate for a while, these mechanisms eventually fail to keep up with the damage caused by inflammatory disease activity. Ultimately neurological reserve the capacity that the CNS has to compensate for injury by remodelling itself - is exhausted (Figure 2b). The clinical consequences of MS then become clear - steady increases in physical and mental disability without remissions, as seen in people who have transitioned to SPMS.

Following this transition, the opportunity to change the course of the disease is diminished. No DMTs have been approved worldwide for NRSPMS, and - even if treatment were possible - reversal of persistent disability is highly unlikely. Additionally, the depletion of neurological reserve means that fewer resources remain to combat the cognitive and physical effects of normal age-related brain atrophy (Schwartz et al., 2013). Effective DMT and lifestyle interventions must, therefore, be initiated as soon as the disease is diagnosed in order to protect neurological reserve and maximize lifelong brain health. This approach is in line with the principles on brain health established by the World Federation of Neurology and promoted across a number of brain and mental health disease areas by the World Brain Alliance (World Federation of Neurology, 2015).

\subsubsection{Treating and managing multiple sclerosis requires a comprehensive approach}

Maximizing lifelong brain health is equivalent to preserving neurological reserve. The results of recent research imply that neurological reserve has two components: brain reserve (brain volume) and cognitive reserve (see Box). Preserving brain volume (Kalincik et al., 2012; Popescu et al., 2013; Sormani et al., 2014; Uher et al., 2014; Radue et al., 2015) and cognitive reserve (Schwartz et al., 2013) protects against disability progression, and these two factors independently protect against disease-related cognitive decline (Sumowski et al., 2013). The therapeutic strategy in MS should aim to preserve as much brain reserve and cognitive reserve as possible by using DMTs to slow down the disease course and by adopting a 'brain-healthy' lifestyle. 
This is an author's draft of an accepted article submitted and

published in Multiple Sclerosis and Related Disorders

DOI : http://www.sciencedirect.com/science/article/pii/S221103481630102X

\section{Neurological reserve comprises brain reserve and cognitive reserve}

Brain reserve can be thought of as the physical quantity of brain tissue present. Initial brain volume is genetically and/or congenitally determined (Bartley et al., 1997; Tramo et al., 1998), and it is normal for healthy adults to experience some brain atrophy as they age (Figure 1). It has been shown that elderly people with greater brain reserve (i.e. who have larger brains) experience cognitive impairment later than those with smaller brains (Reynolds et al., 1999; Tisserand et al., 2001; MacLullich et al., 2002; Farias et al., 2012).

Cognitive reserve can be viewed as the ability of the brain to process tasks and actively compensate for physical damage (Stern, 2002). All other things being equal, people with MS who have a high cognitive reserve lose less cognitive function than those with a low cognitive reserve for the same amount of physical damage (measured in terms of brain atrophy (Pinter et al., 2014; Sumowski et al., 2014; Modica et al., 2016) or lesions (Pinter et al., 2014; Sumowski et al., 2014)).

Cardiovascular fitness correlates with brain volume and cognitive reserve (processing speed) in people with MS (Prakash et al., 2010), and improving it through aerobic exercise should be part of managing MS. Avoidance of smoking should be another component of a 'brain-healthy' lifestyle. Cigarette smoking is associated with decreased brain volume in people with MS (Kappus et al., 2016), as well as with higher relapse rates (B. et al., 2010), increased disability progression (Pittas et al., 2009; B. et al., 2010), increased cognitive impairment(Ozcan et al., 2014) and reduced survival (Jick et al., 2015) compared with not smoking. Additionally, smokers with CIS are nearly twice as likely as non-smokers with CIS to develop further inflammatory lesions and, thus, MS (Di Pauli et al., 2008). Limiting the use of alcohol is also important, because there is evidence that unsafe levels of drinking (currently or in the past) lead to reduced survival in people with MS (Jick et al., 2015).

Activities that enhance cognitive reserve by being intellectually enriching (such as education, reading, hobbies and creative expression) have been shown to protect against cognitive impairment in MS when pursued over a lifetime (Sumowski et al., 2009; Sumowski et al., 2010; Pinter et al., 2014; Sumowski et al., 2014; Modica et al., 2016) and should be prioritized day-to-day.

Minimizing comorbidities (other diseases present alongside MS) will help to reduce their negative effect on the MS disease course and to limit the potential for disability unrelated to MS, which can add to the overall impairment burden.

- $\quad$ In people with MS, high blood pressure and heart disease are both associated with lower brain volume, and obesity is associated with higher lesion numbers (Kappus et al., 2016).

- High blood pressure, type 2 diabetes, dyslipidaemia (high levels of cholesterol and/or fat in the blood) and peripheral artery disease (narrowing of the arteries outside of the heart and brain) are all associated with greater disability progression if they co-exist at any time in the MS disease course (Tettey et al., 2014); so too are vascular diseases in general (those affecting the blood vessel system) (Marrie et al., 2010a).

- Heart disease, influenza, pneumonia, urinary tract infections and cancer are all predictors of reduced survival among people with MS (Jick et al., 2015).

To summarize, maximizing lifelong brain health in MS involves a comprehensive approach that incorporates lifestyle measures such as aerobic exercise, avoidance of smoking and excessive alcohol consumption, activities that enhance cognitive reserve, and steps to minimize comorbidities, in addition to intervention with a DMT (the focus of the remainder of this section). 
This is an author's draft of an accepted article submitted and

published in Multiple Sclerosis and Related Disorders

DOI : http://www.sciencedirect.com/science/article/pii/S221103481630102X

\subsection{A lot of evidence supports early intervention with a DMT}

Long-term studies clearly show that early intervention with a DMT is more likely than late intervention to lead to a better outcome in people with CIS and RRMS (Figure 10) (Miller, 2004). There are three main components to the body of evidence supporting this.

- In people with a diagnosis of CIS, treatment with a DMT increases the time to a second relapse (that is, conversion to RRMS under any diagnostic criteria) and improves MRI outcomes, including brain atrophy rate (Table B.1) (Jacobs et al., 2000; Comi et al., 2001; O'Connor, 2003; Filippi et al., 2004; Kappos et al., 2006a; Comi et al., 2009; Comi et al., 2012; Miller et al., 2014).

- In people with a diagnosis of CIS, initiating treatment with a DMT early in the disease course is associated with better long-term outcomes than delaying treatment (Table B.2) (Kinkel et al., 2012; Comi et al., 2013; Edan et al., 2015).

- In people with a diagnosis of RRMS, initiating treatment with a DMT early in the disease course is associated with better long-term outcomes than delaying treatment (Table B.3) (Prisms Study Group and University of British Columbia MS/MRI Analysis Group, 2001; Johnson et al., 2005; Kappos et al., 2006b; Rovaris et al., 2007; Trojano et al., 2007; Trojano et al., 2009; Bermel et al., 2010; Ebers et al., 2010; Goodin et al., 2012a; Goodin et al., 2012b; Agius et al., 2014; Kappos et al., 2015).

It is important to note that, nowadays, many of the participants in the CIS trials summarized in Tables B.1 and B.2 would have been diagnosed with RRMS according to the 2010 revision of the McDonald diagnostic criteria (Costello et al., 2015). Therefore, this evidence also supports early treatment in RRMS.

In the majority of studies summarized in Tables B.2 and B.3, participants were randomly chosen to receive either a DMT or placebo (a 'dummy' treatment with no therapeutic effect) for an initial period, followed by a DMT for an extended period. These 'placebo-switch' studies therefore show the difference between initiating a DMT early in the disease course and later.

Further evidence that DMTs are most effective early in the disease course is provided by a recent meta-analysis of published randomized clinical trials in RRMS. This showed that DMTs are more effective at slowing disability progression from MS in younger people than in older people; they also reduce the relapse rate most effectively in younger people (rather than older people), in patients with low EDSS scores (rather than high scores) and in those with active lesions (i.e. lesions that are currently inflamed) rather than no active lesions (Signori et al., 2015).

Support for early treatment in RRMS is also provided by real-world evidence from databases and registries (Table B.3) (Trojano et al., 2007; Trojano et al., 2009). In addition, for people with CIS, an analysis of data from an international registry shows that the greater the length of time spent taking a DMT within 12 months of onset, the lower the risk of a sustained increase of at least 1 point on the EDSS in the same time period (Jokubaitis et al., 2015). Furthermore, data from the Swedish registry indicate that earlier treatment with a DMT is associated with slower disability progression (from diagnosis of MS to EDSS score $\geq 4.0$ ) than later treatment (Kavaliunas et al., 2015).

Initiating treatment with a DMT "as early as possible in eligible patients" is also recommended in the 2015 guidelines from the Association of British Neurologists (ABN) (Scolding et al., 2015). Once a transition from RRMS to SPMS has occurred, however, DMTs become ineffective at preventing disability progression (Secondary progressive efficacy clinical trial of recombinant interferon-beta-1a in MS study group, 2001; Cohen et al., 2002; Panitch et al., 2004), although some clinical trials have demonstrated significant effects on the relapse rate (Secondary progressive efficacy clinical trial of recombinant interferon-beta-1a in MS study group, 2001; Cohen et al., 2002), number of new lesions 
This is an author's draft of an accepted article submitted and

published in Multiple Sclerosis and Related Disorders

DOI : http://www.sciencedirect.com/science/article/pii/S221103481630102X

(Li et al., 2001; Cohen et al., 2002; Panitch et al., 2004) and total lesion volume on MRI (Li et al., 2001; Panitch et al., 2004). To date, no DMTs have been approved for PPMS, and the only DMT to have been approved in a small number of jurisdictions for NRSPMS has since been removed from the market in the USA.

\subsubsection{Disease-modifying therapies are not all equally effective}

During the 1990s, several DMTs were approved for relapsing forms of MS; in this report these are collectively referred to as 'established DMTs'. Real-world evidence of their long-term effectiveness is mixed; some studies report that a particular class of established DMT can slow (but not prevent) disability progression (Trojano et al., 2007; Trojano et al., 2009) and conversion to SPMS (Trojano et al., 2007; Tedeholm et al., 2013), but others report no effect on disability progression (Shirani et al., 2012) or on the risk of developing SPMS (Zhang et al., 2015). The results of these studies indicate that established DMTs are, at best, modestly effective in altering the natural disease course of MS.

From the 2000s onwards, several 'newer DMTs' have been developed and approved. A number of these have been shown to be more effective at reducing disability progression, relapse rate and/or burden of lesions when compared head-to-head with established DMTs in clinical trials (Rudick et al., 2006; Coles et al., 2008; Cohen et al., 2010; Cohen et al., 2012; Coles et al., 2012a; Coles et al., 2012b). (It should be noted that many participants in clinical trials are newly diagnosed with MS and are therefore starting treatment with a newer DMT.) Some newer DMTs that have been approved for clinical use have not been subject to head-to-head trials but have instead been compared with placebo (Polman et al., 2006; O'Connor et al., 2011) or tested in a study that was set up to include an established DMT as a reference arm rather than a direct comparator (Fox et al., 2012). Furthermore, a number of other DMTs are in various stages of development $-a$ fact that highlights the increasing complexity of MS management and the need for early specialist referral.

Each of the newer DMTs is associated with a particular set of benefits and risks (e.g. possible side effects) and sits in a unique class of drugs. They also have a variety of mechanisms of action (the biochemical interactions through which drugs mediate their effects), formulations (ways in which the active drug is combined with other ingredients to make the final product) and routes of delivery (for example, pills, injections, infusions). It is therefore not always straightforward to choose the DMT that is most appropriate to the disease course, values, needs, limitations and lifestyle of each person with MS (Section 3.5).

\subsection{Disease-modifying therapy is often started late, with restricted choice}

\subsubsection{Treatment initiation criteria may lag behind diagnostic criteria}

The revised McDonald (2010) diagnostic criteria enable an MS diagnosis to be made on the basis of one attack (relapse) and MRI evidence from a baseline scan (Section 2.4.2). However, in a 2013 global survey of 106 countries, responders from 14 of the 27 countries for which data were provided on criteria for initiating DMT in people diagnosed with RRMS reported that these included the requirement for at least two clinically significant relapses within 2 years (Multiple Sclerosis International Federation, 2013f). This reflects the Poser diagnostic criteria, which have been obsolete for over a decade since the widespread adoption of the McDonald criteria.

Prescribing guidelines governing DMT initiation should evolve in parallel with diagnostic criteria in order to prevent unnecessary loss of cognitive reserve, loss of brain tissue, deterioration in brain health and disability progression as a result of waiting for further relapses to occur before starting treatment. 
This is an author's draft of an accepted article submitted and

published in Multiple Sclerosis and Related Disorders

DOI : http://www.sciencedirect.com/science/article/pii/S221103481630102X

\subsubsection{Initial treatment options may be restricted}

Once the decision has been made to initiate treatment, the choice of initial DMT is influenced by several factors, including DMT licensing, prescribing guidelines, reimbursement, the disease course and the personal attitudes, knowledge and life choices of people with MS and their clinicians (Table 4) (Freedman et al., 2013; Multiple Sclerosis International Federation, 2013f; Wilsdon et al., 2013). Even if several initial DMT options have been approved by regulatory authorities, national/local prescribing guidelines and reimbursement policies may curtail genuine choice. Some regulators and insurers impose treatment sequence restrictions, only allowing people with MS access to some DMTs after they have first experienced treatment failure on an established DMT. This means that a particular DMT may be available for initial use according to its licence, but not be accessible in practice - as illustrated in the following examples.

- In the USA, some insurance companies require a person with MS to experience treatment failure on a DMT from their 'preferred formulary' (typically a less-expensive established DMT) before they will reimburse the cost of a different DMT (Edlin and Sonnenreich, 2008; Owens, 2013).

- In Spain and Italy, prescribing guidelines and formularies operate at a regional level, and the DMTs available for initial use may differ from the list of nationally reimbursed DMTs (Multiple Sclerosis International Federation, 2013f; Wilsdon et al., 2013).

- National reimbursement guidelines in a number of European countries place greater restrictions on the circumstance under which a particular newer DMT will be funded than the licence issued by the European Medicines Agency (EMA) (Section 6.2.2) (Wilsdon et al., 2013).

- In some countries, no DMT costs are reimbursed by the government or insurance companies, and in others, only established DMTs are funded (Multiple Sclerosis International Federation, 2013e; d; c; b). This is discussed further in Section 6.2.1.

\subsection{How is treatment initiated in clinical practice?}

MS is a rapidly evolving specialty, and the publication dates of studies that investigate how treatment is initiated lag behind the available DMT options. According to the results of a number of studies, the most recent of which includes data from 2011, many people with MS do not start treatment with a DMT (Table 5) (Margolis et al., 2011; Visser and van der Zande, 2011; Jokubaitis et al., 2013; Phillips et al., 2015), and most of those who do so receive an established DMT (Table 6) (Tornatore et al., 2012; Bonafede et al., 2013; Jokubaitis et al., 2013; Biogen Idec Limited, Revised 22 December 2014; Novartis Pharma GmbH, Revised 24 July 2014; Genzyme Corporation, Revised: 14 November 2014; Genzyme Therapeutics Ltd, Revised: 25 March 2014). Although these results probably reflect clinical practice at the time, a number of newer DMTs have been approved since these studies were conducted; some of these DMTs have an evidence base that supports superior efficacy to that of established DMTs. Indeed, recently published data from Australia show newer DMT use rising from $8 \%$ of total DMT use in 2011 to $33 \%$ in 2013 (Hollingworth et al., 2014). This study did not differentiate between DMT initiation, continuation and switching, but the results indicate a rapid change of attitude in a country where there are fewer obstacles than in other parts of the world and where treatment can be initiated with any approved therapy.

\subsection{Choice of therapy should be an informed, shared decision}

Following a diagnosis of MS, the objective should be to initiate, and continue, treatment with the DMT that is most appropriate to the disease course, values, needs, limitations and lifestyle of the individual. A 2014 consensus paper by the Multiple Sclerosis Coalition in the USA recommends that the complex factors surrounding DMT choice should be discussed collaboratively by the person with MS and their 
This is an author's draft of an accepted article submitted and published in Multiple Sclerosis and Related Disorders

DOI : http://www.sciencedirect.com/science/article/pii/S221103481630102X

treating MS healthcare professional (Costello et al., 2015). A 2015 position statement by the American Academy of Neurology (AAN) concurs that individualized treatment decisions should be made by people with MS in conjunction with their treatment team (American Academy of Neurology, 2015). Guidelines from the ABN, published in 2015, similarly recommend that risks, benefits and personal factors are discussed, and that the views of people with MS should be taken into account when choosing a DMT (Scolding et al., 2015).

There is evidence that such dialogue is important to people with MS, and is already happening in practice. A 2014 survey of 105 people with MS in the UK showed that $84 \%$ wanted to be part of the decision-making process (Colhoun et al., 2015). In a 2015 survey of about 5000 people with MS in the USA, $43 \%$ reported sharing responsibility for treatment decisions with their healthcare professional and a further $42 \%$ reported that they made the final decision after hearing their doctor's opinion (Cofield et al., 2015).

Our recommendation is that MS healthcare professionals should have the time to help people with MS understand the following so that they can make a fully informed choice of initial DMT:

- the possible outcomes of their disease with no, inadequate or suboptimal treatment

- the benefits of early treatment

- the goal of minimizing disease activity while optimizing safety

- the potential benefits and risks of DMTs

- the role they can play in managing their disease by living a 'brain-healthy' lifestyle and making informed, shared decisions about treatment

- any limitations in the current understanding of MS and DMTs.

People with MS need to be fully aware that they have an irreversible disease and that brain atrophy and deterioration in cognitive reserve may not manifest as clinical symptoms until later. Informing people with MS about their disease has been shown to increase disease-related knowledge, with no negative effect (Kopke et al., 2014). Indeed, a recent UK survey found that $59 \%$ of people who felt adequately informed about treatments for MS were taking a DMT compared with only $27 \%$ of those who did not feel adequately informed (MS Society, 2013).

Adherence to prescribed DMTs is associated with fewer relapses that require hospitalization and lower medical costs than non-adherence (Bunz et al., 2013) - but adherence to established DMTs is incomplete and variable in practice, ranging from $88 \%$ to a worryingly low $41 \%$ in various studies (Menzin et al., 2013). However, when people with MS report that they are well informed about their disease and its treatment (de Seze et al., 2012), and have good, open, trust-based relationships with healthcare professionals (Costello et al., 2008; Remington et al., 2013), their adherence improves. As discussed in Section 2.2.1, MS specialist nurses play a key role in many MS clinical services. As the staff members who often have the closest connection to people with MS, they are well placed to encourage adherence by establishing trust and rapport, and providing education, emotional support and reassurance (Burke et al., 2011).

The benefits of DMTs most desired by people with MS are symptom control and prevention of disability progression (Wilson et al., 2014). Although neurologists and people with MS generally agree that the ability to perform work and other day-to-day activities is the most important component of health status, neurologists tend to identify physical functioning as being key, while people with MS place a strong emphasis on emotional well-being (feeling peaceful, happy and calm) (Kremenchutzky and Walt, 2013). This highlights the importance of good dialogue between MS healthcare professionals and people with MS.

When people with MS were offered a theoretical choice of DMTs with no worse than mild side effects, the most important factors they identified were route of administration (for example, a pill, an injection 
or an infusion) and frequency of administration (Utz et al., 2014). However, a 1\% risk of a serious side effect can reduce patient preference for a particular DMT by fivefold (Wilson et al., 2014). This reluctance among people with MS to use DMTs with a greater potential for serious side effects highlights the need for a shared, informed exploration of the choices available because the attitudes of people with MS towards potential benefits and risks of DMTs may be affected by the options offered by neurologists and how these options are presented.

To summarize, for a person with MS who has the option of receiving a DMT, and has more than one choice of DMT, treatment and management decisions rely on how well they understand their disease, the extent to which they are risk averse, the experiences of others they know, the pros and cons of the available treatments and their neurologist's willingness to prescribe a newer DMT.

First-person account (Borreani et al., 2014)

I only have one appointment a year and don't feel this is enough. I would like to be informed about new research and clinical trials. I am extremely interested in this but have to find this information for myself.

\subsection{Recommendations}

Early intervention in MS is vital and needs to involve people with MS proactively in shared decisionmaking and the management of their disease.

- Align prescribing guidelines with the latest accepted diagnostic criteria to give people with MS the opportunity to start treatment and receive support promptly, as soon as diagnosis is confirmed.

- Ensure that MS healthcare professionals can take the time to educate people with MS about strategies to manage their disease. Emphasize the importance of a 'brainhealthy' lifestyle, the benefits of early treatment with therapies that can modify the disease course, the likely consequences of inadequate or suboptimal treatment and the goal of minimizing disease activity while optimizing safety.

- Implement a shared decision-making process that embodies dialogue between people with MS and healthcare professionals. A well-informed and proactive collaboration between people with MS and their healthcare team is vital to successful management of the disease.

- Make the full range of disease-modifying therapies available to people with active relapsing forms of MS, regardless of their treatment history, to speed up adoption of the most appropriate treatment strategy that optimizes effectiveness and safety for each individual.

- Seek regulatory and health technology assessment approvals to implement these recommendations. 
This is an author's draft of an accepted article submitted and published in Multiple Sclerosis and Related Disorders

DOI : http://www.sciencedirect.com/science/article/pii/S221103481630102X

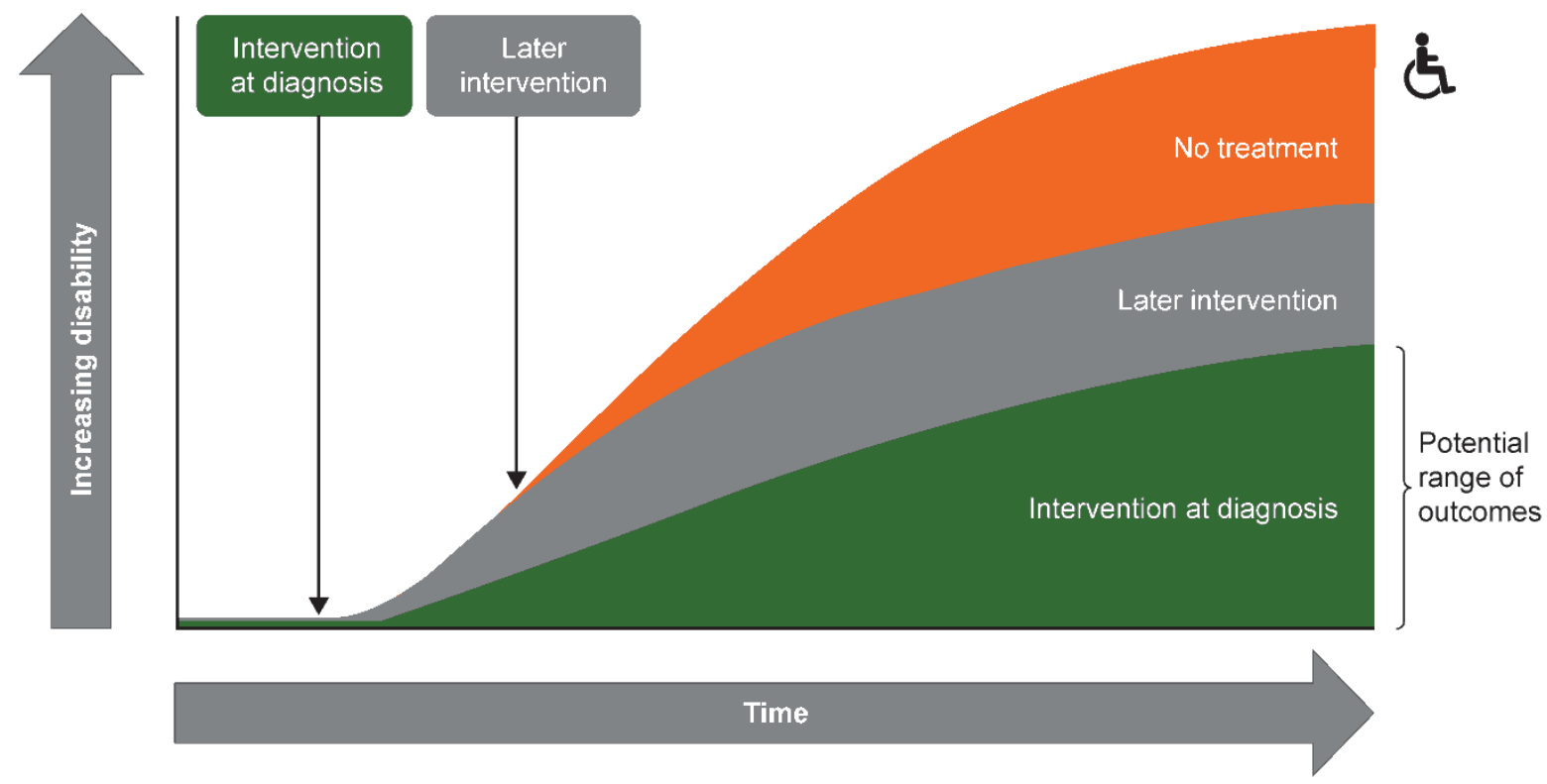

Figure 10. Early intervention with a DMT in MS and CIS is thought to give the best long-term prognosis.

$\mathrm{CIS}$, clinically isolated syndrome; DMT, disease-modifying therapy.

Reproduced with permission from Oxford PharmaGenesis Ltd. @ 2015 Oxford PharmaGenesis Ltd. 


\begin{tabular}{|c|c|c|}
\hline $\begin{array}{l}\text { Factor affecting initial } \\
\text { treatment choice }\end{array}$ & Decision-maker(s) & Who influences what, and why? \\
\hline Licensing & $\begin{array}{l}\text { National/regional } \\
\text { regulatory } \\
\text { authorities } \\
\text { (e.g. EMA, FDA) }\end{array}$ & $\begin{array}{l}\text { The DMT licence dictates the conditions } \\
\text { under which the DMT can be used } \\
\text { Established DMTs are approved as the } \\
\text { initial treatment for MS in all counties } \\
\text { where they are available } \\
\text { - For newer DMTs, there are regional } \\
\text { differences in the licences. Some are } \\
\text { available for treatment initiation and } \\
\text { others can be used only when a person } \\
\text { with MS has experienced an inadequate } \\
\text { response to at least one established } \\
\text { therapy - and these specifics vary by } \\
\text { country/region }\end{array}$ \\
\hline Prescribing guidelines & $\begin{array}{l}\text { National/local } \\
\text { healthcare } \\
\text { authorities }\end{array}$ & $\begin{array}{l}\text { - Prescribing guidelines may be more } \\
\text { restrictive than DMT licences (Wilsdon et } \\
\text { al., 2013) } \\
\text { - Prescribing guidelines may not be in line } \\
\text { with current diagnostic criteria (Multiple } \\
\text { Sclerosis International Federation, } \\
2013 f \text { ) }\end{array}$ \\
\hline Reimbursement & $\begin{array}{l}\text { National/local policy } \\
\text { makers, health } \\
\text { insurance } \\
\text { companies }\end{array}$ & $\begin{array}{l}\text { National and local policy makers (e.g. in } \\
\text { a particular hospital or practice) and } \\
\text { health insurance companies can decide } \\
\text { which DMTs are covered by } \\
\text { reimbursement (i.e. are paid for) } \\
\text { - Such decisions effectively govern which } \\
\text { DMTs are available to people with MS }\end{array}$ \\
\hline Disease course & $\begin{array}{l}\text { People with MS, } \\
\text { neurologists, } \\
\text { regulatory } \\
\text { authorities }\end{array}$ & $\begin{array}{l}\text { Disease severity and speed of } \\
\text { progression should influence choice of } \\
\text { initial DMT (Freedman et al., 2013) } \\
\text { - Some regulatory authorities restrict } \\
\text { access to DMTs, depending on the } \\
\text { disease course }\end{array}$ \\
\hline $\begin{array}{l}\text { Personal attitudes, } \\
\text { knowledge and life } \\
\text { choices }\end{array}$ & $\begin{array}{l}\text { People with MS, } \\
\text { neurologists, MS } \\
\text { specialist nurses }\end{array}$ & $\begin{array}{l}\text { - All parties should consider the } \\
\text { importance of several factors, including } \\
\text { employment, starting or extending a } \\
\text { family, lifestyle, likely adherence to } \\
\text { therapy, attitude to risk, aversion to } \\
\text { injections and existing comorbidities } \\
\text { - A discussion about the relative } \\
\text { convenience, effectiveness and risks of } \\
\text { the DMTs being considered is also } \\
\text { important }\end{array}$ \\
\hline
\end{tabular}

Table 4. Initial treatment choice is affected by DMT licensing, prescribing guidelines and reimbursement, as well as by disease course and personal attitudes.

DMT, disease-modifying therapy; EMA, European Medicines Agency (the European regulatory authority); FDA, Food and Drug Administration (the US regulatory authority). 
This is an author's draft of an accepted article submitted and published in Multiple Sclerosis and Related Disorders

DOI : http://www.sciencedirect.com/science/article/pii/S221103481630102X

\begin{tabular}{|c|c|c|c|}
\hline Country & Data source & $\begin{array}{l}\text { Date/individuals } \\
\text { included }\end{array}$ & Finding \\
\hline Australia & $\begin{array}{l}\text { Registry }(\mathrm{N}= \\
1113)\end{array}$ & $\begin{array}{l}\text { People diagnosed with } \\
\text { RRMS in 1998-2010 }\end{array}$ & $\begin{array}{l}\text { 18\% did not start a DMT during a } \\
\text { median follow-up period of } 2 \text { years } \\
\text { (Jokubaitis et al., 2013) }\end{array}$ \\
\hline Netherlands & $\begin{array}{l}\text { Survey }(\mathrm{N}= \\
1572), 89 \% \\
\text { response rate) }\end{array}$ & People with MS in 2011 & $\begin{array}{l}31 \% \text { had never received a DMT. } \\
\text { Reasons given included concern } \\
\text { about side effects, uncertainty about } \\
\text { the effectiveness of DMTs, disease } \\
\text { course (mild or progressive) and } \\
\text { advice received from neurologists } \\
\text { (Visser and van der Zande, 2011) }\end{array}$ \\
\hline USA & $\begin{array}{l}\text { Insurance claims } \\
\text { database }(N= \\
11061)\end{array}$ & $\begin{array}{l}\text { People diagnosed with } \\
\text { MS in } 2001-2007^{a}\end{array}$ & $\begin{array}{l}57 \% \text { did not start a DMT over an } \\
\text { average follow-up period of } 3 \text { years } \\
\text { (Margolis et al., 2011) }\end{array}$ \\
\hline USA & $\begin{array}{l}\text { Insurance claims } \\
\text { database }(\mathrm{N}= \\
7993)\end{array}$ & $\begin{array}{l}\text { People diagnosed with } \\
\text { MS in 2008-2011 }\end{array}$ & $\begin{array}{l}28 \% \text { did not start a DMT within } \\
6 \text { months of diagnosis (Phillips et } \\
\text { al., 2015) }\end{array}$ \\
\hline
\end{tabular}

Table 5. Many people with MS do not start treatment with a DMT.

aReasons for not starting treatment were not included in the data set.

DMT, disease-modifying therapy; RRMS, relapsing-remitting multiple sclerosis. 


\begin{tabular}{|c|c|c|c|}
\hline $\begin{array}{l}\text { Country/regio } \\
\mathrm{n}\end{array}$ & Data source & $\begin{array}{l}\text { Date/individuals } \\
\text { included }\end{array}$ & Finding \\
\hline Australia & $\begin{array}{l}\text { Registry (N = } \\
771)\end{array}$ & $\begin{array}{l}\text { People diagnosed with } \\
\text { RRMS between } 1998 \text { and } \\
2010 \text { who commenced } \\
\text { treatment with a DMT }\end{array}$ & $\begin{array}{l}\text { Almost } 99 \% \text { of those who } \\
\text { commenced treatment started with } \\
\text { an established DMT. However, a } \\
\text { newer DMT became available only } \\
\text { during the final } 24 \text { months of } \\
\text { the study (Jokubaitis et al., 2013) }\end{array}$ \\
\hline Europe & EMA & As at September 2015 & $\begin{array}{l}\text { The EMA has excluded some newer } \\
\text { DMTs from initial use in most } \\
\text { people with RRMS (Biogen Idec } \\
\text { Limited, Revised } 22 \text { December } \\
\text { 2014; Novartis Pharma GmbH, } \\
\text { Revised } 24 \text { July 2014) }\end{array}$ \\
\hline USA & Survey $(\mathrm{N}=75)$ & $\begin{array}{l}\text { Neurologists from MS } \\
\text { treatment centres, } 2010\end{array}$ & $\begin{array}{l}\text { All recommended initiating a DMT } \\
\text { for a young adult with mild RRMS; } \\
\text { 90-98\% recommended an } \\
\text { established DMT, depending on } \\
\text { other risk factors (Tornatore et al., } \\
\text { 2012) }\end{array}$ \\
\hline USA & $\begin{array}{l}\text { Insurance claims } \\
\text { database }(\mathrm{N}= \\
6181)\end{array}$ & $\begin{array}{l}\text { People with MS who } \\
\text { commenced treatment } \\
\text { with a DMT between } \\
\text { January } 2007 \text { and } \\
\text { September } 2009\end{array}$ & $\begin{array}{l}\text { 93\% commenced treatment with an } \\
\text { established DMT (Bonafede et al., } \\
\text { 2013) }\end{array}$ \\
\hline USA & FDA & As at September 2015 & $\begin{array}{l}\text { There is discrepancy between the } \\
\text { USA and Europe in the licensed } \\
\text { indications for the use of a particular } \\
\text { DMT in people with active RRMS } \\
\text { (Genzyme Corporation, Revised: } 14 \\
\text { November 2014; Genzyme } \\
\text { Therapeutics Ltd, Revised: } 25 \\
\text { March 2014) }\end{array}$ \\
\hline
\end{tabular}

Table 6. Most people with MS who receive a DMT will start with an established treatment.

DMT, disease-modifying therapy; EMA, European Medicines Agency (the European regulatory authority); FDA, Food and Drug Administration (the US regulatory authority); RRMS, relapsing-remitting multiple sclerosis. 


\section{Monitor disease activity and treat to a target}

\section{Key points}

- The practice of monitoring to ensure that disease activity remains below a target level is routine in many areas of medicine.

- In MS, all parameters that predict future relapses and disability progression should be included in the definition of disease activity. This definition should evolve as further evidence becomes available.

- Regular clinical and radiological monitoring of disease activity and recording this information formally need to become commonplace in managing MS in order to identify suboptimal disease control and inform treatment decisions.

\subsection{Monitoring disease activity enables individualized treatment}

There are two primary reasons for monitoring: to evaluate treatment effectiveness and to evaluate safety. The monitoring of parameters that indicate disease activity allows the effectiveness of a DMT for each individual person with MS to be assessed and enables swift action to be taken in the case of treatment failure (Figure 11) (Giovannoni, 2014b) - that is, when disease activity has not been minimized in response to treatment (Section 5). The monitoring process should also incorporate safety and tolerability parameters, individualized for each DMT, to ensure that people with MS are not exposed to unnecessary risk or side effects from their medication (Scolding et al., 2015).

Monitoring can be either routine or driven by clinical events such as relapses or side effects of medication. Parameters that can be monitored may be measured clinically (for example, disability progression and relapses), radiologically (using MRI) or in a laboratory (for example, from a blood sample), or they may be reported by the person with MS (patient-reported outcomes; for example, activity limitations, cognitive status and level of fatigue). Parameters that cannot be measured or observed during a clinical examination are known as subclinical parameters.

The practice of monitoring to ensure that disease activity remains below a target level is routine for several conditions that can cause irreversible damage to major organs.

- In people with diabetes, blood glucose concentrations are routinely monitored, with the aim of maintaining them within the normal range to reduce long-term damage to multiple organ systems, including the heart, eyes, nerves and kidneys (International Diabetes Federation, 2011; International Diabetes Federation Clinical Guidelines Task Force, 2012; Handelsman et al., 2015).

- In people with cardiovascular disease (diseases relating to the heart and blood vessels), blood pressure and cholesterol levels are monitored and treatment is tailored in order to bring them into the normal range. This is done to reduce the risk of cardiovascular events that could damage organs such as the heart (from a heart attack, for example) or the brain (from a stroke) (Atar et al., 2010).

- In people with rheumatoid arthritis, treatment based on monthly monitoring has been shown to improve physical function and quality of life compared with routine care, at no additional cost (routine care here comprised quarterly appointments with specialists, but without a formal composite measure of disease activity). Monitoring the number of swollen joints, joint tenderness, inflammatory markers in the blood and patient-reported measures of disease activity provided the basis for treatment decisions that reduce damage to joints (Grigor et al., 2004). Subsequently, an international task force recommended a 'treat-totarget' strategy based on regular monitoring of composite measures of disease activity with 
This is an author's draft of an accepted article submitted and

published in Multiple Sclerosis and Related Disorders

DOI : http://www.sciencedirect.com/science/article/pii/S221103481630102X

the aim of achieving clinical remission - in this case the absence of significant inflammatory disease activity (Smolen et al., 2010).

Although MS and rheumatoid arthritis cause irreversible damage to different body systems, they have several features in common. Both are degenerative, autoimmune, inflammatory conditions that affect physical function, and both are treated with DMTs that target the respective inflammatory processes. However, in one crucial aspect the management of MS lags behind that of rheumatoid arthritis - in MS, the 'treat-to-target' approach has not yet been adopted in routine clinical practice. Regular monitoring of clinical and subclinical disease activity needs to become central to the management of MS (Figure 11) (Giovannoni, 2014b).

There is also evidence that monitoring can improve adherence to prescribed DMTs (which is associated with fewer serious relapses and lower medical costs than non-adherence (Bunz et al., 2013)) and that data from monitoring can be used to encourage conversations and collaboration between people with MS and their healthcare professionals (Willis et al., 2014). Increased engagement of people with MS in shared treatment decisions, as recommended in this report, is more likely to take place if the routine monitoring of disease activity and safety parameters becomes commonplace.

The remainder of this section presents the evidence for the inclusion of candidate parameters in the overall definition of disease activity.

\section{First-person account}

After receiving a diagnosis of MS in 2005, I began treatment with a DMT. Over the next 5 or 6 years I tried three different treatments but continued to have relapses, so I asked my consultant to prescribe a different drug for me. I really wanted to see my MRI scans to know what was happening inside my brain, but my neurologist was reluctant to show me these.

I had to be very proactive, push for my case and fight to have my opinion heard. Eventually I was switched to a newer treatment. I then realized that this was far more effective than previous drugs had been. I stopped experiencing relapses, and I felt less fatigue and that the 'brain fog' had lifted, which really improved my quality of life. I now visit a different MS neurologist who shares the results of my MRI scans with me. I could see for myself that I had no new MRI lesions while taking this new DMT.

I am happy to make my views clear to neurologists, but not everyone is so comfortable doing this. However, I would encourage others with MS to have an active involvement in all the decisions about their treatment. Some neurologists are more 'conservative' than others and may be reluctant to try new treatments. As the person most affected, though, I appreciate being part of the discussion.

\subsection{Clinical and subclinical indicators of disease activity should be monitored}

Historically, the treatment target for MS was to prevent or reduce clinical disease activity - relapses and, especially, disability progression (Fox and Rhoades, 2012; Stangel et al., 2015). The need to prevent disability progression is underscored by real-world evidence from a large international database of people with MS, which indicates that the EDSS score 5 years after the onset of MS predicts disability progression, and that once disability has progressed, it worsens more rapidly from EDSS score 4.0 onwards than from EDSS score 2.0 onwards (Hughes et al., 2012).

However, neurological reserve is affected by damage to the CNS even when it does not lead directly to disability progression or a relapse (Section 1.2.2); therefore, it makes sense to consider all indicators of disease activity, not just the clinical symptoms at the 'tip of the iceberg'. The remainder of this section discusses the clinical and subclinical parameters illustrated in Figure 12 (Giovannoni, 
This is an author's draft of an accepted article submitted and

published in Multiple Sclerosis and Related Disorders

DOI : http://www.sciencedirect.com/science/article/pii/S221103481630102X

2014a), with the greatest focus on the subclinical parameters with the most substantial evidence base (MRI lesions and brain atrophy).

\subsubsection{Relapses indicate disease activity and predict disability progression}

Studies consistently show a correlation between relapses in the first few years of the disease and later levels of disability (Scalfari et al., 2010; Kieseier, 2014; Scalfari et al., 2014; Stangel et al., 2015). The passage of a short time from the first to the second relapse appears to be a particularly strong predictor of disability progression (Scalfari et al., 2010; Scalfari et al., 2014). In addition, metaanalyses and real-world evidence indicate that correlations exist between the effects of DMT on relapses and disability progression, and that relapses predict disability progression (Table C.2) (Fisniku et al., 2008; Sormani et al., 2009; Sormani et al., 2010; Sormani et al., 2011; Kalincik et al., 2012; Bermel et al., 2013; Fahrbach et al., 2013; Popescu et al., 2013; Sormani and Bruzzi, 2013; Dobson et al., 2014; Uher et al., 2014; Jokubaitis et al., 2015). There is therefore a robust rationale for including relapses in the definition of disease activity.

However, relapses are not the only factor implicated in future disability progression, and there are other problems with simply using the recorded 'relapse rate'. Many relapses go unreported - nearly half of people with MS who responded to a recent UK survey indicated that they had failed to report a relapse to a healthcare professional, and over one-quarter said that they had not reported their most recent relapse (Duddy et al., 2014). In turn, whether or not a relapse is reported can depend on how frequently a person with MS sees a neurologist (Freedman et al., 2013).

\subsubsection{MRI lesions indicate disease activity, and predict relapses and disability progression}

Lesions detectable by MRI scans are already used as evidence of disease activity in the diagnosis of MS (Section 2.4.2) (Polman et al., 2011) and in clinical trials and as a basis for initiating a DMT in many countries (Multiple Sclerosis International Federation, 2013f). Additionally, the EMA recently stated that MS may be defined as 'active' based on clinical and/or MRI evidence (Genzyme Therapeutics Ltd, Revised: 25 March 2014). There is strong evidence for using MRI lesions as a predictor of relapses and disability progression from analyses and meta-analyses of data from clinical trials and real-world sources involving tens of thousands of people with MS (Table 7) (Sormani et al., 2009; Sormani et al., 2010; Kalincik et al., 2012; Fahrbach et al., 2013; Popescu et al., 2013; Sormani and Bruzzi, 2013; Dobson et al., 2014; Uher et al., 2014). The evidence from each of the studies listed in the table is presented in greater detail in Table C.2.

With the increasing availability of MRI scanners (Multiple Sclerosis International Federation, 2013a), the prospect of routinely monitoring brain lesion activity has become viable in many countries. This increases the likelihood of detecting disease activity before irreversible damage to brain tissue and loss of neurological reserve have occurred. Thus, MRI evidence of subclinical disease activity can help to guide treatment decisions in a more timely manner than clinical evidence of disease activity (relapses and disease progression) alone. However, despite the major role that MRI plays in the diagnosis of MS and the decision to initiate DMT, many people with MS are switched to a different DMT only if they experience new clinical symptoms, and not solely on the basis of MRI evidence of new lesions (Section 5.2). Moreover, MRI monitoring is not routinely carried out in clinical practice everywhere. The $A B N$, in their 2015 guidelines, suggest incorporating MRI scanning into a routine annual review process (Scolding et al., 2015). However, a 2014 survey of 108 UK neurologists with an interest in MS revealed that although 59\% of respondents used MRI to monitor treatment response, only $9 \%$ did so routinely (Schmierer et al., 2014). 
This is an author's draft of an accepted article submitted and published in Multiple Sclerosis and Related Disorders

DOI : http://www.sciencedirect.com/science/article/pii/S221103481630102X

\subsubsection{Brain atrophy indicates disease activity and predicts disability progression}

The central theme of this report is that the goal of treating MS should be to preserve brain tissue and by doing so optimize lifelong brain health. Brain atrophy occurs as a result of damage that takes place via a number of different mechanisms. This implies that brain volume should be monitored in addition to active and total numbers of lesions, which represent only one kind of damage. In addition, brain volume is a measurable indicator of brain reserve, and rates of brain atrophy higher than those in the general population indicate MS disease activity.

Evidence from studies suggesting that brain atrophy should be included in the definition of disease activity as a predictor of clinical symptoms of MS are summarized below. Further details of each study are presented in Table C.2 (Kalincik et al., 2012; Popescu et al., 2013; Sormani et al., 2014; Uher et al., 2014; Radue et al., 2015).

- Meta-analyses of clinical trial data show a correlation between the effects of treatment on brain atrophy and disability progression (Sormani et al., 2014; Radue et al., 2015). This is independent of the correlation between the effects of treatment on MRI lesions and disability progression (Sormani et al., 2014) because brain atrophy results from diffuse damage and lesions that are difficult to observe, as well as from lesions observable using MRI scans (Filippi and Rocca, 2005).

- Studies in people with CIS receiving a DMT have shown that those with a greater rate of brain atrophy are more likely to be diagnosed with MS within 2 years (Kalincik et al., 2012), and are more likely to experience a second relapse within 4 years (Uher et al., 2014), than those who experience less brain atrophy.

- Long-term (10 years) disability progression can be predicted by the rate of brain atrophy during the first 1-2 years of treatment (Popescu et al., 2013).

The importance of measuring brain atrophy is already recognized. In a survey of UK neurologists with a special interest in MS, over half of the 56 respondents believed that brain atrophy was a relevant parameter to measure (Schmierer et al., 2014). However, the MRI technology required to measure brain atrophy is not yet widely available in clinical practice.

\subsubsection{Other candidate parameters indicating disease activity are not yet validated}

The evidence base for the other potential markers of disease activity included in Figure 12 (lesions in the grey matter of the brain, spinal fluid neurofilament levels and patient-reported outcomes) is growing, but is not yet sufficiently strong to support their incorporation into the routine clinical monitoring of disease activity in people with MS. In general, we recommend that evidence-based treatment targets should evolve as further evidence becomes available.

The MRI techniques used in current clinical practice can detect lesions in the white matter of the brain (which consists mainly of nerve axons that transmit signals between different parts of the brain), but MS also affects the grey matter (the part of the brain mainly responsible for cognition and processing information). New MRI protocols have been developed to detect lesions in the grey matter (Sethi et al., 2012), but the technology and evidence base do not yet exist for adding grey matter lesions to the current definition of disease activity.

Neurofilaments are the protein 'scaffolding' of nerve fibres and are released when damage occurs. In a recent study in which people with RRMS received one of the newer DMTs for 1 year, reductions in the levels of a particular neurofilament in cerebrospinal fluid correlated with lower numbers of relapses and fewer new lesions during the same time period (Kuhle et al., 2015). In addition, a recent study in people with CIS has shown that levels of the same neurofilament in the blood are high compared with those in healthy people, and that higher levels in individuals with CIS were associated 
This is an author's draft of an accepted article submitted and

published in Multiple Sclerosis and Related Disorders

DOI : http://www.sciencedirect.com/science/article/pii/S221103481630102X

with higher disability scores, numbers of lesions and numbers of active lesions (Disanto et al., 2016). Furthermore, higher levels of another neurofilament in the blood have been shown to be associated with greater numbers of lesions and higher disability scores than lower levels in people with MS (Gresle et al., 2014). If results such as these are confirmed by further studies, blood neurofilament levels have the potential for adoption as an indicator of subclinical disease activity that is accessible even in countries where there are few MRI scanners.

In 2015, a panel of MS experts proposed the inclusion of measures of cognition, fatigue and depression in the definition of disease activity, as these patient-reported outcomes contribute substantially towards quality of life in people with MS (Stangel et al., 2015).

\subsection{Regular monitoring provides a strong basis for treatment decisions}

A proactive approach to monitoring, with a clear treatment target, should be adopted as a core principle of MS management, and people with MS should be encouraged to request this from their clinicians. The proposal of detailed clinical guidelines is beyond the scope of this report, but we recommend that any treatment target should be evidence based, and should evolve as further evidence becomes available.

The evidence base presented in this section indicates that MRI evidence of disease activity (or inactivity) complements clinical measurements of disease progression and can help to guide treatment decisions in a timely manner. Given the strong association between inflammatory lesions and subsequent clinical relapses and disability progression, the appearance of new lesions should be prospectively and accurately monitored by MRI brain scans performed at predefined intervals. Indeed, recent international (Lublin et al., 2014) and Canadian (Traboulsee et al., 2015) consensus papers have recommended that disease activity should be assessed at least annually using MRI.

Ideally, brain volume should also be monitored, because it is a measurable indicator of brain reserve and because high rates of brain atrophy in some people with MS are likely to predict poor outcome. We acknowledge that routine brain volume monitoring will rely on the incorporation of measurement techniques for this parameter into radiological practice, and that the technology required to do this is not yet widely available. However, quality monitoring of lesion development (counting new lesions) in MRI brain scans is currently feasible and should be routinely carried out in people with MS.

Recording the results of monitoring in a database or registry, accessed via a clinical management tool, can facilitate decisions about lifelong care and treatment for each person with MS because it allows MS healthcare professionals to view their full history of disease activity and treatment in one place. Systematically monitoring clinical and subclinical indicators of disease activity can help to identify treatment failure (suboptimal response to the current DMT). This, in turn, enables prompt switching to an alternative DMT to be considered; the evidence that outcomes can be improved by such a switch is presented in Section 5. Data from registries can also be analysed in order to generate a real-world evidence base that may be used to inform future clinical and regulatory practice and demonstrate value to payers (Butzkueven et al., 2006; Flachenecker and Stuke, 2008); this is further discussed in Section 6.

\subsection{Recommendations}

Regular clinical and radiological monitoring of disease activity and recording this information formally are key to the therapeutic strategy recommended in this report.

- Include evidence from monitoring via regular clinical evaluation and scheduled/unscheduled MRI brain scans in any definitions of disease activity or suboptimal 
This is an author's draft of an accepted article submitted and published in Multiple Sclerosis and Related Disorders

DOI : http://www.sciencedirect.com/science/article/pii/S221103481630102X

response, in order to assist in the rapid identification of treatment failure and the decision to switch treatment.

- Ensure that MS healthcare professionals can take the time to monitor disease activity in people with MS.

- Agree and implement standardized data collection techniques, protocols and data sets, nationally and internationally, to track clinical and subclinical events in routine practice. Incorporate these into a clinical management tool to facilitate individualized practice.

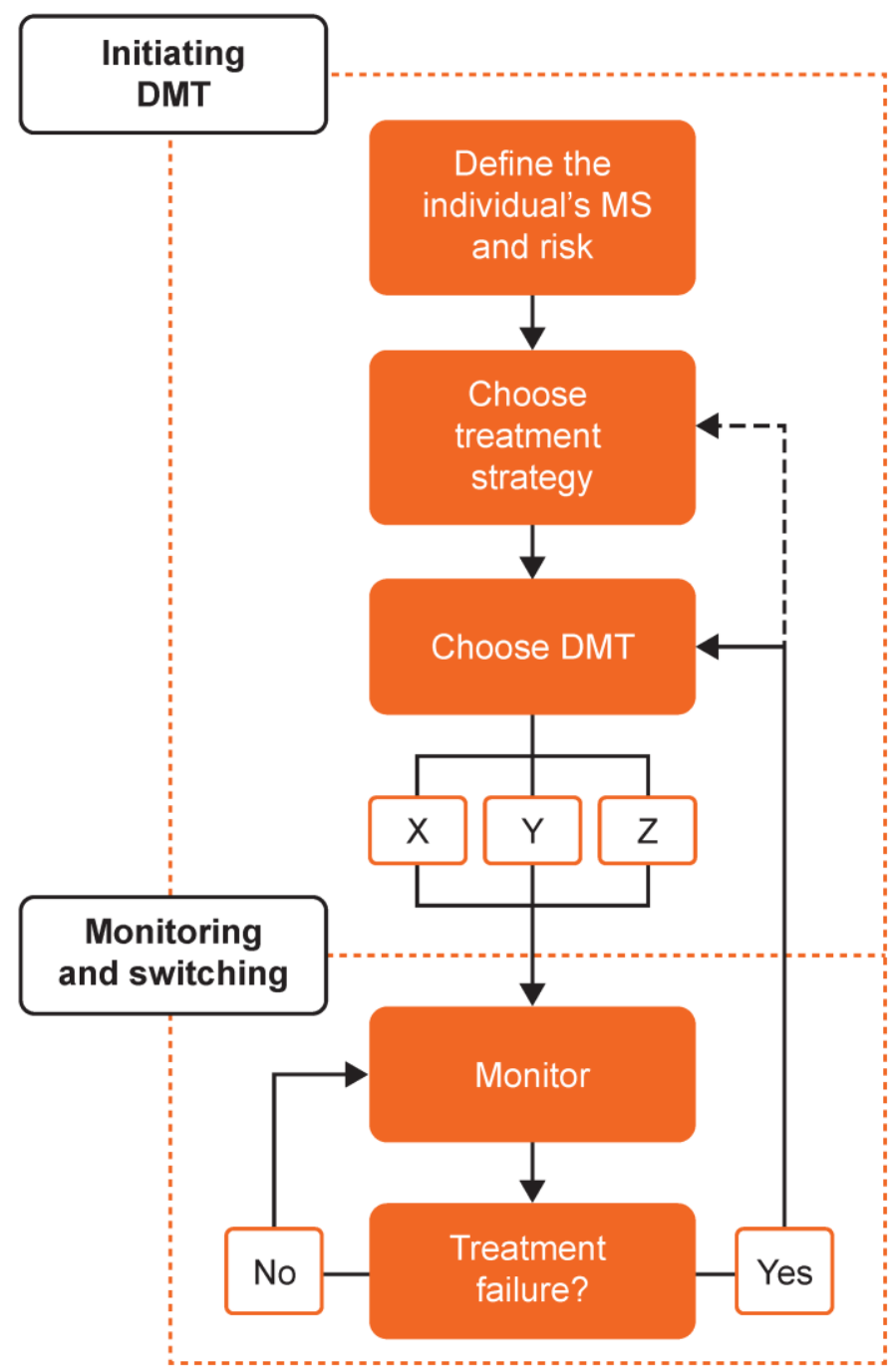

Figure 11. Monitoring is crucial to identifying treatment failure and enabling timely switching to a different DMT (Giovannoni, 2014b).

Reproduced with permission from Oxford PharmaGenesis Ltd. @ 2015 Oxford PharmaGenesis Ltd. 
This is an author's draft of an accepted article submitted and published in Multiple Sclerosis and Related Disorders

DOI : http://www.sciencedirect.com/science/article/pii/S221103481630102X

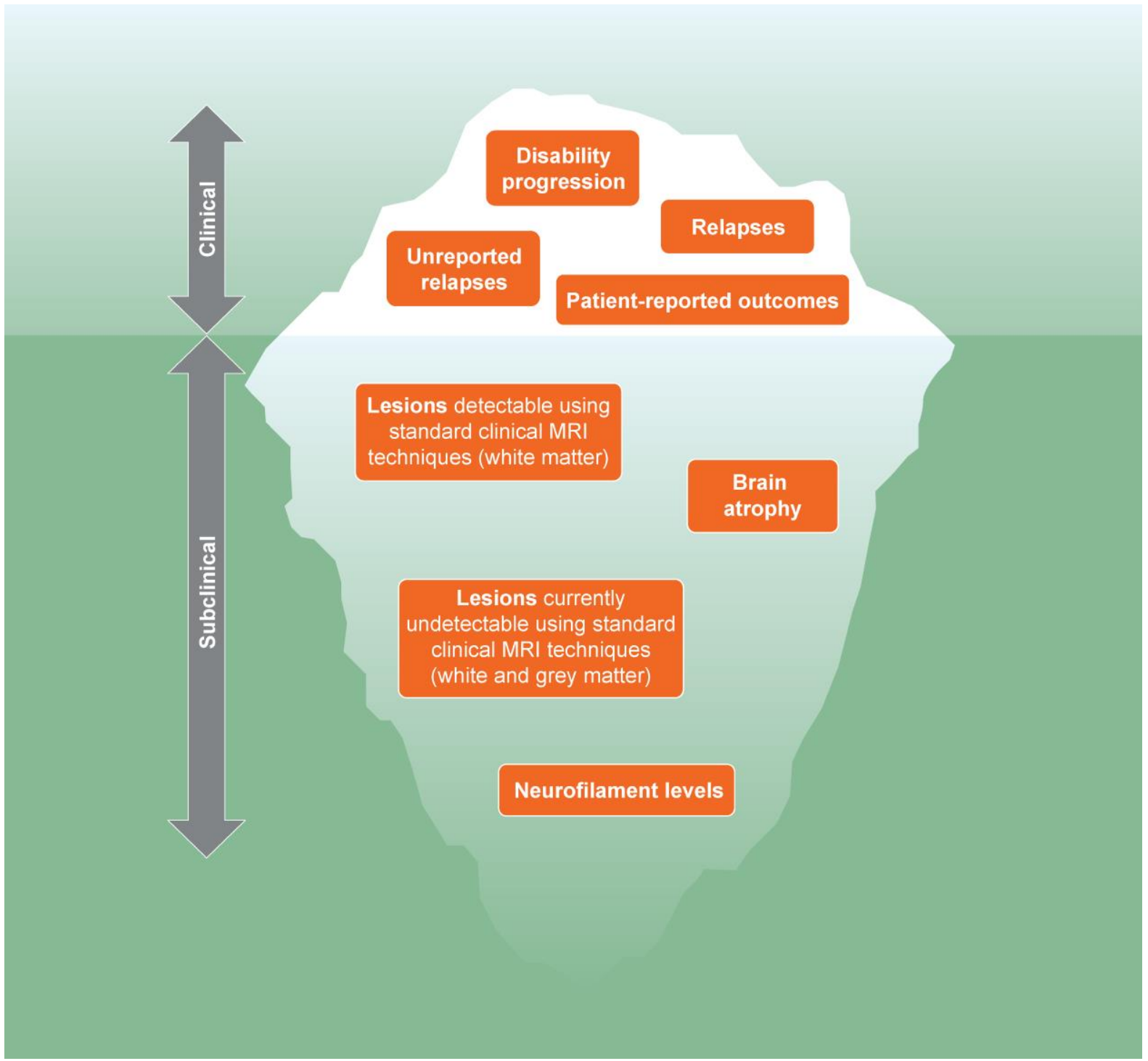

Figure 12. Monitoring disability progression and relapses can be supplemented by other measures of disease activity (Giovannoni, 2014a).

$\mathrm{MRI}$, magnetic resonance imaging.

Reproduced and adapted with permission from Gavin Giovannoni from Biomarkers in MS. EFNS/ENS Joint Congress of Neurology, 31 May-3 June 2014, Istanbul, Turkey (Giovannoni, 2014a). @ Gavin Giovannoni 2014. $\mathrm{X}, \mathrm{Y}$ and $\mathrm{Z}$ represent DMT options.

$\mathrm{DMT}$, disease-modifying therapy.

Reproduced and adapted with permission from Gavin Giovannoni from Personalizing treatment choice.

International MS Physician Summit, 22-23 March 2014, Prague, Czech Republic (Giovannoni, 2014b). @ Gavin Giovannoni 2014. 
Correlations exist between the effects of DMTs and:

- relapses and disability progression (Sormani et al., 2010; Fahrbach et al., 2013)

- MRI lesions and disability progression (Sormani et al., 2010; Fahrbach et al., 2013)

- MRI lesions and relapses (Sormani et al., 2009; Sormani and Bruzzi, 2013)

In people with CIS, the number of new lesions predicts the risk of a second relapse (that is, conversion to RRMS by any diagnostic criteria) (Kalincik et al., 2012; Uher et al., 2014)

The short-term (6-9 months) treatment effect on MRI lesions predicts the medium-term (12-24 months) treatment effect on relapses (Sormani and Bruzzi, 2013)

Changes in total lesion load (total volume of lesions visible on MRI) during the first 1-2 years of treatment predict long-term (10 years) disability progression (Popescu et al., 2013)

The initial treatment effect on MRI lesions predicts the long-term (up to 16 years) treatment effect on relapses and disability progression (Dobson et al., 2014)

Table 7. MRI lesions predict relapses and disability progression.

CIS, clinically isolated syndrome; DMT, disease-modifying therapy; MRI, magnetic resonance imaging; RRMS, relapsing-remitting multiple sclerosis. 


\section{Act swiftly on the evidence of disease activity}

\section{Key points}

- When the results of monitoring indicate suboptimal disease control, swift action should be taken to consider switching the person with MS to a different DMT.

- The traditional approach towards switching has been to increase the dose or injection frequency or to try another DMT with the same mechanism of action (MoA).

- A number of newer DMTs are now available, with different MoAs, and some of these have an evidence base supporting superior efficacy to that of an established DMT.

- Many people with MS may benefit from switching to one of these newer DMTs, as shown by a growing evidence base from clinical trials and real-world studies.

\subsection{Early detection of a suboptimal response to treatment is crucial}

MS is a highly variable disease. No single DMT has yet been shown to be effective in all people with MS, and the likelihood that a particular individual will be a responder or a non-responder to any given DMT cannot be predicted at present. Consequently, many people with MS may need to try several different DMTs before optimal control of disease activity is achieved. Studies have shown that disease activity during treatment with a DMT is predictive of a poor prognosis (Rudick and Polman, 2009). Prompt detection of disease activity that indicates a suboptimal response to a DMT is therefore very important, so that switching to an alternative agent can be considered.

\subsubsection{No consensus exists on the definition of 'suboptimal response'}

There is currently no widely agreed definition of a suboptimal response to DMT, nor are there universally followed guidelines for managing MS in people who are non-responders. A number of authorities have issued guidance, but no single consensus exists (Rudick and Polman, 2009; Havrdova et al., 2010; Freedman et al., 2013; Costello et al., 2015; Stangel et al., 2015; Yamout et al., 2015).

A treatment target of 'no evidence of disease activity' (NEDA) has been adopted in the management of other chronic progressive diseases, such as rheumatoid arthritis (Smolen et al., 2010), spondyloarthritis (Smolen et al., 2014), lupus (Doria et al., 2015) and cancer (Robinson et al., 2014b; a). Similarly, NEDA has been proposed as a treatment target in MS by a panel of experts, and has been defined as no relapses, no increase in disability and no MRI activity (no new or newly enlarged lesions or active lesions) (Havrdova et al., 2009; Havrdova et al., 2010). These experts suggest that people with MS should be offered the opportunity to switch to an alternative DMT when there is evidence of disease activity according to these criteria. The predictive power of the NEDA measure is illustrated by a recent study of 219 people with CIS or RRMS. This showed that if NEDA was reached in an individual after 2 years of treatment with a DMT, there was an almost $80 \%$ chance that their disability would not have progressed 7 years later (by more than 0.5 EDSS points) (Rotstein et al., 2015).

Attaining and maintaining NEDA may not be possible for every person with MS. In the same study, a state of NEDA was reached in $27.5 \%$ of participants after 2 years and in only $7.9 \%$ after 7 years (Rotstein et al., 2015). However, most of the participants took established DMTs (as they were enrolled in the study before any newer DMTs became available), and the numbers included were too low for the relative merits of treatment switching strategies to be evaluated. A similar issue surrounds an analysis of four clinical trials of newer DMTs (with an evidence base supporting superior efficacy to that of an established DMT), the results of which indicated that NEDA was reached in only $32-39 \%$ of participants after 2 years of treatment (Rotstein et al., 2015) - there was no option for participants 
This is an author's draft of an accepted article submitted and published in Multiple Sclerosis and Related Disorders

DOI : http://www.sciencedirect.com/science/article/pii/S221103481630102X

who remained in these trials to switch to a different DMT if they experienced a suboptimal response. There is not yet an evidence base that indicates what proportion of people with MS may be expected to reach NEDA if all DMTs were available and if MRI indicators of disease activity were routinely monitored to enable timely switching.

Recently, it has been suggested that brain atrophy rate should be included in the definition of NEDA (De Stefano et al., 2014b); this would shift the focus of MS treatment to preventing organ damage and promoting brain health. In addition, a panel of MS experts has proposed the inclusion of measures of cognitive function in the NEDA definition because cognition, fatigue and depression contribute substantially towards quality of life in people with MS (Stangel et al., 2015). Furthermore, a measure based on the number of new MRI lesions and relapses during the first year of treatment (the 'modified Rio score') has been shown to predict a poor response to a particular class of established DMT over the course of 3 years (Sormani et al., 2013) and 5 years (Romeo et al., 2015).

\subsection{Demonstrable disease activity should raise questions about treatment strategy}

Complete freedom from disease activity detectable by MRI is unlikely to be possible for all people with MS using current DMTs; however, neurologists should be mindful of the principle and at least aim for the lowest level of subclinical disease activity that is not predictive of further suboptimal response. The Canadian MS Working Group, in a 2013 paper, recommends managing the treatment of people with MS by monitoring three domains: relapses, disability progression and MRI activity (new lesions). A change in management would be warranted by high, medium or low levels of concern in one, two or three of these domains, respectively (Freedman et al., 2013). The Multiple Sclerosis Coalition in the USA, in a 2014 consensus paper, recommends considering switching DMT if there is additional clinical or MRI disease activity; this means that a decision to switch treatment could be based on MRI evidence alone. The paper also recommends that suboptimal response should be "determined by the individual and his or her treating physician" (Costello et al., 2015). The ABN, in its 2015 guidelines, notes that "new MRI lesions are a more sensitive index of inflammatory disease activity than clinical relapses." (Scolding et al., 2015)

However, in practice, switching tends to be based on clinical evidence alone. Regulatory authorities guide the circumstances under which a named DMT can be initiated, but they do not define suboptimal response and seldom provide guidance on when to switch from one DMT to another. Currently, some neurologists will not switch a person with MS to a different DMT without clinical evidence of disease activity (relapses or disability progression), even when clear MRI evidence of disease activity is available (Tornatore et al., 2012; Hanson et al., 2014). In a survey of MS specialist nurses in the UK, conducted in January $2014,72 \%$ of respondents reported that they would wait for two or more relapses before referring a person with MS for a review of their DMT. In addition, most neurologists in the USA recommend a minimum treatment duration of 6-12 months before switching to another DMT for reasons of inadequate disease control (Tornatore et al., 2012), as treatment can take some time to take effect.

The development of a clinical guideline is outside the scope of this report, but we recommend that treatment targets and definitions of 'disease activity' and 'suboptimal response' should be evidence based, should evolve as further evidence becomes available and should aim to maximize lifelong brain health. 
This is an author's draft of an accepted article submitted and

published in Multiple Sclerosis and Related Disorders

DOI : http://www.sciencedirect.com/science/article/pii/S221103481630102X

\subsection{What happens in current clinical practice?}

\subsubsection{Switching among established therapies is common}

The majority of people with relapsing forms of MS start treatment with an established DMT that was approved during the 1990s (Section 3.4). Within 2 years of starting an established DMT, about onethird to two-thirds of people with MS are classified as 'non-responders' or 'suboptimal responders', as defined by a variety of different clinical measures involving relapses and/or disability progression (Romeo et al., 2013; Prosperini et al., 2014). This proportion could be higher if the description of disease activity included MRI measures (Barkhof et al., 1992).

Among the established DMTs, there are only two MoAs. Owing to the limited options available, a traditional strategy for treatment switching was to increase the dose or injection frequency, or to try another DMT with the same MoA. In a US study involving 6181 people with MS who initiated treatment with a DMT in 2007-2009, $79 \%$ of those who switched from an initial established DMT did so to another established DMT; the rest switched to a newer DMT. Of those who switched for a second time, about two-thirds received yet another established DMT (Bonafede et al., 2013). This approach could indicate a reluctance to prescribe more recently approved DMTs until options involving established DMTs have been exhausted. Now that several newer DMTs with a range of MoAs are available, however, a 2014 consensus paper by the Multiple Sclerosis Coalition recommends that non-responders consider switching to a different DMT regimen, for example to one with a different MoA (Costello et al., 2015).

\subsubsection{Attitudes towards newer therapies vary}

The decision to prescribe a newer DMT might be influenced by prescribing guidelines, drug reimbursement policies, insurance company rules at the local, regional or national level, patient choice and concerns regarding potential side effects (Table 4 in Section 3.3.2). Furthermore, some neurologists may be wary of the need to change routine clinical practice in order to meet the monitoring requirements of some newer DMTs. Neurologists are familiar with managing the side effects of established treatments; however, newer DMTs have different safety profiles from those of established DMTs and some require a greater degree of monitoring (Damal et al., 2013; Rommer et al., 2014). Therefore, people with MS and their treating healthcare professionals need to balance the potentially higher efficacy levels of some newer DMTs against their individual risk profiles (Damal et al., 2013; Rommer et al., 2014).

The varying attitudes towards innovation among professionals in specialist fields, such as neurology, should not be underestimated; they can result in geographical differences in the approach to disease management or the speed of adoption of newer treatments. This sociological phenomenon is known as the 'diffusion of innovation' (Rogers, 2003) and, alongside factors such as a lack of up-to-date information, it may account for differences in overall practice patterns.

The proportion of people receiving treatment for MS who were given a newer DMT varied widely between countries in 2013 (Figure 13) (Multiple Sclerosis International Federation, 2013i; h; Wilsdon et al., 2013; Hollingworth et al., 2014; World Bank, 2015b) and even within countries. For example, data from Australia show that newer DMT use rose from $8 \%$ to $33 \%$ of total DMT use in 2011 and 2013, respectively. When the figures for newer DMT use in 2013 are broken down according to states and territories within the country, they range from $17 \%$ to $40 \%$ of total DMT use (Hollingworth et al., 2014).

Combination therapy (i.e. using more than one drug at the same time) has been successfully employed to treat certain types of cancer (Wu et al., 2015), a complex disease in which drugs with different MoAs can have an additive effect. Such an approach is also being investigated for people 
This is an author's draft of an accepted article submitted and

published in Multiple Sclerosis and Related Disorders

DOI : http://www.sciencedirect.com/science/article/pii/S221103481630102X

with MS whose disease is inadequately controlled, but clinical experience is currently limited (Freedman et al., 2013).

\subsubsection{Discontinuation and treatment gaps are common}

Gaps in the treatment of people with active MS are thought to be equivalent to, or worse than, periods of non-adherence, and hence treatment gaps will have a negative impact on the disease course. When switching treatment, $30 \%$ of people with MS have gaps in their therapy exceeding 30 days, and almost $20 \%$ have gaps in excess of 60 days (Margolis et al., 2011). Some regulatory authorities recommend treatment gaps when switching between certain DMTs to avoid the risk of unwanted effects on the immune system that might increase the likelihood of serious infections (Biogen Idec Limited, Revised 22 December 2014; Novartis Pharma GmbH, Revised 24 July 2014). Real-world evidence indicates that such gaps can increase the risk of a relapse; this evidence could be used as a basis for updating recommendations about the maximum length of treatment gaps (Jokubaitis et al., 2014).

\subsection{Choice of therapy should be an evidence-based decision}

Delaying treatment switching, or excluding the use of newer DMTs, may be detrimental to establishing rapid control of the disease before further relapses or disability progression occur. Indeed, a recent position paper by the AAN recommends that people with MS should be able to access all DMTs "when they have the potential to provide clinical benefit" and that any treatment sequences imposed by payers or insurance carriers should be driven by evidence-based data and not DMT costs (American Academy of Neurology, 2015).

There is increasing evidence that people with MS whose disease is inadequately controlled by an established DMT will benefit from receiving an appropriate newer DMT. Several studies have shown that people with MS who switch from an established DMT to a newer DMT (with an evidence base supporting superior efficacy to that of an established DMT) are more likely to be free from relapses (Prosperini et al., 2012; Bergvall et al., 2014; He et al., 2015; Spelman et al., 2015), disability progression (Prosperini et al., 2012; He et al., 2015; Spelman et al., 2015) and new MRI activity (Prosperini et al., 2012) - and can even experience improvements in their disability status (He et al., 2015) - compared with switching to another established DMT. A number of other studies have demonstrated that improvements in disability (Kallweit et al., 2012; Svenningsson et al., 2013; Butzkueven et al., 2014a; Kalincik et al., 2015a), quality of life measures (Khatri et al., 2014), fatigue (Svenningsson et al., 2013) and cognition (Svenningsson et al., 2013) are also possible when people with MS receive a newer DMT (with an evidence base supporting superior efficacy to that of an established DMT; Table D.1) (!!! INVALID CITATION !!! (Khatri et al., 2011; Kallweit et al., 2012; Prosperini et al., 2012; Svenningsson et al., 2013; Baldi et al., 2014; Bergvall et al., 2014; Butzkueven et al., 2014a; Khatri et al., 2014; Meng et al., 2014; He et al., 2015; Kalincik et al., 2015a; Spelman et al., 2015)). As adequate control of disease activity will not always be achieved in all people with MS taking any one DMT, regular monitoring should be the cornerstone of any treatment strategy (Section 4).

The favourable results obtained in the studies that compared treatment switching indicate that neurologists should consider evidence-based approaches to using newer DMTs in people with relapsing forms of MS and suboptimally controlled disease activity. As with treatment initiation (Section 3.6), the full range of DMTs should be considered when switches are made, to enable people with MS and their treating healthcare professionals to make fully informed, shared decisions. 


\subsection{Recommendations}

Rapid switching to another DMT if monitoring reveals a suboptimal response will maximize the chance of achieving the best possible outcome for every person with MS who would be at risk of inflammatory disease activity if they were not receiving treatment.

- Ensure that MS healthcare professionals can take the time to educate people with MS about strategies to manage their disease. Emphasize the importance of a "brainhealthy' lifestyle, the benefits of early treatment with therapies that can modify the disease course, the likely consequences of inadequate or suboptimal treatment and the goal of minimizing disease activity while optimizing safety.

- Implement a shared decision-making process that embodies dialogue between people with MS and healthcare professionals. A well-informed and proactive collaboration between people with MS and their healthcare team is vital to successful management of the disease.

- Make the full range of disease-modifying therapies available to people with active relapsing forms of MS, regardless of their treatment history, to speed up adoption of the most appropriate treatment strategy that optimizes effectiveness and safety for each individual.

- Maintain treatment with a disease-modifying therapy for as long as a person with MS would be at risk of inflammatory disease activity if they were not receiving treatment; in the case of a suboptimal response, make a prompt decision about whether or not to switch therapy.

- Seek regulatory and health technology assessment approvals to implement these recommendations. 
This is an author's draft of an accepted article submitted and published in Multiple Sclerosis and Related Disorders

DOI : http://www.sciencedirect.com/science/article/pii/S221103481630102X

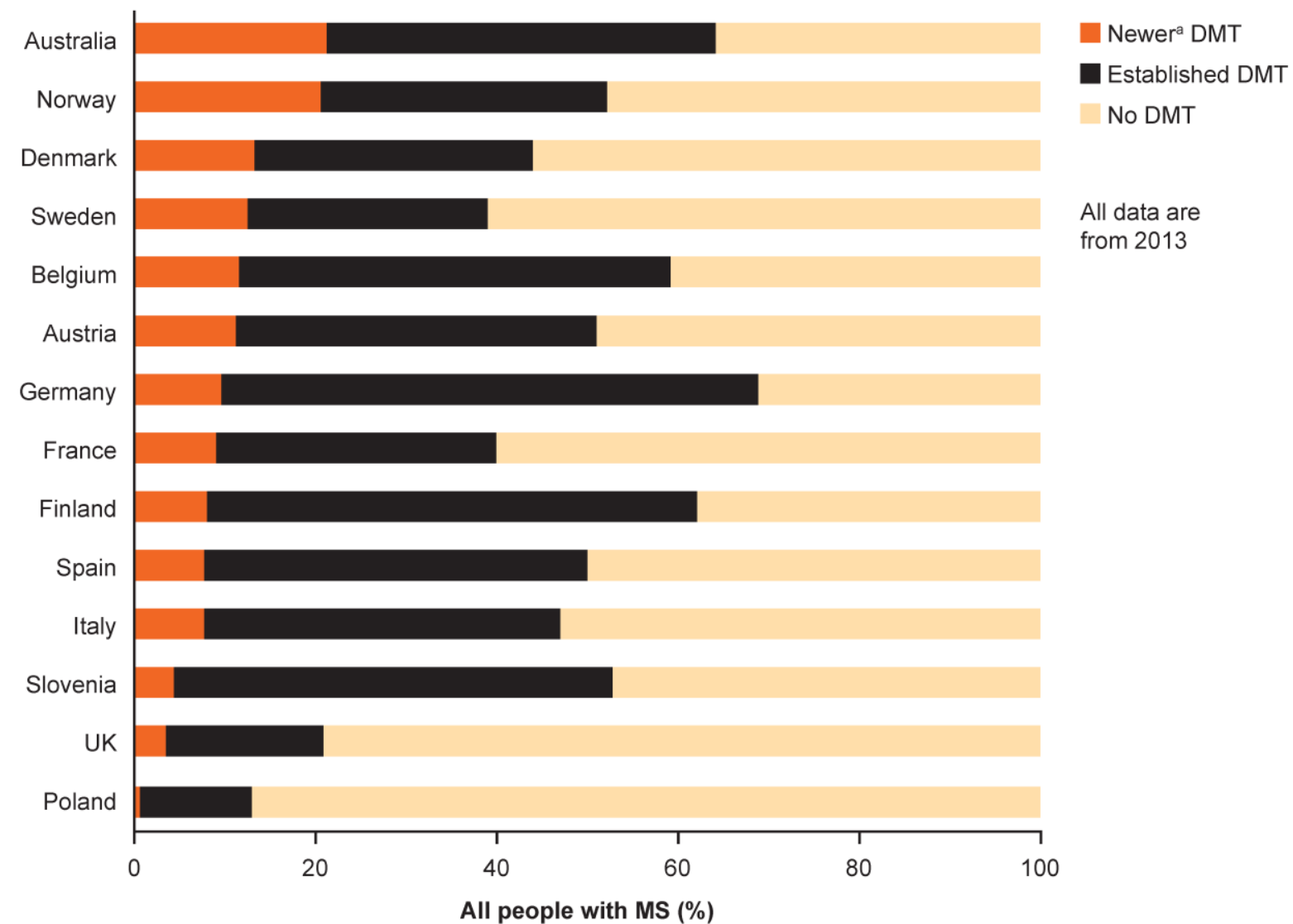

Figure 13. The proportion of people with all forms of MS receiving a newer DMT in 2013 varied considerably between countries.

aAll newer DMTs available at the time that these studies were conducted have an evidence base supporting superior efficacy to that of an established DMT.

The data were generated from DMT sales figures as described in the original sources (Wilsdon et al., 2013;

Hollingworth et al., 2014), and therefore potentially include people with all forms of MS (relapsing or progressive), and do not differentiate between treatment initiation and treatment switching. All DMTs for Australia: calculation based on sales figures (Hollingworth et al., 2014), population (World Bank, 2015b) and number of people with MS (Multiple Sclerosis International Federation, 2013h).

DMT, disease-modifying therapy.

Reproduced with permission from Oxford PharmaGenesis Ltd. @ 2015 Oxford PharmaGenesis Ltd. 


\section{Take a comprehensive economic approach to evaluating treatment cost-effectiveness}

\section{Key points}

- As a person with MS becomes more disabled, costs outside the healthcare system markedly increase until they comprise about two-thirds of all costs.

- The treatment strategy outlined in this report, of early intervention, regular monitoring and timely switching of therapy to maximize lifelong brain health, has the potential to reduce disability progression and therefore to avoid some of these long-term costs.

- However, most health technology assessment (HTA) bodies and reimbursement agencies consider only the costs borne by healthcare and social services. This leads to suboptimal decisions, where DMTs that have the potential to provide an economic benefit to society as a whole may not be considered cost effective.

- The global prices of DMTs - as for other pharmaceutical products - are generally set based on the conditions in high-income countries, and other countries may have difficulties in granting access to these therapies.

- Current financing models focus on the prices of individual DMTs; however, this effectively incentivizes the rationing of individual drugs instead of focusing on finding the optimal therapy for each person with MS. Alternative financing models should, therefore, be investigated.

- For people with MS in low-income countries, access to DMTs can be improved by developing financial support programmes and less-expensive DMTs.

- Recording the results of monitoring in databases or registries will generate real-world evidence of the effectiveness and safety of individual DMTs and therapeutic strategies. This can be used to inform future clinical and regulatory practice.

\subsection{All benefits and costs should be included in economic evaluations}

\subsubsection{Costs outside the healthcare system increase as disability progresses}

As a person with MS becomes more disabled, costs outside the healthcare system, such as informal care and production losses due to incapacity to work, markedly increase until they comprise about two-thirds of all costs (Figure 8 in Section 1.4) (Kobelt et al., 2006b). Diagnosing and treating MS early needs to be coupled with a management strategy based on monitoring, and with increased payer flexibility to switch among all DMTs at the first sign of disease activity; this will help to preserve brain tissue, maximize lifelong brain health and reduce the likelihood of relapses and disability progression (Sections 2-5). Although the immediate direct costs of DMTs and the demands on healthcare resources (such as MRI) are likely to increase with this approach (Russo et al., 2004), the high costs occurring in the later stages of MS will be reduced if unnecessary disability progression can be avoided.

\subsubsection{National health technology assessments evaluate what to fund from the public budget}

When a treatment has been approved by the relevant regulatory authority, a national HTA body will generally assess its value - the health benefits in relation to costs - to decide whether it will be funded from the public budget. A formal economic evaluation of health outcomes and costs is used to support this decision in most countries (International society for pharmacoeconomics and outcomes research (ISPOR), 2015). 
This is an author's draft of an accepted article submitted and published in Multiple Sclerosis and Related Disorders

DOI : http://www.sciencedirect.com/science/article/pii/S221103481630102X

Health outcomes are commonly measured using quality-adjusted life-years (QALYs). These measure the effect of a treatment on length and quality of life and can be compared across diseases (Weinstein et al., 2009). A treatment that reduces the likelihood of a person dying early, or improves health-related quality of life, will have a positive impact on QALYs. Some economic evaluations also consider the impact that informal caregiving has on the health of family members. This is highly applicable to MS - indeed, the results of a recent survey indicate that caregivers' health-related quality of life deteriorates as the person with the disease becomes more disabled (Acaster et al., 2013).

\subsubsection{Costs of informal care and incapacity to work are not always considered}

It is widely accepted that economic evaluations of health outcomes should include all potential health benefits to all parties. It is logical, therefore, that economic evaluations should also consider the potential costs to all parties (Jonsson, 2009); in other words, they should take a societal perspective. However, most HTA bodies and reimbursement agencies have adopted a payer perspective, where only the costs borne by healthcare and social services are considered. The costs to wider society, such as informal care and incapacity to work, are often considered only in a secondary analysis - or not at all.

\subsubsection{Direct costs commonly accrue in one part of society and benefits in another}

Adopting a payer perspective (narrow cost model) leads to suboptimal decisions, with the result that treatments with the potential to provide an economic benefit to society (other than savings to healthcare services) may not be considered to be cost effective (Jonsson, 2009). It is quite normal for direct costs to accrue in one part of society and benefits in another. As the health-related benefits of treatment are enjoyed by people with the disease and their families, it is only fair to factor in also the burden of informal care and indirect costs that would otherwise be borne by these parties to a large extent. In the case of MS in particular - a chronic, progressive disease that starts at a young age taking a societal viewpoint is crucial when evaluating the potential for the long-term health benefits of early treatment with a DMT to outweigh the costs. Our recommendation is that economic evaluations should be carried out from a societal perspective; in other words, that they should consider health benefits and costs to all parties.

\subsection{Access to disease-modifying therapies should be improved}

\subsubsection{Access to DMTs varies widely}

Access to DMTs depends not only on clinical effectiveness and the decisions of regulatory authorities (Table 4) but also on affordability. In the USA, prices have increased five to seven times more rapidly than prescription drug inflation, and currently no DMTs cost less than US\$50000 (€37500) per year for an individual person with MS. These US costs are two to three times higher than those in Australia, Canada or the UK (Hartung et al., 2015). As global prices for DMTs are generally set based on the conditions in high-income countries, healthcare providers in some other countries may have difficulties in granting wide access to them. Compared with a more wealthy nation, healthcare expenditure in a low-income country will not only be less in absolute terms but will also constitute a lower proportion of total expenditure as health care competes with other basic necessities. As a consequence, reimbursement of the costs of DMTs in different countries varies from no funding at all, particularly for newer therapies, to full reimbursement (Figure 14) (Multiple Sclerosis International Federation, 2013e; d; c; b; World Health Organization, 2015).

Policy makers could encourage the pharmaceutical industry to expand the scope of existing financial support programmes, so as to improve access where it is currently limited. Offering discounts in this way, however, could create the problem of parallel trade (the import of DMTs purchased elsewhere at 
This is an author's draft of an accepted article submitted and

published in Multiple Sclerosis and Related Disorders

DOI : http://www.sciencedirect.com/science/article/pii/S221103481630102X

a lower price), which would need to be controlled - a topic that is beyond the scope of this report. The development and use of less-expensive DMTs (for example, generic versions) could also help to make these drugs more accessible to people with MS in low-income countries.

\subsubsection{Access to newer DMTs varies widely}

Even in high-income and upper-middle-income countries where the costs of newer DMTs are fully reimbursed, access to these therapies varies widely. Given that newer DMTs tend to be more expensive than established DMTs (Hartung et al., 2015), much of this difference appears related to affordability. A correlation exists between the proportion of people with MS who are on treatment and receiving a newer DMT and the per capita spending on health care (Figure 15) (Wilsdon et al., 2013; Hollingworth et al., 2014; World Health Organization, 2015).

Sometimes, additional administrative restrictions are put in place to limit the number of people with MS who can receive treatment and, thus, limit the budget that can be spent on DMTs. In some Eastern European countries, affordability has historically led to waiting lists or limits on the length of time for which a person with MS can be prescribed a DMT (Wilsdon et al., 2013).

HTA bodies have restricted reimbursement to a narrower group of people with MS than that specified by the EMA in some high-income countries. For example, the EMA indicates that a particular newer DMT can be used in (a) people with RRMS whose disease has failed to respond to at least 1 year of treatment with an established DMT, or (b) those with rapidly evolving, severe RRMS (Biogen Idec Limited, Revised 22 December 2014). In the Netherlands, however, reimbursement is restricted to people in group (a), while in England reimbursement is restricted to those in group (b). In Italy, the restrictions for group (a) regarding recent relapses are tighter than the EMA indication, while in Belgium the DMT costs will only be reimbursed for people below a certain disability level on the EDSS (Wilsdon et al., 2013).

\subsection{Alternative financing models should continue to be investigated}

Our recommendation is that the full range of DMTs should be available to people with active relapsing forms of MS, regardless of their disease history, so that they and their treating healthcare professionals can make shared, informed decisions about treatment. Established DMTs feature prominently in budgets set aside for specialty drugs that are used in all disease areas (Express Scripts, 2015). In order to provide greater access to newer DMTs, investigations into alternative financing models should be continued.

Current payment systems tend to focus on the cost per pack/vial of medicine, which was an important factor in the 1990s, when fewer DMTs were available than today. In this context, the advent of biosimilar drugs (generic versions of biological drugs that can be marketed once the original patent has expired) and the approval of further newer DMTs is likely to drive an overall focus on reducing the cost per pack/vial of DMT. Improved outcomes for people with MS, however, are seldom the consequence of treatment with just one DMT. Rather, they result from a therapeutic strategy that aims to find the most appropriate DMT for each individual by switching treatment if there is evidence of disease activity. It is not logical from a societal perspective, therefore, for payment systems to focus on the costs of individual DMTs rather than the optimal treatment for each person with MS.

One possible solution is a capitation, or 'payment per patient per month', scheme in which a fixed payment is made in return for a negotiated range of services (NHS England, 2014). Such payments may be combined with additional payments that are conditional on meeting selected quality or outcome standards. This could help to incentivize keeping each person with MS as well as possible, and it may promote an integrated approach to care, with optimized procedures for diagnosis, monitoring and treatment switching. 
This is an author's draft of an accepted article submitted and published in Multiple Sclerosis and Related Disorders

DOI : http://www.sciencedirect.com/science/article/pii/S221103481630102X

\subsection{Real-world evidence should drive regulatory and funding decisions}

The therapeutic strategy of early treatment, monitoring and switching, with the full range of DMTs available, will change the economic picture of MS and has the potential to reduce the long-term costs of the disease significantly. Regulatory authorities and payers, however, make initial decisions about DMTs based on their efficacy and safety in short-term clinical trials - an environment in which it is not possible to switch to a different DMT if disease activity is inadequately controlled. Consideration of real-world evidence from registries and databases of the long-term effectiveness and safety of DMTs and therapeutic strategies will help regulatory authorities, HTA bodies and payers to ensure that these decisions do not become out of date or rigid, denying people with MS the flexibility to benefit from the most recent evidence.

The registries that currently exist, however, have been set up independently of one another, for different reasons, and they cover different kinds of patient populations. As a result, the parameters collected, and the data collection techniques and protocols that are followed, are often not standardized (Flachenecker et al., 2014). In this context, two international data sets that have overcome some of these hurdles are worthy of note:

- MSBase is an online registry that individual MS clinics can choose to sign up to (Butzkueven et al., 2006). As of July 2015, it contains over 35000 patient records from 199 clinics in 69 counties (MSBase, 2015), and it has led to the publication of a number of papers, including several presenting real-world evidence of the effectiveness of DMTs (Section 5.4) (Spelman et al., 2013; Butzkueven et al., 2014b; Jokubaitis et al., 2014; He et al., 2015; Kalincik et al., 2015a; Kalincik et al., 2015b; Spelman et al., 2015).

- The European Register for Multiple Sclerosis (EUReMS) aims to unite existing national MS registries around a core data set (Pugliatti et al., 2012). To date, data have been provided from 13 registries, although only three participating national registries contain the parameters necessary for inclusion in a study assessing the effectiveness and accessibility of DMTs (European Multiple Sclerosis Platform, 2014).

The routine monitoring of people with MS with an agreed minimum data set has not yet been widely adopted, although we earlier recommended standardizing and recording the results of treatment and routine monitoring in the context of a clinical management tool to facilitate individualized practice (Section 4.3). Additionally, we recommend incorporating such results into national and international MS registries and databases in order to generate real-world evidence of the long-term effectiveness and safety of individual DMTs. This would also enable the effectiveness of overarching therapeutic strategies to be evaluated, for example the predictive power of NEDA (by any definition covered by the data set) on clinical outcomes or the effect of variations in practice patterns on disease activity and health outcomes for people with MS. For this to be possible, we further recommend that the curators of databases and registries should ensure accessibility of data to those performing HTAs and economic evaluations.

\subsection{Recommendations}

The therapeutic strategy of early treatment, monitoring and switching, with the full range of DMTs available, will change the economic picture of MS and has the potential to reduce the long-term costs of the disease significantly.

- Carry out economic evaluations of therapies and other healthcare interventions from a societal perspective, considering the health benefits and costs to all parties, to improve assessments of true cost-effectiveness. 
- Encourage the continuing investigation, development and use of cost-effective therapeutic strategies, of approaches that reduce the costs of managing MS and of alternative financing models, to improve access to treatment.

- Agree and implement standardized data collection techniques, protocols and data sets, nationally and internationally, to track clinical and subclinical events in routine practice. Incorporate these into national and international MS registries and databases to generate real-world evidence of the long-term effectiveness and safety of therapeutic strategies; such evidence can be used by regulatory bodies and payers, and will enable differences in practice patterns to be assessed and addressed.

- Ensure that access to multiple sclerosis registries and databases is available for those carrying out health technology assessments and economic evaluations. 
This is an author's draft of an accepted article submitted and published in Multiple Sclerosis and Related Disorders

DOI : http://www.sciencedirect.com/science/article/pii/S221103481630102X

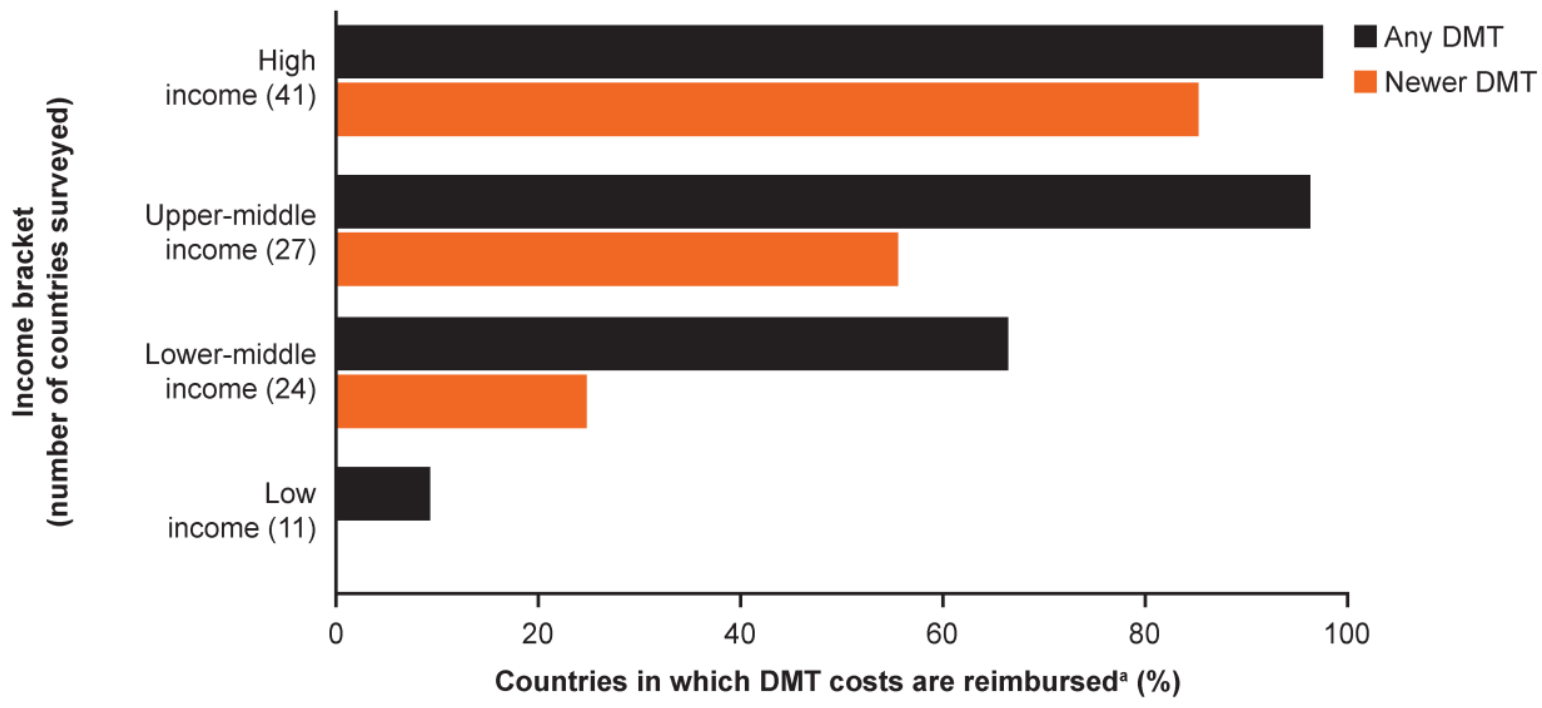

Figure 14. The costs of DMTs, especially newer DMTs, are more likely to be reimbursed in higherincome countries than in lower-income countries (Multiple Sclerosis International Federation, 2013e; d; c; b; World Health Organization, 2015).

aBy the government and/or by health insurance.

DMT, disease-modifying therapy; high-income country, gross national income per capita $\geq \$ 12746$ in 2013 ; upper-middle-income country, gross national income per capita $\geq \$ 4125$ and $<\$ 12746$ in 2013; lower-middleincome country, gross national income per capita $\geq \$ 1045$ and $<\$ 4125$ in 2013 ; low-income country, gross national income per capita $\leq \$ 1045$ in 2013 (World Bank, 2015a).

Reproduced with permission from Oxford PharmaGenesis Ltd. (C) 2015 Oxford PharmaGenesis Ltd. 
This is an author's draft of an accepted article submitted and published in Multiple Sclerosis and Related Disorders

DOI : http://www.sciencedirect.com/science/article/pii/S221103481630102X

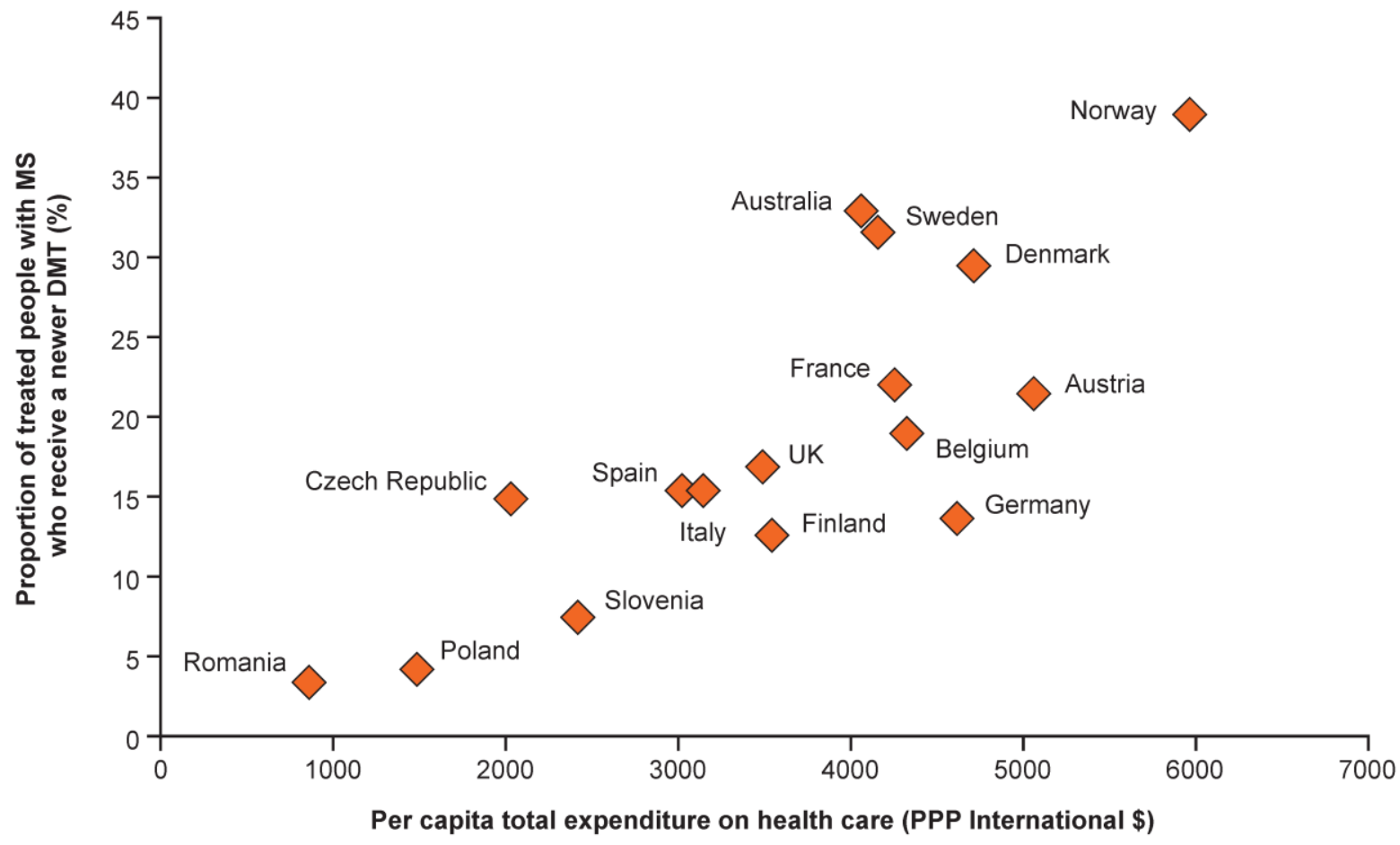

Figure 15. The prescription of newer DMTs (as a proportion of total DMTs) (Wilsdon et al., 2013; Hollingworth et al., 2014) is highest in countries with high per capita healthcare expenditure (World Health Organization, 2015).

All countries shown offer full or partial government reimbursement for the cost of established therapies and for at least one newer DMT.

DMT, disease-modifying therapy; PPP, purchasing power parity.

Reproduced with permission from Oxford PharmaGenesis Ltd. (C) 2015 Oxford PharmaGenesis Ltd. 


\section{Appendix A. Recommendations}

Multiple sclerosis has a profound personal, social and economic impact. Better outcomes for people with MS and those who care for them can be achieved if organizations implement the following three sets of recommendations.

1. Minimize delays in the diagnosis of MS and in the time to treatment initiation as these can result in irreversible disability progression.

- Educate the general public to take prompt action if early symptoms of MS develop, by visiting a healthcare professional. Awareness campaigns that highlight the typical initial symptoms, the negative impact of delaying treatment and the personal and societal costs of the disease would support this.

- Educate family and primary care physicians about the importance of promptly referring people with suspected MS to a neurologist, and ultimately to a specialist clinic, to speed up diagnosis and treatment initiation.

- Recommend that general neurologists refer people suspected of having the disease to specialist MS neurologists.

- Improve access to specialist care for MS: make diagnostic and monitoring procedures more widely accessible, increase the numbers of healthcare professionals who specialize in the management of MS, and ensure that these specialists provide prompt diagnostic and support services for people with suspected MS and those who have been newly diagnosed with the disease.

- Adopt the latest accepted diagnostic criteria, in order to diagnose MS as early as possible.

- Align prescribing guidelines with the latest accepted diagnostic criteria to give people with MS the opportunity to start treatment and receive support promptly, as soon as diagnosis is confirmed.
National bodies

Patient groups

National bodies

Professional bodies

Healthcare providers

National bodies

Professional bodies

Healthcare providers

National bodies

Healthcare providers

Reimbursement

agencies

National and international bodies

Healthcare providers

National bodies

Healthcare providers 
This is an author's draft of an accepted article submitted and

published in Multiple Sclerosis and Related Disorders

DOI : http://www.sciencedirect.com/science/article/pii/S221103481630102X

2. Set goals for treatment and ongoing management that aim for the best possible outcome for every person with MS.

- Ensure that MS healthcare professionals can take the time to educate people with MS about strategies to manage their

disease. Emphasize the importance of a 'brain-healthy' lifestyle, the benefits of early treatment with therapies that can modify the disease course, the likely consequences of inadequate or suboptimal treatment and the goal of minimizing disease activity while optimizing safety.

- Implement a shared decision-making process that embodies dialogue between people with MS and healthcare professionals. A well-informed and proactive collaboration between people with MS and their healthcare team is vital to successful management of the disease.

- Make the full range of disease-modifying therapies available to people with active relapsing forms of MS, regardless of their treatment history, to speed up adoption of the most appropriate treatment strategy that optimizes effectiveness and safety for each individual.

- Include evidence from monitoring via regular clinical evaluation and scheduled/unscheduled MRI brain scans in any definitions of disease activity or suboptimal response, in order to assist in the rapid identification of treatment failure and the decision to switch treatment.

- Ensure that MS healthcare professionals can take the time to monitor disease activity in people with MS.

- Agree and implement standardized data collection techniques, protocols and data sets, nationally and internationally, to track clinical and subclinical events in routine practice. Incorporate these into a clinical management tool to facilitate individualized practice.

- Maintain treatment with a disease-modifying therapy for as long as a person with MS would be at risk of inflammatory disease activity if they were not receiving treatment; in the case of a suboptimal response, make a prompt decision about whether or not to switch therapy.

- Seek regulatory and health technology assessment approvals to implement these recommendations.
National bodies

Professional bodies

Healthcare providers

National bodies

Professional bodies

Healthcare providers

Regulatory authorities Healthcare providers Health technology assessors

Reimbursement agencies

Healthcare providers Regulatory authorities

National bodies

Healthcare providers

National and international bodies Healthcare providers Curators of registries and databases

Healthcare providers Reimbursement agencies

Pharmaceutical companies

Professional bodies

Patient groups 
Any other stakeholders

3. Consult the most robust evidence base possible, and generate further evidence, in order to make good decisions about therapeutic and management strategies for MS.

- Carry out economic evaluations of therapies and other healthcare interventions from a societal perspective, considering the health benefits and costs to all parties, to improve assessments of true cost-effectiveness.

- Encourage the continuing investigation, development and use of cost-effective therapeutic strategies, of approaches that reduce the costs of managing MS and of alternative financing models, to improve access to treatment.

- Agree and implement standardized data collection techniques, protocols and data sets, nationally and internationally, to track clinical and subclinical events in routine practice. Incorporate these into national and international MS registries and databases to generate real-world evidence of the long-term effectiveness and safety of therapeutic strategies; such evidence can be used by regulatory bodies and payers, and will enable differences in practice patterns to be assessed and addressed.

- Ensure that access to multiple sclerosis registries and databases is available for those carrying out health technology assessments and economic evaluations.

\author{
Health technology \\ assessors \\ Reimbursement \\ agencies \\ Patient groups
}

Regulatory authorities Healthcare providers Health technology assessors

Reimbursement agencies

National and international bodies Healthcare providers Curators of registries and databases

National and international bodies Healthcare providers Curators of registries and databases

National bodies may include government departments or private organizations, depending on the country in question. 
This is an author's draft of an accepted article submitted and published in Multiple Sclerosis and Related Disorders

DOI : http://www.sciencedirect.com/science/article/pii/S221103481630102X

\section{Aim: maximize lifelong brain health}

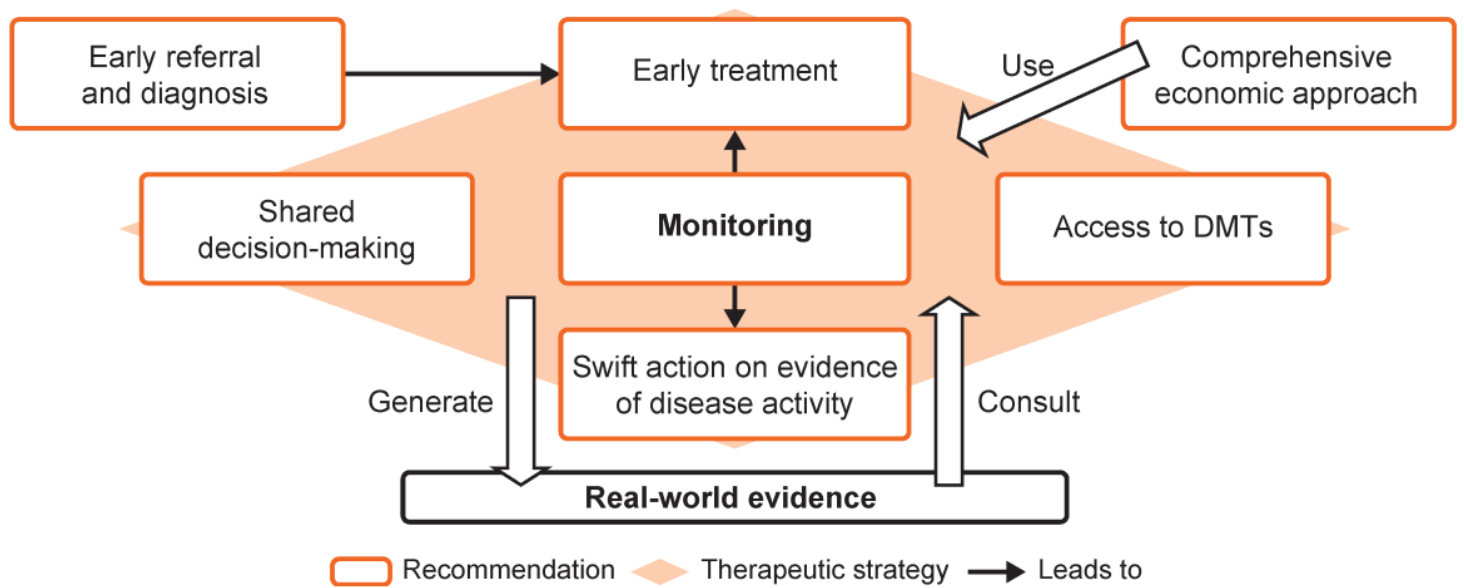

Figure A.1. We recommend a therapeutic strategy that aims to preserve central nervous system tissue and maximize lifelong neurological reserve (an important component of brain health) by reducing disease activity.

Reproduced with permission from Oxford PharmaGenesis Ltd. @ 2015 Oxford PharmaGenesis Ltd. 
This is an author's draft of an accepted article submitted and published in Multiple Sclerosis and Related Disorders

DOI : http://www.sciencedirect.com/science/article/pii/S221103481630102X

\section{Appendix B. Evidence supports the benefit of early treatment}

Results from clinical trials and real-world studies support early intervention with a DMT in CIS and RRMS.

Table B.1. In people with a diagnosis of CIS, treatment with a DMT increases the time to a second relapse and improves MRI outcomes in randomized controlled trials.

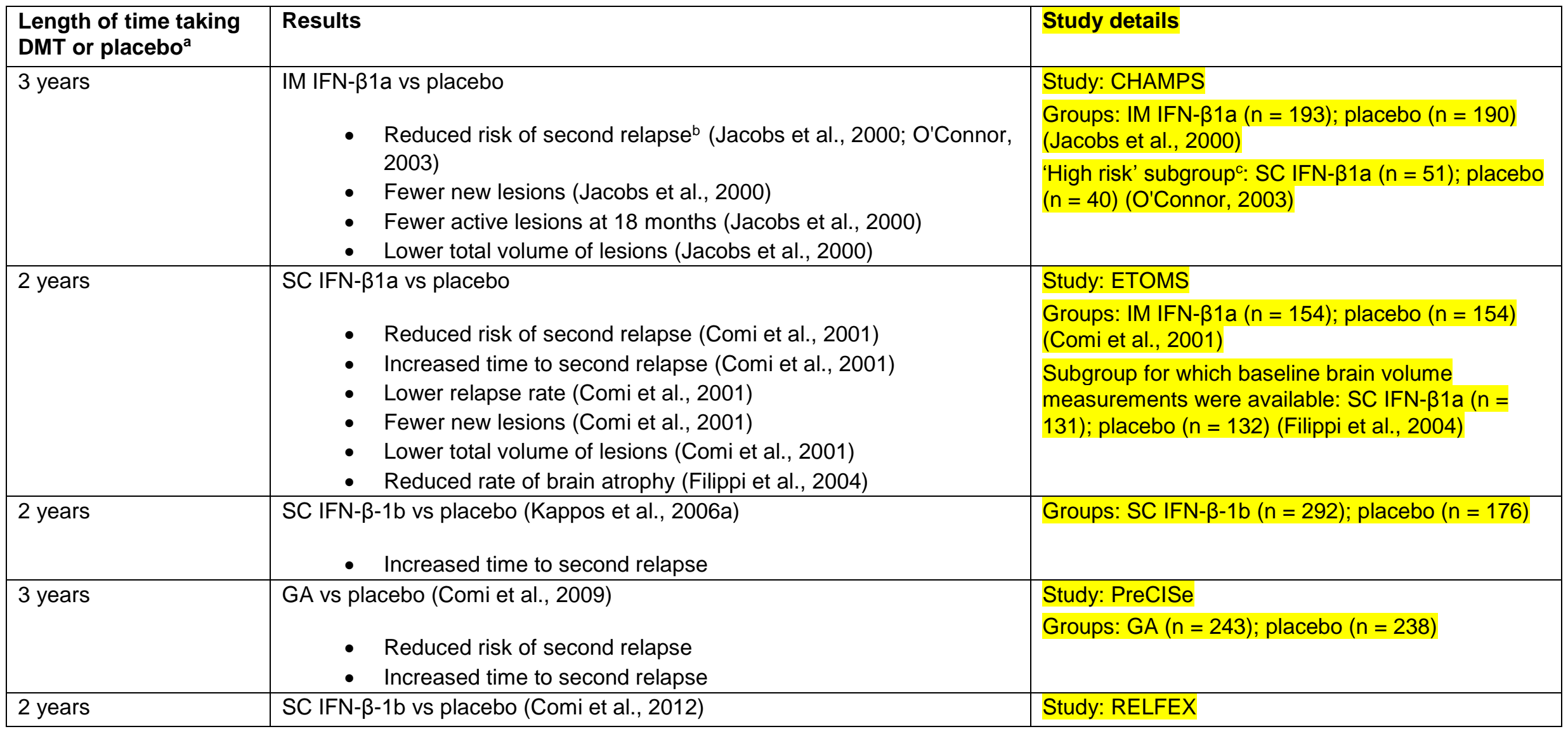


This is an author's draft of an accepted article submitted and published in Multiple Sclerosis and Related Disorders

DOI : http://www.sciencedirect.com/science/article/pii/S221103481630102X

\begin{tabular}{|c|c|c|}
\hline & - Reduced risk of second relapse & $\begin{array}{l}\text { Groups: SC IFN- } \beta-1 \text { b } 3 \text { times a week }(n=171) \text {; SC } \\
\text { IFN- } \beta-1 \text { b once per week }(n=175) \text {; placebo }(n= \\
\text { 171) }\end{array}$ \\
\hline 2 years & $\begin{array}{c}\text { Teriflunomide vs placebo (Miller et al., 2014) } \\
\text { - Reduced risk of second relapse } \\
\text { - Reduced risk of new lesions }\end{array}$ & $\begin{array}{l}\text { Study: TOPIC } \\
\text { Groups: Teriflunomide, } 14 \mathrm{mg}(\mathrm{n}=216), 7 \mathrm{mg}(\mathrm{n}= \\
\text { 205); placebo, } \mathrm{n}=197\end{array}$ \\
\hline
\end{tabular}

Participants in all studies had been diagnosed with CIS and had clinically silent MRI lesions. All positive outcomes shown were statistically significant.

aOr until a second relapse.

bBoth in the main trial and in a post hoc analysis of a 'high risk' subgroupc

cParticipants with $\geq 9$ T2 lesions or $\geq 1$ gadolinium-enhancing lesion at baseline

CHAMPS, Controlled High-risk subjects Avonex Multiple sclerosis Prevention Study; CIS, clinically isolated syndrome; DMT, disease-modifying therapy; ETOMS, Early

Treatment of Multiple Sclerosis; GA, glatiramer acetate; IFN- $\beta$, interferon beta; IM, intramuscular; MRI, magnetic resonance imaging; PreCISe, Evaluate early glatiramer

acetate treatment in delaying conversion to clinically definite multiple sclerosis of subjects Presenting with Clinically Isolated Syndrome; REFLEX, REbif FLEXible Dosing in

Early Multiple Sclerosis; SC, subcutaneous; TOPIC, Oral teriflunomide versus placebo in Patients with first clinical symptom of multiple sclerosis. 
This is an author's draft of an accepted article submitted and published in Multiple Sclerosis and Related Disorders

DOI : http://www.sciencedirect.com/science/article/pii/S221103481630102X

Table B.2. In people with a diagnosis of CIS, starting treatment early in the disease course is associated with better long-term outcomes than delaying treatment in randomized controlled trials with subsequent extension studies.

\begin{tabular}{|c|c|c|c|}
\hline $\begin{array}{l}\text { Length of time taking } \\
\text { DMT or placebo }\end{array}$ & $\begin{array}{l}\text { Subsequent length of } \\
\text { time taking DMT }\end{array}$ & Results & Study details \\
\hline 3 years & 2 years & $\begin{array}{c}\text { Early DMT vs later DMT (Comi et al., 2013) } \\
\text { - } \text { Reduced risk of second relapse } \\
\text { - Increased time to second relapse } \\
\text { - Less brain atrophy } \\
\text { - Fewer new lesions per year } \\
\text { - Lower total lesion volume }\end{array}$ & $\begin{array}{l}\text { Study: PreCISe open-label extension } \\
\text { DMT: GA } \\
\text { Groups: early DMT }(n=198) \text {; later DMT ( } n= \\
211)\end{array}$ \\
\hline 3 years & 10 years & $\begin{array}{c}\text { Early DMT vs later DMT (Kinkel et al., 2012) } \\
\text { - } \quad \text { Reduced risk of second relapse } \\
\text { - } \quad \text { Lower relapse rate between years } \\
\text { - } \\
\text { No effect on disability progression, } \\
\text { new lesions or proportion of people } \\
\text { developing progressive MS }\end{array}$ & $\begin{array}{l}\text { Study: CHAMPIONS (open-label extension of } \\
\text { CHAMPS) } \\
\text { DMT: IM IFN- } \beta 1 \mathrm{a} \\
\text { Groups: early DMT }(\mathrm{n}=81) \text {; later DMT }(\mathrm{n}=74)\end{array}$ \\
\hline 2 years & 9 years & $\begin{array}{l}\text { Early DMT vs later DMT (Edan et al., 2015) } \\
\begin{aligned} \text { - } & \text { Increased time to second relapse } \\
\text { - } & \text { Lower relapse rate } \\
\text { - } & \text { No effect on disability progression }\end{aligned}\end{array}$ & $\begin{array}{l}\text { Study: BENEFIT11 } \\
\text { DMT: SC IFN- } \beta 1 b \\
\text { Groups: early DMT }(n=178) \text {; later DMT }(n= \\
\text { 106) (Edan et al., 2014) }\end{array}$ \\
\hline
\end{tabular}

Participants in all studies had been diagnosed with CIS and had clinically silent MRI lesions. All positive outcomes shown were statistically significant. aOr until a second relapse.

BENEFIT11, Betaferon/ Betaseron in Newly Emerging Multiple Sclerosis for Initial Treatment 11-year follow-up; CHAMPS, Controlled High-risk subjects Avonex Multiple sclerosis Prevention Study; CHAMPIONS Controlled High-risk Avonex Multiple sclerosis Prevention study In Ongoing Neurological Surveillance; CIS, clinically isolated syndrome; DMT, disease-modifying therapy; GA, glatiramer acetate; IFN- $\beta$, interferon beta; IM, intramuscular; PreCISe, Evaluate early glatiramer acetate treatment in delaying conversion to clinically definite multiple sclerosis of subjects Presenting with Clinically Isolated Syndrome; SC, subcutaneous 
This is an author's draft of an accepted article submitted and published in Multiple Sclerosis and Related Disorders

DOI : http://www.sciencedirect.com/science/article/pii/S221103481630102X

Table B.3 In people with a diagnosis of RRMS, starting treatment early in the disease course is associated with better long-term outcomes than delaying treatment.

\begin{tabular}{|c|c|c|c|c|}
\hline Study type & $\begin{array}{l}\text { Length of time } \\
\text { taking DMT or } \\
\text { placebo }\end{array}$ & $\begin{array}{l}\text { Subsequent } \\
\text { part of study: } \\
\text { length of time } \\
\text { and treatment }\end{array}$ & Results & Study details \\
\hline $\begin{array}{l}\text { RCT, then } \\
\text { extension }\end{array}$ & 2 years & $\begin{array}{l}2 \text { years, DMT } \\
\text { (blinded) }\end{array}$ & $\begin{array}{l}\text { Early DMT vs later DMT (Prisms Study Group } \\
\text { and University of British Columbia MS/MRI } \\
\text { Analysis Group, 2001) } \\
\text { - } \quad \text { Longer time to sustained disability } \\
\text { - } \text { progression } \\
\text { - } \quad \text { Lewer new lesions } \\
\text { Lower total brain lesion volume }\end{array}$ & $\begin{array}{l}\text { Study: PRISMS-4 } \\
\text { DMT: SC IFN- } \beta 1 \mathrm{a} \\
\text { Groups: early DMT } 22 \mu \mathrm{g}(\mathrm{n}=167), 44 \mu \mathrm{g}(\mathrm{n} \\
=167) \text {; later DMT } 22 \mu \mathrm{g}(\mathrm{n}=97), 44 \mu \mathrm{g}(\mathrm{n}= \\
\text { 95) }\end{array}$ \\
\hline $\begin{array}{l}\mathrm{RCT} \text {, then } \\
\text { open-label } \\
\text { extension }\end{array}$ & 2 years & 4 years, DMT & $\begin{array}{l}\text { Early DMT vs later DMT (Kappos et al., 2015) } \\
\text { - Less disability progression } \\
\text { - Lower relapse rate } \\
\text { - Less brain atrophy }\end{array}$ & $\begin{array}{l}\text { Study: FREEDOMS extension } \\
\text { DMT: Fingolimod } \\
\text { Groups a: early DMT, } 0.5 \mathrm{mg}(\mathrm{n}=330), 1.25 \\
\mathrm{mg}(\mathrm{n}=287) ; \text { later DMT, } 0.5 \mathrm{mg}(\mathrm{n}=154) \text {, } \\
1.25 \mathrm{mg}(\mathrm{n}=145)\end{array}$ \\
\hline $\begin{array}{l}\mathrm{RCT} \text {, then } \\
\text { extension }\end{array}$ & 2 years & $\begin{array}{l}4 \text { years, DMT }{ }^{\mathrm{b}} \\
\text { then } 1-2 \text { years, } \\
\text { treatment at } \\
\text { discretion of } \\
\text { physician }\end{array}$ & $\begin{array}{l}\text { Early DMT vs later DMT (Kappos et al., } \\
\text { 2006b) } \\
\text { - Lower risk of disease progression } \\
\text { - Lower relapse rate } \\
\text { - Lower total brain lesion volume } \\
\text { - No effect on brain atrophy }\end{array}$ & $\begin{array}{l}\text { Study: PRISMS long-term follow-up } \\
\text { DMT: SC IFN- } \beta 1 \mathrm{a} \\
\text { Groups: early DMT } 22 \mu \mathrm{g}(\mathrm{n}=123), 44 \mu \mathrm{g}(\mathrm{n} \\
=136) ; \text { later DMT } 22 \mu \mathrm{g}(\mathrm{n}=66), 44 \mu \mathrm{g}(\mathrm{n}= \\
63)\end{array}$ \\
\hline $\begin{array}{l}\text { RCT, then } \\
\text { open-label } \\
\text { extension }\end{array}$ & 9 months & $\begin{array}{l}9 \text { months DMT } \\
\text { then } 3.8-4.9 \\
\text { years treatment } \\
\text { at discretion of } \\
\text { physician }\end{array}$ & 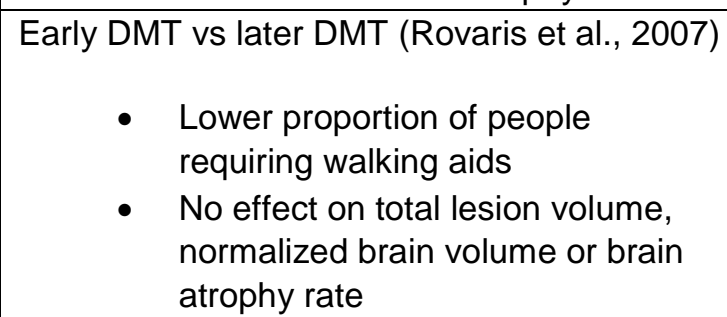 & $\begin{array}{l}\text { Study: European/Canadian GA study long- } \\
\text { term follow up } \\
\text { DMT: GA } \\
\text { Groups: early DMT (GA since study initiation) } \\
\text { ( } n=73 \text { ), later DMT ( } n=69)\end{array}$ \\
\hline
\end{tabular}


This is an author's draft of an accepted article submitted and published in Multiple Sclerosis and Related Disorders

DOI : http://www.sciencedirect.com/science/article/pii/S221103481630102X

\begin{tabular}{|c|c|c|c|c|}
\hline $\begin{array}{l}\mathrm{RCT} \text {, then } \\
\text { open-label } \\
\text { extension }\end{array}$ & 2.5 years & 5.5 years, DMT & $\begin{array}{l}\text { Early DMT vs later DMT (Johnson et al., } \\
\text { 2005) } \\
\begin{array}{ll}\text { - } & \text { Higher proportion of people with } \\
& \text { stable or improved EDSS score } \\
& \text { (i.e. lower risk of disability } \\
\text { progression) } \\
\text { - } & \text { No effect on relapse rate } \\
\end{array}\end{array}$ & $\begin{array}{l}\text { Study: Copolymer I Multiple Sclerosis Study } \\
\text { open label extension } \\
\text { DMT: GA } \\
\text { Groups } \text { : early DMT }(n=72) \text {, later DMT ( }= \\
70 \text { ) }\end{array}$ \\
\hline $\begin{array}{l}\text { RCT, then } \\
\text { treatment at } \\
\text { discretion of } \\
\text { physician }\end{array}$ & 2 years & $\begin{array}{l}15 \text { years, } \\
\text { treatment at } \\
\text { discretion of } \\
\text { physician }\end{array}$ & $\begin{array}{l}\text { Early DMT vs later treatment (Bermel et al., } \\
\text { 2010) } \\
\text { - No statistically significant effect on } \\
\text { disability progression }\end{array}$ & $\begin{array}{l}\text { Study: ASSURANCE (follow-up of MSCRG) } \\
\text { DMT: IM IFN- } \beta 1 \text { a } \\
\text { Groups: early DMT ( } n=69 \text { ); later treatment } \\
(n=67)\end{array}$ \\
\hline $\begin{array}{l}\text { RCT, then } \\
\text { treatment at } \\
\text { discretion of } \\
\text { physician }\end{array}$ & 5 years & $\begin{array}{l}16 \text { years, } \\
\text { treatment at } \\
\text { discretion of } \\
\text { physician }\end{array}$ & $\begin{array}{l}\text { Early DMT vs later treatment } \\
\text { Better survival rates: risk of death } \\
47 \% / 46 \% \text { lower (early } 250 \mu \mathrm{g} / \\
\text { early } 50 \mu \mathrm{g} \text { DMT respectively } \\
\text { versus later treatment) (Goodin et } \\
\text { al., } 2012 \mathrm{~b} \text { ); } 78 \% \text { (54/69) of deaths } \\
\text { in delayed treatment group } \\
\text { adjudicated to be from MS-related } \\
\text { causes (Goodin et al., } 2012 \mathrm{a}) \\
\text { - } \\
\text { No effect on disability progression, } \\
\text { relapse rate or MRI parameters } \\
\text { (Ebers et al., 2010) }\end{array}$ & 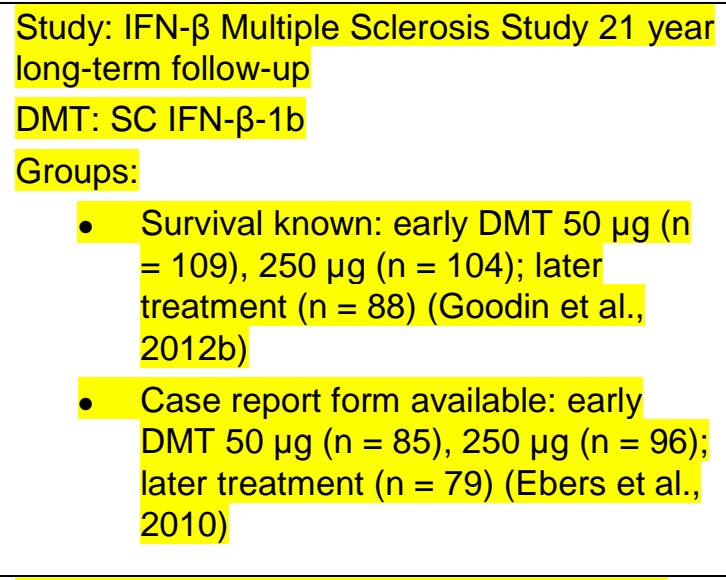 \\
\hline $\begin{array}{l}\text { Post hoc } \\
\text { analysis of } \\
\text { two RCTs }\end{array}$ & $\begin{array}{l}1 \text { year } \\
\text { (TRANSFORM } \\
\text { S) / } 2 \text { years } \\
\text { (FREEDOMS) }\end{array}$ & - & $\begin{array}{l}\text { Time between onset of symptoms and } \\
\text { treatment: }<3 \text { years vs } \geq 3 \text { years (Agius et } \\
\text { al., 2014) } \\
\text { - Greater reduction in relapse rate } \\
\text { vs placebo and vs IM IFN- } \beta 1 \text { a }\end{array}$ & $\begin{array}{l}\text { Studies: TRANSFORMS and FREEDOMS } \\
\text { DMT: Fingolimod or IM IFN- } \beta 1 \text { a } \\
\text { Subgroups: } \\
\text { Time from symptoms to treatment }<3 \text { years } \\
\text { fingolimod ( } n=132 \text { in TRANSFORMS, } n= \\
113 \text { in FREEDOMS); IM IFN- } \beta 1 \text { a }(n=140 \\
\text { TRANSFORMS); placebo }(n=104 \text { in }\end{array}$ \\
\hline
\end{tabular}


This is an author's draft of an accepted article submitted and published in Multiple Sclerosis and Related Disorders

DOI : http://www.sciencedirect.com/science/article/pii/S221103481630102X

\begin{tabular}{|c|c|c|c|c|}
\hline & & & $\begin{array}{ll}\text { - } & \text { Fewer new/newly enlarged } \\
\text { lesions/year vs placebo and vs IM } \\
\text { IFN- } \beta 1 \text { a } \\
\text { - } & \text { Fewer active lesions vs placebo }\end{array}$ & $\begin{array}{l}\text { FREEDOMS). } \\
\text { Time from symptoms to treatment } \geq 3 \text { years: } \\
\text { fingolimod }(n=297 \text { in TRANSFORMS, } n= \\
312 \text { in FREEDOMS), IM IFN- } \beta 1 a(n=291 \text { in } \\
\text { TRANSFORMS), placebo }(n=314 \text { in } \\
\text { FREEDOMS) }\end{array}$ \\
\hline $\begin{array}{l}\text { Real-world } \\
\text { evidence } \\
\text { from registry }\end{array}$ & $\begin{array}{l}\text { Treatment } \\
\text { initiation } \\
\text { occurred within } \\
1-5 \text { years of } \\
\text { onset of MS }\end{array}$ & - & $\begin{array}{l}\text { Early treatment (within } 1 \text { year of onset) vs } \\
\text { later treatment (Trojano et al., 2009) } \\
\begin{array}{l}\text { - } \\
\text { Reduced risk of disability } \\
\text { progression (a 1-point increase in } \\
\text { EDSS score) } \\
\text { - } \quad \text { Reduced risk of reaching EDSS } \\
\text { score } \geq 4.0\end{array}\end{array}$ & $\begin{array}{l}\text { Study: A cohort of RRMS patients }(\mathrm{N}=2570) \\
\text { was prospectively followed for up to } 7 \text { years } \\
\text { DMT: IFN- } \beta \text { preparation }\end{array}$ \\
\hline $\begin{array}{l}\text { Real-world } \\
\text { evidence } \\
\text { from registry }\end{array}$ & $\begin{array}{l}7 \text { years (DMT or } \\
\text { no DMT) }\end{array}$ & - & $\begin{array}{ll}\text { DMT vs no DMT (Trojano et al., 2007) } \\
\text { - } & \text { Reduced risk of transition to SPMS } \\
\text { - } & \text { Reduced risk of reaching EDSS } \\
\text { - } & \text { Incore } \geq 4.0 \\
\text { - } & \text { Score } \geq 4.0 \\
\text { - } & \text { Reduced risk of reaching EDSS } \\
\text { - } & \text { Increased time to reaching EDSS } \\
& \text { score } \geq 6.0\end{array}$ & $\begin{array}{l}\text { Study: A cohort of RRMS patients }(\mathrm{N}=1504) \\
\text { was prospectively followed for up to } 7 \text { years } \\
\text { DMT: IFN- } \beta \text { preparation } \\
\text { Groups: DMT ( } n=1103) \text {; no DMT }(n=401)\end{array}$ \\
\hline
\end{tabular}

Participants in all studies had been diagnosed with RRMS. All positive outcomes shown were statistically significant.

alntention to treat population.

b2 year blinded extension, followed by a further 2 year extension (blinded or open label as chosen by each individual patient).

cn for 8 year data

ASSURANCE, ASSessment of Drug Utilization, EaRly TreAtmeNt, and Clinical OutcomEs; DMT, disease-modifying therapy; EDSS, Kurtzke Expanded Disability Status Scale; FREEDOMS, FTY720 Research Evaluating Effects of Daily Oral Therapy in MS; GA, glatiramer acetate; IFN- $\beta$, interferon beta; IM, intramuscular; MRI, magnetic resonance imaging; MSCRG, Multiple Sclerosis Collaborative Research Group; PRISMS, Prevention of Relapses and disability by Interferon beta-1a Subcutaneously in Multiple Sclerosis; RCT, randomized controlled trial; RRMS, relapsing-remitting multiple sclerosis; SC, subcutaneous; SPMS, secondary progressive multiple sclerosis; TRANSFORMS, Efficacy 
This is an author's draft of an accepted article submitted and published in Multiple Sclerosis and Related Disorders

DOI : http://www.sciencedirect.com/science/article/pii/S221103481630102X

and safety of fingolimod in patients with relapsing-remitting multiple sclerosis with optional extension phase. 
This is an author's draft of an accepted article submitted and published in Multiple Sclerosis and Related Disorders

DOI : http://www.sciencedirect.com/science/article/pii/S221103481630102X

\section{Appendix C. Relapses, lesions and brain atrophy indicate disease activity}

Table C.1 Relapses predict disability progression; MRI lesions predict relapses and disability progression.

\begin{tabular}{|c|c|c|c|}
\hline Study type & Outcomes & Results & Study details \\
\hline Meta-analysis & $\begin{array}{l}\text { Disability progression } \\
\text { Relapse rate } \\
\text { New lesions }\end{array}$ & $\begin{array}{l}\text { Treatment effects on relapses and } \\
\text { disability progression are correlated } \\
\left(R^{2}=0.75\right) \\
\text { - Treatment effects on new lesions and } \\
\text { disability progression are correlated } \\
\left(R^{2}=0.64\right)\end{array}$ & $\begin{array}{l}\text { Included all clinical trials in CIS, RRMS and } \\
\text { SPMS published between } 1 \text { January } 1993 \\
\text { and } 3 \text { June } 2013(\mathrm{~N}=18809) \text { (Fahrbach et } \\
\text { al., 2013) }\end{array}$ \\
\hline Meta-analysis & $\begin{array}{l}\text { Relapse rate } \\
\text { Active lesions }\end{array}$ & $\begin{array}{l}\text { - Treatment effects on active lesions and } \\
\text { relapses are correlated }\left(R^{2}=0.81\right)\end{array}$ & $\begin{array}{l}\text { Included all clinical trials in RRMS published } \\
\text { before } 1 \text { September } 2008 \text { ( } 23 \text { trials, } N= \\
6591 \text { ) (Sormani et al., 2009) }\end{array}$ \\
\hline Meta-analysis & $\begin{array}{l}\text { Relapse rate } \\
\text { New or active lesions }\end{array}$ & $\begin{array}{l}\text { - Treatment effect on MRI lesions (after 6-9 } \\
\text { months) predicts treatment effect on } \\
\text { relapses (after 12-24 months) } \\
\text { - Concurrent treatment effects on MRI } \\
\text { lesions and relapses are correlated } \\
\left(R^{2}=0.71\right)\end{array}$ & $\begin{array}{l}\text { Included all clinical trials in RRMS published } \\
\text { between } 1 \text { September } 2008 \text { and } 31 \text { October } \\
2012 \text { ( } 31 \text { trials, } N=18901 \text { ) (Sormani and } \\
\text { Bruzzi, 2013) }\end{array}$ \\
\hline Meta-analysis & $\begin{array}{l}\text { Disability progression } \\
\text { Relapse rate } \\
\text { MRI lesions }\end{array}$ & $\begin{array}{l}\text { Treatment effects on relapses and } \\
\text { disability progression are correlated } \\
\left(R^{2}=0.71\right) \\
\text { Treatment effects on MRI lesions and } \\
\text { disability progression are correlated } \\
\left(R^{2}=0.57\right)\end{array}$ & $\begin{array}{l}\text { Included all published clinical trials in RRMS } \\
\text { (19 trials, } N=10009 \text { ) (Sormani et al., 2010) }\end{array}$ \\
\hline Meta-analysis & $\begin{array}{l}\text { Disability progression } \\
\text { Relapses } \\
\text { Active lesions } \\
\text { New lesions }\end{array}$ & $\begin{array}{l}\text { Initial poor response to IFN- } \beta \text {, as } \\
\text { measured by active and new lesions, } \\
\text { predicts clinical outcomes (relapses and } \\
\text { disability progression) up to } 16 \text { years after } \\
\text { treatment initiation }\end{array}$ & $\begin{array}{l}\text { Included clinical trials of IFN- } \beta \text { preparations } \\
\text { in CIS and RRMS published between } 1 \\
\text { January } 2000 \text { and } 21 \text { May } 2013 \text { (11 trials, N } \\
=2171 \text { ) (Dobson et al., 2014) }\end{array}$ \\
\hline Retrospective analysis & $\begin{array}{l}\text { Disability progression } \\
\text { (after } 10 \text { years) }\end{array}$ & $\begin{array}{l}\text { - Changes in brain atrophy and lesion load } \\
\text { both predict EDSS disability progression }\end{array}$ & $\begin{array}{l}\text { MRI scans conducted in people with MS who } \\
\text { also had 10-year follow-up disability data }\end{array}$ \\
\hline
\end{tabular}


This is an author's draft of an accepted article submitted and published in Multiple Sclerosis and Related Disorders

DOI : http://www.sciencedirect.com/science/article/pii/S221103481630102X

\begin{tabular}{|c|c|c|c|}
\hline & $\begin{array}{l}\text { Total volume of lesions } \\
\text { (change over } 1-2 \text { years) } \\
\text { Brain atrophy } \\
\text { (change over } 1-2 \text { years) }\end{array}$ & $\begin{array}{l}10 \text { years after the initial MRI scan in a } \\
\text { 'relapse onset' subgroup containing people } \\
\text { with CIS, RRMS and SPMS }\end{array}$ & $(\mathrm{N}=166)($ Popescu et al., 2013) \\
\hline RWE & $\begin{array}{l}\text { Disability progression } \\
\text { New lesions } \\
\text { Brain atrophy }\end{array}$ & $\begin{array}{l}\text { - Number of lesions at baseline and rate of } \\
\text { brain atrophy during first } 6 \text { months of } \\
\text { observation predict conversion to RRMS }\end{array}$ & $\begin{array}{l}\text { Real-world study of people with CIS treated } \\
\text { with IM IFN- } \beta 1 \text { 1a for } 2 \text { years }(N=220) \\
\text { (Kalincik et al., 2012) }\end{array}$ \\
\hline
\end{tabular}

All results shown were statistically significant.

$R^{2}$ is a measure of how much of the variability in one item (e.g. disability progression) is shared with another item (e.g. new lesions). For example, $R^{2}=0.64$ means that $64 \%$ of the variation in one item is explained by variation in the other.

CIS, clinically isolated syndrome; DMT, disease-modifying therapy; EDSS, Kurtzke Expanded Disability Status Scale; IFN- $\beta$, interferon beta; IM, intramuscular; MRI, magnetic resonance imaging; MSCRG, Multiple Sclerosis Collaborative Research Group; RCT, randomized controlled trial; RRMS, relapsing-remitting multiple sclerosis; RWE, realworld evidence; SPMS, secondary progressive multiple sclerosis. 
This is an author's draft of an accepted article submitted and published in Multiple Sclerosis and Related Disorders

DOI : http://www.sciencedirect.com/science/article/pii/S221103481630102X

Table C.2 Brain atrophy predicts relapses and disability progression.

\begin{tabular}{|c|c|c|c|}
\hline Study type & Outcomes & Results & Study details \\
\hline Meta-analysis & $\begin{array}{l}\text { Disability progression } \\
\text { New/enlarging lesions } \\
\text { Brain atrophy }\end{array}$ & $\begin{array}{l}\text { - Treatment effects on brain atrophy } \\
\text { and disability progression are } \\
\text { correlated }\left(R^{2}=0.48\right) \\
\text { - Treatment effects on new/enlarging } \\
\text { MRI lesions and disability } \\
\text { progression are correlated } \\
\left(R^{2}=0.61\right) \\
\text { The correlation with disability } \\
\text { progression is greater when both of } \\
\text { these MRI markers are combined } \\
\left(R^{2}=0.75\right)\end{array}$ & $\begin{array}{l}\text { Included all published clinical trials in RRMS of } \\
\text { at least } 2 \text { years in duration published before } \\
\text { December } 2012(13 \text { trials, } N>13500) \\
\text { (Sormani et al., 2014) }\end{array}$ \\
\hline Post hoc analysis & $\begin{array}{l}\text { Disability progression } \\
\text { Brain atrophy }\end{array}$ & $\begin{array}{l}\text { Rate of brain atrophy is associated } \\
\text { with disability progression }\end{array}$ & $\begin{array}{l}\text { Analysis of three published clinical trials of } \\
\text { fingolimod in RRMS ( } N=3635) \text { (Radue et al., } \\
2015 \text { ) }\end{array}$ \\
\hline Retrospective analysis & $\begin{array}{l}\text { Disability progression (after } 10 \\
\text { years) } \\
\text { Total volume of lesions visible on } \\
\text { MRI (change over first } 1-2 \text { years) } \\
\text { Brain atrophy (change over first } \\
1-2 \text { years) }\end{array}$ & $\begin{array}{l}\text { - Brain atrophy and lesion volume } \\
\text { both predict EDSS disability } \\
\text { progression } 10 \text { years after the initial } \\
\text { MRI scan in a 'relapse onset' } \\
\text { subgroup containing people with } \\
\text { CIS, RRMS and SPMS }\end{array}$ & $\begin{array}{l}\text { MRI scans conducted in people with MS who } \\
\text { also had 10-year follow-up disability data }(\mathrm{N}= \\
\text { 166) (Popescu et al., 2013) }\end{array}$ \\
\hline RWE & $\begin{array}{l}\text { Disability progression } \\
\text { Relapses } \\
\text { New lesions } \\
\text { Brain atrophy }\end{array}$ & $\begin{array}{l}\text { - Number of new lesions and brain } \\
\text { atrophy predict a second relapse } \\
\text { (that is, conversion to RRMS under } \\
\text { any diagnostic criteria) within } 4 \text { years }\end{array}$ & $\begin{array}{l}\text { Included people with CIS treated with IM IFN- } \\
\beta 1 \text { a for } 4 \text { years }(N=210) \text { (Uher et al., 2014) }\end{array}$ \\
\hline RWE & $\begin{array}{l}\text { Disability progression } \\
\text { New lesions } \\
\text { Brain atrophy }\end{array}$ & $\begin{array}{l}\text { - Lesion volume at baseline and rate } \\
\text { of brain atrophy during first } 6 \text { months } \\
\text { of observation predict conversion to } \\
\text { RRMS }\end{array}$ & $\begin{array}{l}\text { Included people with CIS treated with IM IFN- } \\
\beta 1 \text { a for } 2 \text { years }(N=220) \text { (Kalincik et al., 2012) }\end{array}$ \\
\hline
\end{tabular}

All results shown were statistically significant. 
This is an author's draft of an accepted article submitted and published in Multiple Sclerosis and Related Disorders

DOI : http://www.sciencedirect.com/science/article/pii/S221103481630102X

$R^{2}$ is a measure of how much of the variability in one item (e.g. disability progression) is shared with another item (e.g. new lesions). For example, $R^{2}=0.64$ means that $64 \%$ of the variation in one item is explained by variation in the other.

CIS, clinically isolated syndrome; DMT, disease-modifying therapy; EDSS, Kurtzke Expanded Disability Status Scale; IFN- $\beta$, interferon beta; MRI, magnetic resonance

imaging; MS, multiple sclerosis; RRMS, relapsing-remitting multiple sclerosis; RWE, real-world evidence; SPMS, secondary progressive multiple sclerosis. 
This is an author's draft of an accepted article submitted and published in Multiple Sclerosis and Related Disorders

DOI : http://www.sciencedirect.com/science/article/pii/S221103481630102X

\section{Appendix D. Growing evidence supports the use of appropriate newer therapies}

Table D.1 There is increasing evidence that people with MS whose disease is inadequately controlled by an established DMT will benefit from receiving an appropriate newer DMT.

\begin{tabular}{|c|c|c|}
\hline Study type & Results & Study details \\
\hline $\begin{array}{l}\text { RCT and open label } \\
\text { extension }\end{array}$ & $\begin{array}{l}\text { Early fingolimod vs later fingolimod } \\
\begin{array}{l}\text { - } \\
\text { - }\end{array} \text { Fower relapse rate (Khatri et al., 2011) } \\
\text { - } \text { Fewer people with active lesions (Khatri et al., 2011) } \\
\text { - No effect on disability progression (Khatri et al., } \\
\text { - } 2011 \text { ) } \\
\text { Longer time to next relapse (Meng et al., 2014) }\end{array}$ & $\begin{array}{l}\text { RCT (TRANSFORMS): } 1 \text { year of treatment } \\
\text { with fingolimod or IM IFN- } \beta 1 \mathrm{a} \\
\text { Extension: } 1 \text { year of treatment with fingolimod } \\
(\mathrm{N}=1027 ; \text { continuous fingolimod: } 0.5 \mathrm{mg} \\
\text { [ } \mathrm{n}=356], 1.25 \mathrm{mg}(\mathrm{n}=330) \text {; switch from IM IFN- } \\
\beta 1 \mathrm{a} \text { to fingolimod: } 0.5 \mathrm{mg} \text { [ } \mathrm{n}=167], 1.25 \mathrm{mg} \text { [n } \\
=174])\end{array}$ \\
\hline $\begin{array}{l}\text { RWE, propensity } \\
\text { matched groups }\end{array}$ & $\begin{array}{l}\text { Switch to natalizumab vs switch between established DMTs } \\
\text { (GA or IFN- } \beta \text { preparations) (Spelman et al., 2015) } \\
\text { - Reduced disability progression over } 2 \text { years } \\
\text { - Reduced relapse rate in year } 1 \\
\text { - Reduced risk of first on-treatment relapse in year } 1 \\
\text { - Reduced risk of disability progression in first } 3 \\
\text { months }\end{array}$ & $\begin{array}{l}2 \text { years of treatment with natalizumab, GA or } \\
\text { an IFN- } \beta \text { preparation following an on-treatment } \\
\text { relapse in the } 12 \text { months before switching } \\
\text { while taking GA or an IFN- } \beta \text { preparation ( } N= \\
1838 ; \text { switch to natalizumab, } n=869 \text { [from } \\
\text { TOP]; switch to GA/IFN- } \beta, n=869 \text { [from } \\
\text { MSBase]) }\end{array}$ \\
\hline RWE & $\begin{array}{l}\text { Switch to natalizumab vs switch between established DMTs } \\
\text { (GA or IFN- } \beta \text { preparations) (Prosperini et al., 2012) } \\
\text { - Greater proportion of people with no relapses, no } \\
\text { disability progression and no new MRI lesions after } \\
2 \text { years } \\
\text { - No significant differences after } 1 \text { year }\end{array}$ & $\begin{array}{l}2 \text { years of treatment with natalizumab, GA or } \\
\text { an IFN- } \beta \text { preparation following treatment } \\
\text { failure }{ }^{\text {b }} \text { with } \text { GA or an IFN- } \beta \text { preparation }(N= \\
285 ; \text { switch to natalizumab, } n=106^{c} \text {; switch } \\
\left.\text { among established DMTs, } n=161^{c}\right)\end{array}$ \\
\hline $\begin{array}{l}\text { RWE, propensity } \\
\text { matched groups }\end{array}$ & $\begin{array}{l}\text { Natalizumab or fingolimod vs baseline (before switching from } \\
\text { an established DMT) (Kalincik et al., 2015a) } \\
\text { - Reduced relapse rate } \\
\text { - Greater improvements in disability (i.e. improved } \\
\text { function) }\end{array}$ & $\begin{array}{l}12 \text { months (on average) of treatment with } \\
\text { natalizumab or fingolimod following an on- } \\
\text { treatment relapse and/or disability progression } \\
\text { while taking GA or an IFN- } \beta \text { preparation } \\
(\mathrm{N}=578 ; \text { natalizumab, } \mathrm{n}=407 \text {; fingolimod, } \mathrm{n}= \\
171)\end{array}$ \\
\hline
\end{tabular}


This is an author's draft of an accepted article submitted and published in Multiple Sclerosis and Related Disorders

DOI : http://www.sciencedirect.com/science/article/pii/S221103481630102X

\begin{tabular}{|c|c|c|}
\hline $\begin{array}{l}\text { RWE, propensity } \\
\text { matched groups }\end{array}$ & $\begin{array}{l}\text { Switch to fingolimod vs switch between established DMTs (He } \\
\text { et al., 2015) } \\
\text { - Reduced relapse rate } \\
\text { - Reduced risk of a further relapse } \\
\text { - Reduced risk of disability progression } \\
\text { - Increased probability of improvements in disability } \\
\text { (i.e. improved function) }\end{array}$ & $\begin{array}{l}13 \text { months (on average) of treatment with } \\
\text { fingolimod, GA or an IFN- } \beta \text { preparation } \\
\text { following an on-treatment relapse and/or } \\
\text { disability progression while taking GA or an } \\
\text { IFN- } \beta \text { preparation }(N=527 ; n=148 \\
\text { fingolimod, } n=379 \text { GA or an IFN- } \beta \\
\text { preparation) }\end{array}$ \\
\hline $\begin{array}{l}\text { RWE, propensity } \\
\text { matched groups }\end{array}$ & $\begin{array}{l}\text { Switch to fingolimod vs switch to GA (Bergvall et al., 2014) } \\
\text { - Reduced relapse rate } \\
\text { - Reduced probability of a further relapse }\end{array}$ & $\begin{array}{l}\text { Treatment with fingolimod or GA following } \\
\text { switching from an IFN- } \beta \text { preparation }(N=264 ; \\
\text { fingolimod, } n=132 ; G A, n=132)\end{array}$ \\
\hline $\begin{array}{l}\text { Open label study } \\
\text { (TOP) }\end{array}$ & $\begin{array}{l}\text { Natalizumab vs baseline (before starting treatment with } \\
\text { natalizumab) (Butzkueven et al., 2014a) } \\
\text { - No worsening in disability on average (unchanged } \\
\text { mean EDSS scores) } \\
\text { - Annual relapse rate lower at years } 1-5 \text { than at } \\
\text { baseline }\end{array}$ & $\begin{array}{l}\text { Up to } 5 \text { years of treatment with natalizumab } \\
(\mathrm{N}=4821)\end{array}$ \\
\hline RWE & $\begin{array}{l}\text { Natalizumab vs baseline (before starting treatment with } \\
\text { natalizumab) (Kallweit et al., 2012) } \\
\text { - Improvements in disability on average (i.e. improved } \\
\text { function) during first year of treatment } \\
\text { - No worsening in disability between baseline and } \\
\text { year } 3(n=23) \\
\text { - Annual relapse rate fell between baseline and year } 3 \\
(n=23)\end{array}$ & $\begin{array}{l}\text { Up to } 3 \text { years of treatment with natalizumab } \\
(N=64)\end{array}$ \\
\hline $\begin{array}{l}\text { Open label study } \\
\text { (TYNERGY) }\end{array}$ & $\begin{array}{l}\text { Natalizumab vs baseline (before starting treatment with } \\
\text { natalizumab) (Svenningsson et al., 2013) } \\
\text { - Improvements in disability (i.e. improved function), } \\
\text { walking speed, quality of life, cognition, fatigue, } \\
\text { depression and sleepiness compared with baseline }\end{array}$ & 1 year of treatment with natalizumab $(\mathrm{N}=195)$ \\
\hline $\begin{array}{l}\text { Open label study } \\
\text { (TRUST) }\end{array}$ & $\begin{array}{l}\text { Natalizumab vs baseline (before starting treatment with } \\
\text { natalizumab) (Khatri et al., 2014) }\end{array}$ & $\begin{array}{l}6 \text { months of treatment with natalizumab in } \\
\text { people with } \mathrm{MS} \text { and disabling bladder } \\
\text { dysfunction }(\mathrm{N}=30)\end{array}$ \\
\hline
\end{tabular}


This is an author's draft of an accepted article submitted and published in Multiple Sclerosis and Related Disorders

DOI : http://www.sciencedirect.com/science/article/pii/S221103481630102X

\begin{tabular}{|l|l|l|}
\hline & $\bullet \begin{array}{l}\text { Improvements in incontinence-related quality of life } \\
\text { after } 6 \text { months compared with baseline }\end{array}$ & \\
\hline
\end{tabular}

All results shown were statistically significant.

aAnalysis carried out post hoc; switch from IM IFN- $\beta 1$ a to fingolimod (observed) compared with model of continued IM IFN- $\beta 1$ a (estimated).

bTreatment failure was defined as the occurrence of $\geq 2$ relapses or 1 relapse with residual disability.

cNumber of patients included in analysis.

DMT, disease-modifying therapy; EDSS, Kurtzke Expanded Disability Status Scale; GA, glatiramer acetate; IFN- $\beta$, interferon beta; MRI, magnetic resonance imaging;

RCT, randomized controlled trial; RWE, real-world evidence; TOP, Tysabri (natalizumab) Observational Program; TRUST, EvaluaTion of Bladder Function in Relapsing-

Remitting Multiple Sclerosis Patients Treated with Natalizumab; TYNERGY, Effects of Tysabri (natalizumab) over 12 months on MS-related fatigue in participants with RRMS. 
This is an author's draft of an accepted article submitted and

published in Multiple Sclerosis and Related Disorders

DOI : http://www.sciencedirect.com/science/article/pii/S221103481630102X

\section{Acknowledgements}

The authors thank the following members of the wider working group, who contributed to two drafts and the approval version, for their support and consultation on the document: Professor Maria Pia Amato (Department of Neurology, University of Florence, Florence, Italy), Ms Amy Bowen (Multiple Sclerosis Trust, Letchworth Garden City, UK), Professor William Carroll (Centre for Neuromuscular and Neurological Disorders, Western Australian Neuroscience Research Institute, University of Western Australia, Perth, WA, Australia), Professor Giancarlo Comi (Department of Neurology and Institute of Experimental Neurology, Università Vita-Salute San Raffaele, Milan, Italy), Ms Kathleen Costello (Vice President, Healthcare Access, National Multiple Sclerosis Society, USA), Ms June Halper (Consortium of Multiple Sclerosis Centers/International Organization of Multiple Sclerosis Nurses, Hackensack, NJ, USA), Professor Eva Havrdová (Department of Neurology, Charles University in Prague, Prague, Czech Republic), Professor Bengt Jönsson (Department of Economics, Stockholm School of Economics, Stockholm, Sweden), Professor Ludwig Kappos (Departments of Neurology and Biomedicine, University Hospital Basel, University of Basel, Basel, Switzerland), Professor Dawn Langdon (Department of Psychology, Royal Holloway, University of London, Egham, UK), Professor Xavier Montalban, (Multiple Sclerosis Centre of Catalonia (Cemcat), Vall d'Hebron University Hospital, Barcelona, Spain), Professor Fredrik Piehl (Department of Clinical Neuroscience, Karolinska Institutet, Solna, Sweden), Mr Nick Rijke (Multiple Sclerosis Society, London, UK), Professor Maria Trojano (Department of Basic Medical Sciences, Neuroscience and Sense Organs, University of Bari, Bari, Italy).

Preparation of the report and its recommendations was funded by an educational grant from $\mathrm{F}$. Hoffmann-La Roche, who had no influence on the content.

Support for the independent writing and editing of this publication was provided by Ruth Bentley, Heather Lang and Tom Potter of Oxford PharmaGenesis Ltd, UK, and was funded by an educational grant from F. Hoffmann-La Roche, who had no influence on the content.

Support for 'MS Brain Health' activities and materials, including the preparation of this manuscript for submission to MSARD, has been provided by Oxford PharmaGenesis Ltd, UK, funded by grants from AbbVie, Actelion Pharmaceuticals and Sanofi Genzyme and by educational grants from Biogen, F. Hoffmann-La Roche, Merck Serono and Novartis, all of whom had no influence on the content.

For further information about the MS Brain Health initiative, please see www.msbrainhealth.org (C) 2015 Oxford PharmaGenesis Ltd

The views expressed in this publication are not necessarily those of the sponsor or publisher. 
This is an author's draft of an accepted article submitted and

published in Multiple Sclerosis and Related Disorders

DOI : http://www.sciencedirect.com/science/article/pii/S221103481630102X

\section{References}

. !!! INVALID CITATION !!! (Khatri et al., 2011; Kallweit et al., 2012; Prosperini et al., 2012;

Svenningsson et al., 2013; Baldi et al., 2014; Bergvall et al., 2014; Butzkueven et al., 2014a; Khatri et al., 2014; Meng et al., 2014; He et al., 2015; Kalincik et al., 2015a; Spelman et al., 2015).

Acaster S, Perard R, Chauhan D, Lloyd AJ. A forgotten aspect of the NICE reference case: an observational study of the health related quality of life impact on caregivers of people with multiple sclerosis. BMC health services research. 2013;13:346.

Adamec I, Barun B, Gabelic T, Zadro I, Habek M. Delay in the diagnosis of multiple sclerosis in Croatia. Clinical neurology and neurosurgery. 2013;115 Suppl 1:S70-2.

Agius M, Meng X, Chin P, Grinspan A, Hashmonay R. Fingolimod therapy in early multiple sclerosis: an efficacy analysis of the TRANSFORMS and FREEDOMS studies by time since first symptom. CNS neuroscience \& therapeutics. 2014;20:446-51.

American Academy of Neurology. Availability of disease modifying therapies (DMT) for treatment of relapsing forms of multiple sclerosis.2015 [accessed 4 June 2015, at $<$ https://www.aan.com/uploadedFiles/Website_Library_Assets/Documents/6.Public_Policy/1.Stay_Inf ormed/2.Position_Statements/DiseaseModTheraMS_PosStatement.pdf>].

American Diabetes Association. Economic costs of diabetes in the U.S. in 2012. Diabetes Care. 2013;36:1033-46.

Atar D, Birkeland KI, Uhlig T. 'Treat to target': moving targets from hypertension, hyperlipidaemia and diabetes to rheumatoid arthritis. Annals of the rheumatic diseases. 2010;69:629-30.

B. DHM, Nagels G, Bissay V, De Keyser J. Modifiable factors influencing relapses and disability in multiple sclerosis. Multiple sclerosis (Houndmills, Basingstoke, England). 2010;16:773-85.

Barkhof F, Scheltens P, Frequin ST, Nauta JJ, Tas MW, Valk J, et al. Relapsing-remitting multiple sclerosis: sequential enhanced MR imaging vs clinical findings in determining disease activity. AJR American journal of roentgenology. 1992;159:1041-7.

Bartley AJ, Jones DW, Weinberger DR. Genetic variability of human brain size and cortical gyral patterns. Brain : a journal of neurology. 1997;120(Pt 2):257-69.

Barts Health NHS Trust. Barts health - neurosciences for patients.2015 [accessed 28 January 2015, at <http://www.bartshealth.nhs.uk/our-services/services-a-z/n/neurosciences/for-patients/>].

Benedict RH, Wahlig E, Bakshi R, Fishman I, Munschauer F, Zivadinov R, et al. Predicting quality of life in multiple sclerosis: accounting for physical disability, fatigue, cognition, mood disorder, personality, and behavior change. Journal of the neurological sciences. 2005;231:29-34.

Berg-Hansen P, Moen SM, Harbo HF, Celius EG. High prevalence and no latitude gradient of multiple sclerosis in Norway. Multiple sclerosis (Houndmills, Basingstoke, England). 2014;20:1780-2.

Bergvall N, Makin C, Lahoz R, Agashivala N, Pradhan A, Capkun G, et al. Relapse rates in patients with multiple sclerosis switching from interferon to fingolimod or glatiramer acetate: a US claims database study. PloS one. 2014;9:e88472.

Berkovich R. Treatment of acute relapses in multiple sclerosis. Neurotherapeutics : the journal of the American Society for Experimental NeuroTherapeutics. 2013;10:97-105. 
This is an author's draft of an accepted article submitted and published in Multiple Sclerosis and Related Disorders

DOI : http://www.sciencedirect.com/science/article/pii/S221103481630102X

Bermel RA, Weinstock-Guttman B, Bourdette D, Foulds P, You X, Rudick RA. Intramuscular interferon beta-1a therapy in patients with relapsing-remitting multiple sclerosis: a 15-year follow-up study. Multiple sclerosis (Houndmills, Basingstoke, England). 2010;16:588-96.

Bermel RA, You X, Foulds P, Hyde R, Simon JH, Fisher E, et al. Predictors of long-term outcome in multiple sclerosis patients treated with interferon beta. Ann Neurol. 2013;73:95-103.

Biogen Idec Inc. Plegridy: prescribing information (Reference ID: 3608472). Cambridge, MA, USA: Biogen Idec Inc.; 15 August 2014 [accessed 16 February 2015, at <http://www.accessdata.fda.gov/drugsatfda_docs/label/2014/125499lbl.pdf>].

Biogen Idec Inc. Tecfidera: prescribing information (Reference ID: 3666921). Cambridge, MA, USA: Biogen Idec Inc.; Revised: 3 December 2014 [accessed 16 February 2015, at <http://www.accessdata.fda.gov/drugsatfda_docs/label/2014/204063s003s008s010lbl.pdf>].

Biogen Idec Limited. Tysabri: EPAR - Product Information (EMEA/H/C/000603 -N/0073).

Maidenhead, UK: Biogen Idec Limited; Revised 22 December 2014 [accessed 18 February 2015, at $<$ http://www.ema.europa.eu/docs/en_GB/document_library/EPAR_-

_Product_Information/human/000603/WC500044686.pdf >].

Biogen Idec Ltd. Plegridy: EPAR - product information (EMEA/H/C/002827 -N/0005). Maidenhead, UK: Biogen Idec Ltd.; Revised: 18 December 2014 [accessed 16 February 2015, at $<$ http://www.ema.europa.eu/docs/en_GB/document_library/EPAR_-

_Product_Information/human/002827/WC500170302.pdf>].

Biogen Idec Ltd. Tecfidera: EPAR - product information (EMEA/H/C/002601 -IB/0008). Maidenhead, UK: Biogen Idec Ltd.; Revised: 23 December 2014 [accessed 16 February 2015, at $<$ http://www.ema.europa.eu/docs/en_GB/document_library/EPAR__Product_Information/human/002601/WC500162069.pdf>].

Bonafede MM, Johnson BH, Wenten M, Watson C. Treatment patterns in disease-modifying therapy for patients with multiple sclerosis in the United States. Clinical therapeutics. 2013;35:1501-12.

Borreani C, Bianchi E, Pietrolongo E, Rossi I, Cilia S, Giuntoli M, et al. Unmet needs of people with severe multiple sclerosis and their carers: qualitative findings for a home-based intervention. PloS one. 2014;9:e109679.

Braman SS. The global burden of asthma. Chest. 2006;130 (Suppl 1):s4-12.

Breuer J, Schwab N, Schneider-Hohendorf T, Marziniak M, Mohan H, Bhatia U, et al. Ultraviolet B light attenuates the systemic immune response in central nervous system autoimmunity. Ann Neurol. 2014;75:739-58.

Bronnum-Hansen $\mathrm{H}$, Stenager E, Hansen T, Koch-Henriksen $\mathrm{H}$. Survival and mortality rates among Danes with MS. Int MS J. 2006;13:66-71.

Bunz TJ, Xu C, Regine ML, Couto JE. Clinical and economic impact of five-year adherence to disease-modifying therapies in a commercially insured multiple sclerosis population. Value in health : the journal of the International Society for Pharmacoeconomics and Outcomes Research.

2013;16:A109.

Burke T, Dishon S, McEwan L, Smrtka J. The evolving role of the multiple sclerosis nurse: an international perspective. Int J MS Care. 2011;13:105-12.

Butzkueven H, Chapman J, Cristiano E, Grand'Maison F, Hoffmann M, Izquierdo G, et al. MSBase: an international, online registry and platform for collaborative outcomes research in multiple sclerosis. Multiple sclerosis (Houndmills, Basingstoke, England). 2006;12:769-74. 
This is an author's draft of an accepted article submitted and published in Multiple Sclerosis and Related Disorders

DOI : http://www.sciencedirect.com/science/article/pii/S221103481630102X

Butzkueven H, Kappos L, Pellegrini F, Trojano M, Wiendl H, Patel RN, et al. Efficacy and safety of natalizumab in multiple sclerosis: interim observational programme results. Journal of neurology, neurosurgery, and psychiatry. 2014a;85:1190-7.

Butzkueven H, Spelman T, Kalincik T, Pellegrini F, Zhang A, Trojano M, et al. Patients who switch to natalizumab have better outcomes than those who continue on the same platform therapy after a relapse. Joint Congress of European Neurology, Istanbul, Turkey, 31 May-3 June 2014b [accessed 2 April 2015, at <http://www.professionalabstracts.com/istanbul2014/planner/index.php?go=abstract\&action=abstract _show\&absno=1006\&ISTANBUL2014=er2227cou91clp2oo1b126ji0vs5egt8>].

Cahill A, Fredine H, Zilberman L. Prevalence of paralysis including spinal cord injuries in the United States, 2008 Christopher and Dana Reeve Foundation Paralysis Resource Center (PRC); Division of Disability and Health Policy, Center for Development and Disability (CDD) of the University of New Mexico School of Medicine; 2009 [accessed 21 January 2015, at <http://cdd.unm.edu/\%5C/dhpd/pdfs/InitialBriefing32609.pdf>].

Carton H, Vlietinck R, Debruyne J, De Keyser J, D'Hooghe MB, Loos R, et al. Risks of multiple sclerosis in relatives of patients in Flanders, Belgium. Journal of neurology, neurosurgery, and psychiatry. 1997;62:329-33.

Chapman KR, Mannino DM, Soriano JB, Vermeire PA, Buist AS, Thun MJ, et al. Epidemiology and costs of chronic obstructive pulmonary disease. Eur Respir J. 2006;27:188-207.

Cofield SS, Tyry T, Thomas N, McNeal S, Fox RJ, Marrie RA, et al. Disease modifying therapy and the decision making process for MS patients in NARCOMS. Annual Meeting of the Consotrium of Multiple Sclerosis Centers, Indianapolis, IN, USA, 2015 [accessed 5 June 2015, at <https://cmscactrims.confex.com/cmscactrims/2015/webprogram/Paper3794.html>].

Cohen JA, Barkhof F, Comi G, Hartung HP, Khatri BO, Montalban X, et al. Oral fingolimod or intramuscular interferon for relapsing multiple sclerosis. The New England journal of medicine. 2010;362:402-15.

Cohen JA, Coles AJ, Arnold DL, Confavreux C, Fox EJ, Hartung HP, et al. Alemtuzumab versus interferon beta $1 \mathrm{a}$ as first-line treatment for patients with relapsing-remitting multiple sclerosis: a randomised controlled phase 3 trial. Lancet. 2012;380:1819-28.

Cohen JA, Cutter GR, Fischer JS, Goodman AD, Heidenreich FR, Kooijmans MF, et al. Benefit of interferon beta-1a on MSFC progression in secondary progressive MS. Neurology. 2002;59:679-87.

Coles AJ, Compston DA, Selmaj KW, Lake SL, Moran S, Margolin DH, et al. Alemtuzumab vs. interferon beta-1a in early multiple sclerosis. The New England journal of medicine. 2008;359:1786801.

Coles AJ, Fox E, Vladic A, Gazda SK, Brinar V, Selmaj KW, et al. Alemtuzumab more effective than interferon beta-1a at 5-year follow-up of CAMMS223 clinical trial. Neurology. 2012a;78:1069-78.

Coles AJ, Twyman CL, Arnold DL, Cohen JA, Confavreux C, Fox EJ, et al. Alemtuzumab for patients with relapsing multiple sclerosis after disease-modifying therapy: a randomised controlled phase 3 trial. Lancet. 2012b;380:1829-39.

Colhoun S, Wilkinson C, Izat A, White S, Pull E, Roberts M. Multiple sclerosis and disease modifying therapies: results of two UK surveys on factors influencing choice. British Journal of Neuroscience Nursing. 2015;11:7-13.

Comi G, De Stefano N, Freedman MS, Barkhof F, Polman CH, Uitdehaag BM, et al. Comparison of two dosing frequencies of subcutaneous interferon beta- $1 \mathrm{a}$ in patients with a first clinical 
This is an author's draft of an accepted article submitted and

published in Multiple Sclerosis and Related Disorders

DOI : http://www.sciencedirect.com/science/article/pii/S221103481630102X

demyelinating event suggestive of multiple sclerosis (REFLEX): a phase 3 randomised controlled trial. The Lancet Neurology. 2012;11:33-41.

Comi G, Filippi M, Barkhof F, Durelli L, Edan G, Fernandez O, et al. Effect of early interferon treatment on conversion to definite multiple sclerosis: a randomised study. Lancet. 2001;357:157682.

Comi G, Martinelli V, Rodegher M, Moiola L, Bajenaru O, Carra A, et al. Effect of glatiramer acetate on conversion to clinically definite multiple sclerosis in patients with clinically isolated syndrome (PreCISe study): a randomised, double-blind, placebo-controlled trial. Lancet. 2009;374:1503-11.

Comi G, Martinelli V, Rodegher M, Moiola L, Leocani L, Bajenaru O, et al. Effects of early treatment with glatiramer acetate in patients with clinically isolated syndrome. Multiple sclerosis (Houndmills, Basingstoke, England). 2013;19:1074-83.

Compston A, Coles A. Multiple sclerosis. Lancet. 2002;359:1221-31.

Compston A, Coles A. Multiple sclerosis. Lancet. 2008;372:1502-17.

Confavreux C, Vukusic S, Moreau T, Adeleine P. Relapses and progression of disability in multiple sclerosis. The New England journal of medicine. 2000;343:1430-8.

Costello K, Halper J, Kalb R, Skutnik L, Rapp R. The use of disease-modifying therapies in multiple sclerosis: principles and current evidence. Multiple Sclerosis Coalition; 2015 [accessed 13 May 2015, at <http://www.nationalmssociety.org/getmedia/5ca284d3-fc7c-4ba5-b005-

ab537d495c3c/DMT_Consensus_MS_Coalition_color>].

Costello K, Kennedy P, Scanzillo J. Recognizing nonadherence in patients with multiple sclerosis and maintaining treatment adherence in the long term. Medscape journal of medicine. 2008;10:225.

Cutter G, Chin P, Francis G, Meng X, Hashmonay R, Lublin F. Relapse is associated with residual deficits in relapsing-remitting multiple sclerosis: analysis of FREEDOMS Data (P07.118). Neurology. 2013;80(Meeting Abstracts 1):P07.118.

Dalton CM, Brex PA, Miszkiel KA, Hickman SJ, MacManus DG, Plant GT, et al. Application of the new McDonald criteria to patients with clinically isolated syndromes suggestive of multiple sclerosis. Ann Neurol. 2002;52:47-53.

Damal K, Stoker E, Foley JF. Optimizing therapeutics in the management of patients with multiple sclerosis: a review of drug efficacy, dosing, and mechanisms of action. Biologics. 2013;7:247-58.

De Broe S, Christopher F, Waugh N. The role of specialist nurses in multiple sclerosis: a rapid and systematic review. Health Technol Assess. 2001;5:1-47.

De Jager PL, Jia X, Wang J, de Bakker PI, Ottoboni L, Aggarwal NT, et al. Meta-analysis of genome scans and replication identify CD6, IRF8 and TNFRSF1A as new multiple sclerosis susceptibility loci. Nat Genet. 2009;41:776-82.

de Seze J, Borgel F, Brudon F. Patient perceptions of multiple sclerosis and its treatment. Patient preference and adherence. 2012;6:263-73.

De Stefano N, Airas L, Grigoriadis N, Mattle HP, O'Riordan J, Oreja-Guevara C, et al. Clinical relevance of brain volume measures in multiple sclerosis. CNS drugs. 2014a;28:147-56.

De Stefano N, Giorgio A, Battaglini M, Rovaris M, Sormani MP, Barkhof F, et al. Assessing brain atrophy rates in a large population of untreated multiple sclerosis subtypes. Neurology.

2010;74:1868-76. 
This is an author's draft of an accepted article submitted and published in Multiple Sclerosis and Related Disorders

DOI : http://www.sciencedirect.com/science/article/pii/S221103481630102X

De Stefano N, Narayanan S, Francis GS, Arnaoutelis R, Tartaglia MC, Antel JP, et al. Evidence of axonal damage in the early stages of multiple sclerosis and its relevance to disability. Arch Neurol. $2001 ; 58: 65-70$.

De Stefano N, Sprenger T, Freedman MS, Cree BAC, Sormani MP, Häring DA, et al. Including threshold rates of brain volume loss in the definition of disease activity-free in multiple sclerosis using fingolimod phase 3 data. Joint ACTRIMS-ECTRIMS meeting, Boston, MA, USA, September 10-13 2014b [accessed 23 June 2015, at <http://www.abstractstosubmit.com/msboston2014/eposter/main.php?do=YToyOntzOjU6Im1vZHVsljt zOjY6ImRldGFpbCl7czo4OiJkb2N1bWVudCl7aTo3NzQ7fQ==\&>].

De Stefano N, Stromillo ML, Giorgio A, Bartolozzi ML, Battaglini M, Baldini M, et al. Establishing pathological cut-offs of brain atrophy rates in multiple sclerosis. Journal of neurology, neurosurgery, and psychiatry. 2016;87:93-9.

Di Pauli F, Reindl M, Ehling R, Schautzer F, Gneiss C, Lutterotti A, et al. Smoking is a risk factor for early conversion to clinically definite multiple sclerosis. Multiple sclerosis (Houndmills, Basingstoke, England). 2008;14:1026-30.

Disanto G, Adiutori R, Dobson R, Martinelli V, Dalla Costa G, Runia T, et al. Serum neurofilament light chain levels are increased in patients with a clinically isolated syndrome. Journal of neurology, neurosurgery, and psychiatry. 2016;87:126-9.

Disanto G, Pakpoor J, Morahan JM, Hall C, Meier UC, Giovannoni G, et al. Epstein-Barr virus, latitude and multiple sclerosis. Multiple sclerosis (Houndmills, Basingstoke, England). 2013;19:362-5.

Dobson R, Rudick RA, Turner B, Schmierer K, Giovannoni G. Assessing treatment response to interferon-beta: is there a role for MRI? Neurology. 2014;82:248-54.

Doria A, Gatto M, laccarino L, Punzi L. Value and goals of treat-to-target in systemic lupus erythematosus: knowledge and foresight. Lupus. 2015;24:507-15.

Duddy M, Lee M, Pearson O, Nikfekr E, Chaudhuri A, Percival F, et al. The UK patient experience of relapse in multiple sclerosis treated with first disease modifying therapies. Mult Scler Relat Disord. 2014;3:450-56.

Ebers GC, Traboulsee A, Li D, Langdon D, Reder AT, Goodin DS, et al. Analysis of clinical outcomes according to original treatment groups 16 years after the pivotal IFNB-1b trial. Journal of neurology, neurosurgery, and psychiatry. 2010;81:907-12.

Edan G, Freedman M, Montalban X, Miller D, Hartung H, Hemmer B, et al. Long-term Impact of Early MS Treatment with Interferon Beta-1b (IFNB-1b): Clinical, MRI, Employment, and Patient-Reported Outcomes (PROs) at the 11-Year Follow-up of BENEFIT (BENEFIT 11). Neurology. 2015;84:Suppl: P7.012.

Edan G, Kappos L, Montalban X, Polman CH, Freedman MS, Hartung HP, et al. Long-term impact of interferon beta- $1 \mathrm{~b}$ in patients with CIS: 8-year follow-up of BENEFIT. Journal of neurology, neurosurgery, and psychiatry. 2014;85:1183-9.

Edlin M, Sonnenreich P. Trends in managing multiple sclerosis. P \& T : a peer-reviewed journal for formulary management. 2008;33:611-14.

Etemadifar M, Sajjadi S, Nasr Z, Firoozeei TS, Abtahi SH, Akbari M, et al. Epidemiology of multiple sclerosis in Iran: a systematic review. European neurology. 2013;70:356-63.

European Multiple Sclerosis Platform. A collaborative initiative to improve MS research and policy across Europe: better outcomes with better data (EUReMS project report 2011-2014). Brussels, 
This is an author's draft of an accepted article submitted and

published in Multiple Sclerosis and Related Disorders

DOI : http://www.sciencedirect.com/science/article/pii/S221103481630102X

Belgium: European Multiple Sclerosis Platform; 2014 [accessed 3 June 2015, at <http://www.eurems.eu/attachments/article/107/140930_EUReMS_Report-spreads.pdf>].

European Multiple Sclerosis Platform. European employment pact for people with multiple sclerosis. Brussels, Belgium: European Multiple Sclerosis Platform; 2015a [accessed 24 April 2015, at $<$ http://www.emsp.org/attachments/article/299/EMSP_PACT.pdf>].

European Multiple Sclerosis Platform. MS Nurse Professional. European Multiple Sclerosis Platform; 2015b [accessed 2 April 2015, at <http://www.msnursepro.org/>].

Eurostat. Employment (main characteristics and rates) - annual averages [lfsi_emp_a]. Employment rate (25 to 54 years) and employment rate (55 to 64 years) in 2005. Eurostat; 2015 [accessed 17 June 2015, at <http://tinyurl.com/Eurostat-employment-rate>].

Express Scripts. 2014 drug trend report.2015 [accessed 2 June 2015, at <http://lab.expressscripts.com/drug-trend-report/>].

Fahrbach K, Huelin R, Martin AL, Kim E, Dastani HB, Rao S, et al. Relating relapse and T2 lesion changes to disability progression in multiple sclerosis: a systematic literature review and regression analysis. BMC neurology. 2013;13:180.

Farias ST, Mungas D, Reed B, Carmichael O, Beckett L, Harvey D, et al. Maximal brain size remains an important predictor of cognition in old age, independent of current brain pathology. Neurobiology of aging. 2012;33:1758-68.

Fernandez O, Fernandez V, Arbizu T, Izquierdo G, Bosca I, Arroyo R, et al. Characteristics of multiple sclerosis at onset and delay of diagnosis and treatment in Spain (the Novo Study). Journal of neurology. 2010;257:1500-7.

Fiddes B, Wason J, Sawcer S. Confounding in association studies: month of birth and multiple sclerosis. Journal of neurology. 2014;261:1851-6.

Filippi M, Rocca MA. MRI evidence for multiple sclerosis as a diffuse disease of the central nervous system. Journal of neurology. 2005;252 Suppl 5:16-24.

Filippi M, Rovaris M, Inglese M, Barkhof F, De Stefano N, Smith S, et al. Interferon beta-1a for brain tissue loss in patients at presentation with syndromes suggestive of multiple sclerosis: a randomised, double-blind, placebo-controlled trial. Lancet. 2004;364:1489-96.

Finkelstein J, Lapshin O, Castro H, Cha E, Provance PG. Home-based physical telerehabilitation in patients with multiple sclerosis: a pilot study. Journal of rehabilitation research and development. 2008;45:1361-73.

Fisniku LK, Brex PA, Altmann DR, Miszkiel KA, Benton CE, Lanyon R, et al. Disability and T2 MRI lesions: a 20-year follow-up of patients with relapse onset of multiple sclerosis. Brain : a journal of neurology. 2008;131:808-17.

Flachenecker P, Buckow K, Pugliatti M, Kes VB, Battaglia MA, Boyko A, et al. Multiple sclerosis registries in Europe - results of a systematic survey. Multiple sclerosis (Houndmills, Basingstoke, England). 2014;20:1523-32.

Flachenecker P, Stuke K. National MS registries. Journal of neurology. 2008;255 Suppl 6:102-8.

Fox EJ, Rhoades RW. New treatments and treatment goals for patients with relapsing-remitting multiple sclerosis. Current opinion in neurology. 2012;25 Suppl:s11-9. 
This is an author's draft of an accepted article submitted and published in Multiple Sclerosis and Related Disorders

DOI : http://www.sciencedirect.com/science/article/pii/S221103481630102X

Fox RJ, Miller DH, Phillips JT, Hutchinson M, Havrdova E, Kita M, et al. Placebo-controlled phase 3 study of oral BG-12 or glatiramer in multiple sclerosis. The New England journal of medicine. 2012;367:1087-97.

Freedman MS, Selchen D, Arnold DL, Prat A, Banwell B, Yeung M, et al. Treatment Optimization in MS: Canadian MS Working Group Updated Recommendations. Can J Neurol Sci. 2013;40:307-23.

Genzyme Corporation. Aubagio: prescribing information (Reference ID: 3645193). Cambridge, MA, USA: Genzyme Corporation; 17 October 2014 [accessed 16 February 2015, at <http://www.accessdata.fda.gov/drugsatfda_docs/label/2014/202992s001lbl.pdf >].

Genzyme Corporation. Lemtrada: prescribing information (Reference ID: 3658409). Cambridge, MA, USA: Genzyme Corporation; Revised: 14 November 2014 [accessed 16 February 2015, at $<$ http://www.accessdata.fda.gov/drugsatfda_docs/label/2014/103948s5139lbl.pdf>].

Genzyme Therapeutics Ltd. Lemtrada: EPAR - product information (EMEA/H/C/003718 -IB/06). Oxford, UK: Genzyme Therapeutics Ltd; Revised: 25 March 2014 [accessed 16 February 2015, at <http://www.ema.europa.eu/docs/en_GB/document_library/EPAR_-

_Product_Information/human/003718/WC500150521.pdf >].

Giovannoni G. Biomarkers in MS. EFNS/ENS Joint Congress of Neurology, Istanbul, Turkey, 31 May3 June 2014a [accessed 29 May 2015, at <http://www.slideshare.net/gavingiovannoni/biomarkers-inms-efnsens-meeting-istanbul-2014>].

Giovannoni G. Personalizing treatment choice. International MS Physician Summit, Prague, Czech Republic, 22-23 March 2014b [accessed 29 May 2015, at <http://www.slideshare.net/gavingiovannoni/personalizing-treatment-choice>].

Giovannoni G, Foley J, Brandes D. Hidden disabilities in multiple sclerosis - the impact of multiple sclerosis on patients and their caregivers. Eur Neurol Rev. 2012;7:2-9.

Glanz BI, Healy BC, Rintell DJ, Jaffin SK, Bakshi R, Weiner HL. The association between cognitive impairment and quality of life in patients with early multiple sclerosis. Journal of the neurological sciences. 2010;290:75-9.

Gold R, Wolinsky JS, Amato MP, Comi G. Evolving expectations around early management of multiple sclerosis. Therapeutic advances in neurological disorders. 2010;3:351-67.

Goodin DS, Ebers GC, Cutter G, Cook SD, O'Donnell T, Reder AT, et al. Cause of death in MS: longterm follow-up of a randomised cohort, 21 years after the start of the pivotal IFNbeta-1b study. BMJ Open. 2012a;2.

Goodin DS, Reder AT, Ebers GC, Cutter G, Kremenchutzky M, Oger J, et al. Survival in MS: a randomized cohort study 21 years after the start of the pivotal IFNbeta- $1 \mathrm{~b}$ trial. Neurology. 2012b;78:1315-22.

Gresle MM, Liu Y, Dagley LF, Haartsen J, Pearson F, Purcell AW, et al. Serum phosphorylated neurofilament-heavy chain levels in multiple sclerosis patients. Journal of neurology, neurosurgery, and psychiatry. 2014;85:1209-13.

Grigor C, Capell H, Stirling A, McMahon AD, Lock P, Vallance R, et al. Effect of a treatment strategy of tight control for rheumatoid arthritis (the TICORA study): a single-blind randomised controlled trial. Lancet. 2004;364:263-9.

Grytten Torkildsen N, Lie SA, Aarseth JH, Nyland H, Myhr KM. Survival and cause of death in multiple sclerosis: results from a 50-year follow-up in Western Norway. Multiple sclerosis (Houndmills,

Basingstoke, England). 2008;14:1191-8. 
This is an author's draft of an accepted article submitted and published in Multiple Sclerosis and Related Disorders

DOI : http://www.sciencedirect.com/science/article/pii/S221103481630102X

Handel AE, Williamson AJ, Disanto G, Dobson R, Giovannoni G, Ramagopalan SV. Smoking and multiple sclerosis: an updated meta-analysis. PloS one. 2011;6:e16149.

Handelsman Y, Bloomgarden ZT, Grunberger G, Umpierrez G, Zimmerman RS, Bailey TS, et al. American association of clinical endocrinologists and american college of endocrinology - clinical practice guidelines for developing a diabetes mellitus comprehensive care plan - 2015. Endocr Pract. 2015;21:1-87.

Handunnetthi L, Ramagopalan SV, Ebers GC. Multiple sclerosis, vitamin D, and HLA-DRB1*15. Neurology. 2010;74:1905-10.

Hanson KA, Agashivala N, Wyrwich KW, Raimundo K, Kim E, Brandes DW. Treatment selection and experience in multiple sclerosis: survey of neurologists. Patient preference and adherence. 2014;8:415-22.

Hartung DM, Bourdette DN, Ahmed SM, Whitham RH. The cost of multiple sclerosis drugs in the US and the pharmaceutical industry: Too big to fail? Neurology. 2015;84:2185-92.

Havrdova E, Galetta S, Hutchinson M, Stefoski D, Bates D, Polman CH, et al. Effect of natalizumab on clinical and radiological disease activity in multiple sclerosis: a retrospective analysis of the Natalizumab Safety and Efficacy in Relapsing-Remitting Multiple Sclerosis (AFFIRM) study. The Lancet Neurology. 2009;8:254-60.

Havrdova E, Galetta S, Stefoski D, Comi G. Freedom from disease activity in multiple sclerosis. Neurology. 2010;74 Suppl 3:S3-7.

Hawkes $\mathrm{CH}$, Giovannoni $\mathrm{G}$. The McDonald criteria for multiple sclerosis: time for clarification. Multiple sclerosis (Houndmills, Basingstoke, England). 2010;16:566-75.

He A, Spelman T, Jokubaitis V, Havrdova E, Horakova D, Trojano M, et al. Comparison of switch to fingolimod or interferon beta/glatiramer acetate in active multiple sclerosis. JAMA neurology. 2015;72:405-13.

Hillman L. Caregiving in multiple sclerosis. Physical medicine and rehabilitation clinics of North America. 2013;24:619-27.

Hirst C, Ingram G, Pickersgill T, Swingler R, Compston DA, Robertson NP. Increasing prevalence and incidence of multiple sclerosis in South East Wales. Journal of neurology, neurosurgery, and psychiatry. 2009;80:386-91.

Hollingworth S, Walker K, Page A, Eadie M. Multiple sclerosis disease modifying medicine utilisation in Australia. Journal of clinical neuroscience : official journal of the Neurosurgical Society of Australasia. 2014;21:2083-7.

Hughes S, Spelman T, Trojano M, Lugaresi A, Izquierdo G, Grand'maison F, et al. The Kurtzke EDSS rank stability increases 4 years after the onset of multiple sclerosis: results from the MSBase Registry. Journal of neurology, neurosurgery, and psychiatry. 2012;83:305-10.

International Diabetes Federation. Global IDF/ISPAD guideline for diabetes in childhood and adolescence.2011 [accessed 5 June 2015, at <http://www.idf.org/sites/default/files/Diabetes-inChildhood-and-Adolescence-Guidelines.pdf $>$ ].

International Diabetes Federation Clinical Guidelines Task Force. Global guidance for type 2 diabetes.2012 [accessed 5 June 2015, at <http://www.idf.org/sites/default/files/IDF-Guideline-forType-2-Diabetes.pdf>]. 
This is an author's draft of an accepted article submitted and published in Multiple Sclerosis and Related Disorders

DOI : http://www.sciencedirect.com/science/article/pii/S221103481630102X

International society for pharmacoeconomics and outcomes research (ISPOR). Pharmacoeconomic guidelines around the world.2015 [accessed 9 February 2015, at

$<$ http://www.ispor.org/peguidelines/index.asp>].

Jacobs LD, Beck RW, Simon JH, Kinkel RP, Brownscheidle CM, Murray TJ, et al. Intramuscular interferon beta-1a therapy initiated during a first demyelinating event in multiple sclerosis. CHAMPS Study Group. The New England journal of medicine. 2000;343:898-904.

Jarvis N. The years of pain that lead to a diagnosis. Multiple Sclerosis Trust; 2012 [accessed 11 February 2015, at <http://www.mstrust.org.uk/mystory/nick-jarvis.jsp\#nj>].

Jick SS, Li L, Falcone GJ, Vassilev ZP, Wallander MA. Epidemiology of multiple sclerosis: results from a large observational study in the UK. Journal of neurology. 2015;262:2033-41.

Johansson E, Gustavsson A, Miltenburger C, Karampampa K, Rumbach L, Rerat K, et al. Treatment experience, burden and unmet needs (TRIBUNE) in MS study: results from France. Multiple sclerosis (Houndmills, Basingstoke, England). 2012;18:17-22.

Johnson KP, Ford CC, Lisak RP, Wolinsky JS. Neurologic consequence of delaying glatiramer acetate therapy for multiple sclerosis: 8-year data. Acta Neurol Scand. 2005;111:42-7.

Jokubaitis VG, Li V, Kalincik T, Izquierdo G, Hodgkinson S, Alroughani R, et al. Fingolimod after natalizumab and the risk of short-term relapse. Neurology. 2014;82:1204-11.

Jokubaitis VG, Spelman T, Kalincik T, Izquierdo G, Grand'Maison F, Duquette P, et al. Predictors of disability worsening in clinically isolated syndrome. Annals of clinical and translational neurology. 2015;2:479-91.

Jokubaitis VG, Spelman T, Lechner-Scott J, Barnett M, Shaw C, Vucic S, et al. The Australian Multiple Sclerosis (MS) immunotherapy study: a prospective, multicentre study of drug utilisation using the MSBase platform. PloS one. 2013;8:e59694.

Jonsson B. Ten arguments for a societal perspective in the economic evaluation of medical innovations. The European journal of health economics : HEPAC : health economics in prevention and care. 2009;10:357-9.

Julian LJ, Vella L, Vollmer T, Hadjimichael O, Mohr DC. Employment in multiple sclerosis. Exiting and re-entering the work force. Journal of neurology. 2008;255:1354-60.

Kalincik T, Horakova D, Spelman T, Jokubaitis V, Trojano M, Lugaresi A, et al. Switch to natalizumab versus fingolimod in active relapsing-remitting multiple sclerosis. Ann Neurol. 2015a;77:425-35.

Kalincik T, Jokubaitis V, Izquierdo G, Duquette P, Girard M, Grammond P, et al. Comparative effectiveness of glatiramer acetate and interferon beta formulations in relapsing-remitting multiple sclerosis. Multiple sclerosis (Houndmills, Basingstoke, England). 2015b;21:1159-71.

Kalincik T, Vaneckova M, Tyblova M, Krasensky J, Seidl Z, Havrdova E, et al. Volumetric MRI markers and predictors of disease activity in early multiple sclerosis: a longitudinal cohort study. PloS one. 2012;7:e50101.

Kallweit U, Jelcic I, Braun N, Fischer H, Zorner B, Schreiner B, et al. Sustained efficacy of natalizumab in the treatment of relapsing-remitting multiple sclerosis independent of disease activity and disability at baseline: real-life data from a Swiss cohort. Clinical neuropharmacology. 2012;35:7780.

Kalmar JH, Gaudino EA, Moore NB, Halper J, Deluca J. The relationship between cognitive deficits and everyday functional activities in multiple sclerosis. Neuropsychology. 2008;22:442-9. 
This is an author's draft of an accepted article submitted and published in Multiple Sclerosis and Related Disorders

DOI : http://www.sciencedirect.com/science/article/pii/S221103481630102X

Kane RL, Bever CT, Ehrmantraut M, Forte A, Culpepper WJ, Wallin MT. Teleneurology in patients with multiple sclerosis: EDSS ratings derived remotely and from hands-on examination. Journal of telemedicine and telecare. 2008;14:190-4.

Kappos L, Moeri D, Radue EW, Schoetzau A, Schweikert K, Barkhof F, et al. Predictive value of gadolinium-enhanced magnetic resonance imaging for relapse rate and changes in disability or impairment in multiple sclerosis: a meta-analysis. Gadolinium MRI Meta-analysis Group. Lancet. 1999;353:964-9.

Kappos L, O'Connor P, Radue EW, Polman C, Hohlfeld R, Selmaj K, et al. Long-term effects of fingolimod in multiple sclerosis: the randomized FREEDOMS extension trial. Neurology. 2015;84:1582-91.

Kappos L, Polman CH, Freedman MS, Edan G, Hartung HP, Miller DH, et al. Treatment with interferon beta- $1 \mathrm{~b}$ delays conversion to clinically definite and McDonald MS in patients with clinically isolated syndromes. Neurology. 2006a;67:1242-9.

Kappos L, Traboulsee A, Constantinescu C, Eralinna JP, Forrestal F, Jongen P, et al. Long-term subcutaneous interferon beta-1a therapy in patients with relapsing-remitting MS. Neurology. 2006b;67:944-53.

Kappus N, Weinstock-Guttman B, Hagemeier J, Kennedy C, Melia R, Carl E, et al. Cardiovascular risk factors are associated with increased lesion burden and brain atrophy in multiple sclerosis. Journal of neurology, neurosurgery, and psychiatry. 2016;87:181-7.

Karabudak R, Karampampa K, Caliskan Z, Group TS. Treatment experience, burden and unmet needs (TRIBUNE) in MS study: results from Turkey. Journal of medical economics. 2015;18:69-75.

Karampampa K, Gustavsson A, Miltenburger C, Kindundu CM, Selchen DH. Treatment experience, burden, and unmet needs (TRIBUNE) in multiple sclerosis: the costs and utilities of MS patients in Canada. Journal of population therapeutics and clinical pharmacology $=$ Journal de la therapeutique des populations et de la pharamcologie clinique. 2012a;19:e11-25.

Karampampa K, Gustavsson A, Miltenburger C, Mora S, Arbizu T. Treatment experience, burden and unmet needs (TRIBUNE) in MS study: results from Spain. Multiple sclerosis (Houndmills, Basingstoke, England). 2012b;18:35-9.

Karampampa K, Gustavsson A, Miltenburger C, Neidhardt K, Lang M. Treatment experience, burden and unmet needs (TRIBUNE) in MS study: results from Germany. Multiple sclerosis (Houndmills, Basingstoke, England). 2012c;18:23-7.

Karampampa K, Gustavsson A, Miltenburger C, Teruzzi C, Fattore G. Treatment experience, burden and unmet needs (TRIBUNE) in MS study: results from Italy. Multiple sclerosis (Houndmills, Basingstoke, England). 2012d;18:29-34.

Karampampa K, Gustavsson A, Miltenburger C, Tyas D. Treatment experience, burden and unmet needs (TRIBUNE) in MS study: results from the United Kingdom. Multiple sclerosis (Houndmills, Basingstoke, England). 2012e;18:41-5.

Karampampa K, Gustavsson A, van Munster ET, Hupperts RM, Sanders EA, Mostert J, et al. Treatment experience, burden, and unmet needs (TRIBUNE) in multiple sclerosis study: the costs and utilities of MS patients in The Netherlands. Journal of medical economics. 2013;16:939-50.

Kaufman DW, Reshef S, Golub HL, Peucker M, Corwin MJ, Goodin DS, et al. Survival in commercially insured multiple sclerosis patients and comparator subjects in the U.S. Mult Scler Relat Disord. 2014;3:364-71. 
This is an author's draft of an accepted article submitted and published in Multiple Sclerosis and Related Disorders

DOI : http://www.sciencedirect.com/science/article/pii/S221103481630102X

Kavaliunas A, Stawiarz L, Hedbom J, Glaser A, Hillert J. The influence of immunomodulatory treatment on the clinical course of multiple sclerosis. Advances in experimental medicine and biology. 2015;822:19-24.

Kaye HS, Kang T, LaPlante MP. Mobility device use in the United States. National Institute on Disability and Rehabilitation Research, US Department of Education; 2000 [accessed 3 July 2015, at $<$ http://www.disabled-world.com/pdf/mobility-report.pdf>].

Kelly SB, Chaila E, Kinsella K, Duggan M, McGuigan C, Tubridy N, et al. Multiple sclerosis, from referral to confirmed diagnosis: an audit of clinical practice. Multiple sclerosis (Houndmills, Basingstoke, England). 2011;17:1017-21.

Khan F, Amatya B, Galea M. Management of fatigue in persons with multiple sclerosis. Frontiers in neurology. 2014;5:177.

Khan F, Amatya B, Kesselring J, Galea MP. Telerehabilitation for persons with multiple sclerosis. A Cochrane review. European journal of physical and rehabilitation medicine. 2015;51:311-25.

Khatri B, Barkhof F, Comi G, Hartung HP, Kappos L, Montalban X, et al. Comparison of fingolimod with interferon beta-1a in relapsing-remitting multiple sclerosis: a randomised extension of the TRANSFORMS study. The Lancet Neurology. 2011;10:520-9.

Khatri BO, Foley JF, Fink J, Kramer JF, Cha C, You X, et al. The TRUST (evaluation of bladder function in relapsing-remitting multiple sclerosis patients treated with natalizumab) observational study. Int J MS Care. 2014;16:40-7.

Kieseier BC. The challenges of measuring disability accumulation in relapsing-remitting multiple sclerosis: evidence from interferon beta treatments. Expert review of neurotherapeutics. 2014;14:105-20.

Kingwell E, Leung AL, Roger E, Duquette P, Rieckmann P, Tremlett H. Factors associated with delay to medical recognition in two Canadian multiple sclerosis cohorts. Journal of the neurological sciences. 2010;292:57-62.

Kinkel RP, Dontchev M, Kollman C, Skaramagas TT, O'Connor PW, Simon JH. Association between immediate initiation of intramuscular interferon beta-1a at the time of a clinically isolated syndrome and long-term outcomes: a 10-year follow-up of the Controlled High-Risk Avonex Multiple Sclerosis Prevention Study in Ongoing Neurological Surveillance. Arch Neurol. 2012;69:183-90.

Kobelt G, Berg J, Atherly D, Hadjimichael O. Costs and quality of life in multiple sclerosis: a crosssectional study in the United States. Neurology. 2006a;66:1696-702.

Kobelt G, Berg J, Lindgren P, Fredrikson S, Jonsson B. Costs and quality of life of patients with multiple sclerosis in Europe. Journal of neurology, neurosurgery, and psychiatry. 2006b;77:918-26.

Kobelt G, Berg J, Lindgren P, Kerrigan J, Russell N, Nixon R. Costs and quality of life of multiple sclerosis in the United Kingdom. The European journal of health economics : HEPAC : health economics in prevention and care. 2006c;7 Suppl 2:S96-104.

Kobelt G, Kasteng F. Access to innovative treatments in multiple sclerosis in Europe. The European Federation of Pharmaceutical Industry Associations (EFPIA) 2009 [accessed 20 January 2015, at $<$ http://www.comparatorreports.se/Access\%20to\%20MS\%20treatments\%20\%200ctober\%202009.pdf >].

Kobelt G, Texier-Richard B, Lindgren P. The long-term cost of multiple sclerosis in France and potential changes with disease-modifying interventions. Multiple sclerosis (Houndmills, Basingstoke, England). 2009;15:741-51. 
This is an author's draft of an accepted article submitted and

published in Multiple Sclerosis and Related Disorders

DOI : http://www.sciencedirect.com/science/article/pii/S221103481630102X

Koch M, Kingwell E, Rieckmann $\mathrm{P}$, Tremlett $\mathrm{H}$. The natural history of secondary progressive multiple sclerosis. Journal of neurology, neurosurgery, and psychiatry. 2010;81:1039-43.

Kopke S, Solari A, Khan F, Heesen C, Giordano A. Information provision for people with multiple sclerosis. The Cochrane database of systematic reviews. 2014;4:Cd008757.

Kremenchutzky M, Walt L. Perceptions of health status in multiple sclerosis patients and their doctors. Can J Neurol Sci. 2013;40:210-18.

Kuhle J, Disanto G, Lorscheider J, Stites T, Chen Y, Dahlke F, et al. Fingolimod and CSF neurofilament light chain levels in relapsing-remitting multiple sclerosis. Neurology. 2015;84:1639-43.

Kuhlmann T, Lingfeld G, Bitsch A, Schuchardt J, Bruck W. Acute axonal damage in multiple sclerosis is most extensive in early disease stages and decreases over time. Brain : a journal of neurology. 2002;125:2202-12.

Kurtzke JF. Rating neurologic impairment in multiple sclerosis: an expanded disability status scale (EDSS). Neurology. 1983;33:1444-52.

Leary SM, Porter B, Thompson AJ. Multiple sclerosis: diagnosis and the management of acute relapses. Postgrad Med J. 2005;81:302-8.

Lerdal A, Celius EG, Krupp L, Dahl AA. A prospective study of patterns of fatigue in multiple sclerosis. Eur J Neurol. 2007;14:1338-43.

Levin LI, Munger KL, O'Reilly EJ, Falk KI, Ascherio A. Primary infection with the Epstein-Barr virus and risk of multiple sclerosis. Ann Neurol. 2010;67:824-30.

Levin LI, Munger KL, Rubertone MV, Peck CA, Lennette ET, Spiegelman D, et al. Temporal relationship between elevation of Epstein-Barr virus antibody titers and initial onset of neurological symptoms in multiple sclerosis. JAMA. 2005;293:2496-500.

Li DK, Zhao GJ, Paty DW. Randomized controlled trial of interferon-beta-1a in secondary progressive MS: MRI results. Neurology. 2001;56:1505-13.

Lobentanz IS, Asenbaum S, Vass K, Sauter C, Klosch G, Kollegger H, et al. Factors influencing quality of life in multiple sclerosis patients: disability, depressive mood, fatigue and sleep quality. Acta Neurol Scand. 2004;110:6-13.

Lublin FD, Baier M, Cutter G. Effect of relapses on development of residual deficit in multiple sclerosis. Neurology. 2003;61:1528-32.

Lublin FD, Reingold SC, Cohen JA, Cutter GR, Sorensen PS, Thompson AJ, et al. Defining the clinical course of multiple sclerosis: the 2013 revisions. Neurology. 2014;83:278-86.

Luccichenti G, Cademartiri F, Pichiecchio A, Bontempi E, Sabatini U, Bastianello S. User interface of a teleradiology system for the MR assessment of multiple sclerosis. Journal of digital imaging. 2010;23:632-8.

MacLullich AM, Ferguson KJ, Deary IJ, Seckl JR, Starr JM, Wardlaw JM. Intracranial capacity and brain volumes are associated with cognition in healthy elderly men. Neurology. 2002;59:169-74.

Margolis JM, Fowler R, Johnson BH, Kassed CA, Kahler K. Disease-modifying drug initiation patterns in commercially insured multiple sclerosis patients: a retrospective cohort study. BMC neurology. 2011;11:122. 
This is an author's draft of an accepted article submitted and published in Multiple Sclerosis and Related Disorders

DOI : http://www.sciencedirect.com/science/article/pii/S221103481630102X

Marrie RA, Cutter G, Tyry T, Hadjimichael O, Campagnolo D, Vollmer T. Changes in the ascertainment of multiple sclerosis. Neurology. 2005;65:1066-70.

Marrie RA, Elliott L, Marriott J, Cossoy M, Blanchard J, Leung S, et al. Effect of comorbidity on mortality in multiple sclerosis. Neurology. 2015;85:240-7.

Marrie RA, Rudick R, Horwitz R, Cutter G, Tyry T, Campagnolo D, et al. Vascular comorbidity is associated with more rapid disability progression in multiple sclerosis. Neurology. 2010a;74:1041-7.

Marrie RA, Yu N, Blanchard J, Leung S, Elliott L. The rising prevalence and changing age distribution of multiple sclerosis in Manitoba. Neurology. 2010b;74:465-71.

Marsh-Wakefield F, Byrne SN. Photoimmunology and Multiple Sclerosis. Current topics in behavioral neurosciences. 2015;26:117-41.

Martyn CN, Cruddas M, Compston DA. Symptomatic Epstein-Barr virus infection and multiple sclerosis. Journal of neurology, neurosurgery, and psychiatry. 1993;56:167-8.

Mayo Clinic. Sharing Mayo Clinic. ESCP (Edie's Spinal Cord Problem). Mayo Clinic; 2010 [accessed 11 February 2015, at <http://sharing.mayoclinic.org/discussion/escp-edies-spinal-cord-problem/>].

McDonald WI, Compston A, Edan G, Goodkin D, Hartung HP, Lublin FD, et al. Recommended diagnostic criteria for multiple sclerosis: guidelines from the International Panel on the diagnosis of multiple sclerosis. Ann Neurol. 2001;50:121-7.

Meng X, Chin PS, Hashmonay R, Zahur Islam M, Cutter G. Effect of switching from intramuscular interferon beta-1a to oral fingolimod on time to relapse in patients with relapsing-remitting multiple sclerosis enrolled in a 1-year extension of TRANSFORMS. Contemporary clinical trials. 2014;41C:6974.

Menzin J, Caon C, Nichols C, White LA, Friedman M, Pill MW. Narrative review of the literature on adherence to disease-modifying therapies among patients with multiple sclerosis. Journal of managed care pharmacy : JMCP. 2013;19:S24-40.

Miller A, Dishon S. Health-related quality of life in multiple sclerosis: the impact of disability, gender and employment status. Qual Life Res. 2006;15:259-71.

Miller AE, Wolinsky JS, Kappos L, Comi G, Freedman MS, Olsson TP, et al. Oral teriflunomide for patients with a first clinical episode suggestive of multiple sclerosis (TOPIC): a randomised, doubleblind, placebo-controlled, phase 3 trial. The Lancet Neurology. 2014;13:977-86.

Miller D, Barkhof F, Montalban X, Thompson A, Filippi M. Clinically isolated syndromes suggestive of multiple sclerosis, part I: natural history, pathogenesis, diagnosis, and prognosis. The Lancet Neurology. 2005;4:281-8.

Miller DH, Leary SM. Primary-progressive multiple sclerosis. The Lancet Neurology. 2007;6:903-12.

Miller JR. The importance of early diagnosis of multiple sclerosis. Journal of managed care pharmacy : JMCP. 2004;10(3 Suppl B):s4-11.

Miravitlles M, Sicras A, Crespo C, Cuesta M, Brosa M, Galera J, et al. Costs of chronic obstructive pulmonary disease in relation to compliance with guidelines: a study in the primary care setting. Ther Adv Respir Dis. 2013;7:139-50.

Modica CM, Bergsland N, Dwyer MG, Ramasamy DP, Carl E, Zivadinov R, et al. Cognitive reserve moderates the impact of subcortical gray matter atrophy on neuropsychological status in multiple sclerosis. Multiple sclerosis (Houndmills, Basingstoke, England). 2016;22:36-42. 
This is an author's draft of an accepted article submitted and published in Multiple Sclerosis and Related Disorders

DOI : http://www.sciencedirect.com/science/article/pii/S221103481630102X

Montalban X, Tintore M, Swanton J, Barkhof F, Fazekas F, Filippi M, et al. MRI criteria for MS in patients with clinically isolated syndromes. Neurology. 2010;74:427-34.

Moore P, Hirst C, Harding KE, Clarkson H, Pickersgill TP, Robertson NP. Multiple sclerosis relapses and depression. Journal of psychosomatic research. 2012;73:272-6.

MS Society. A lottery of treatment and care - MS services across the UK. London, UK: MS Society; 2013 [accessed 20 April 2015, at <http://mslottery.mssociety.org.uk/wp-content/uploads/2013/04/UKms-lottery.pdf>].

MSBase. Overview of MSBase registry.2015 [accessed 13 July 2015, at <https://www.msbase.org/>].

Multiple Sclerosis International Federation. Atlas of MS 2013: mapping multiple sclerosis around the world. Multiple Sclerosis International Federation; 2013a [accessed 19 January 2015, at <http://www.msif.org/wp-content/uploads/2014/09/Atlas-of-MS.pdf>].

Multiple Sclerosis International Federation. Atlas of MS database data export: all or part of the cost of disease modifying treatments for MS paid for by health insurance (natalizumab and fingolimod), 2013.2013b [accessed 3 February 2015, at <http://www.atlasofms.org>].

Multiple Sclerosis International Federation. Atlas of MS database data export: all or part of the cost of disease modifying treatments for MS paid for by health insurance, 2013.2013c [accessed 3 February 2015, at <http://www.atlasofms.org>].

Multiple Sclerosis International Federation. Atlas of MS database data export: all or part of the cost of disease modifying treatments for MS paid for by the government (natalizumab and fingolimod), 2013.2013d [accessed 3 February 2015, at <http://www.atlasofms.org >].

Multiple Sclerosis International Federation. Atlas of MS database data export: all or part of the cost of disease modifying treatments for MS paid for by the government, 2013.2013e [accessed 30 January 2015, at <http://www.atlasofms.org>].

Multiple Sclerosis International Federation. Atlas of MS database data export: criteria for the prescription of disease modifying drugs in MS, 2013.2013f [accessed 3 February 2015, at $<$ http://www.atlasofms.org $>$ ].

Multiple Sclerosis International Federation. Atlas of MS database data export: diagnosis, 2013.2013g [accessed 27 January 2015, at <http://www. atlasofms.org>].

Multiple Sclerosis International Federation. Atlas of MS database data export: number of people with MS, 2013.2013h [accessed 3 February 2015, at <http://www.atlasofms.org >].

Multiple Sclerosis International Federation. Atlas of MS database data export: prevalence of MS, 2013.2013i [accessed 6 February 2015, at <http://www.atlasofms.org>].

Multiple Sclerosis Society UK. Every day is different. Multiple Sclerosis Society UK; 2015 [accessed 29 January 2015, at <http://www.mssociety.org.uk/ms-support/community-blog/2015/01/every-daydifferent>].

Mynors G, Perman S, Morse M. Defining the value of MS specialist nurses. Multiple Sclerosis Trust; 2012 [accessed 12 March 2015, at <http://www.mstrust.org.uk/downloads/defining-the-value-of-msspecialist-nurses-2012.pdf>].

Naci H, Fleurence R, Birt J, Duhig A. Economic burden of multiple sclerosis: a systematic review of the literature. PharmacoEconomics. 2010;28:363-79. 
This is an author's draft of an accepted article submitted and published in Multiple Sclerosis and Related Disorders

DOI : http://www.sciencedirect.com/science/article/pii/S221103481630102X

NHS England. Capitation: a potential new payment model to enable integrated care. NHS England; 2014 [accessed 1 June 2015, at <https://www.gov.uk/government/uploads/system/uploads/attachment_data/file/381940/Local_payme nt_example_Capitation.pdf>].

Novartis Pharma GmbH. Gilenya: EPAR - product information (EMEA/H/C/002202 -II-26-G). Nuremberg, Germany: Novartis Pharma GmbH; Revised 24 July 2014 [accessed 16 February 2015, at <http://www.ema.europa.eu/docs/en_GB/document_library/EPAR_-

_Product_Information/human/002202/WC500104528.pdf>].

Novartis Pharmaceuticals Corporation. Gilenya: prescribing information (Reference ID: 3494793). East Hanover, NJ, USA: Novartis Pharmaceuticals Corporation; Revised: 30 April 2014 [accessed 16 February 2015, at <http://www.accessdata.fda.gov/drugsatfda_docs/label/2014/022527s009lbl.pdf>].

O'Connor P. The effects of intramuscular interferon beta-la in patients at high risk for development of multiple sclerosis: a post hoc analysis of data from CHAMPS. Clinical therapeutics. 2003;25:2865-74.

O'Connor P, Wolinsky JS, Confavreux C, Comi G, Kappos L, Olsson TP, et al. Randomized trial of oral teriflunomide for relapsing multiple sclerosis. The New England journal of medicine.

2011;365:1293-303.

Okuda DT, Mowry EM, Beheshtian A, Waubant E, Baranzini SE, Goodin DS, et al. Incidental MRI anomalies suggestive of multiple sclerosis: the radiologically isolated syndrome. Neurology. 2009;72:800-5.

Okuda DT, Siva A, Kantarci O, Inglese M, Katz I, Tutuncu M, et al. Radiologically isolated syndrome: 5-year risk for an initial clinical event. PloS one. 2014;9:e90509.

Oleen-Burkey M, Castelli-Haley J, Lage MJ, Johnson KP. Burden of a multiple sclerosis relapse: the patient's perspective. The patient. 2012;5:57-69.

Olesen J, Gustavsson A, Svensson M, Wittchen HU, Jonsson B, group Cs, et al. The economic cost of brain disorders in Europe. Eur J Neurol. 2012;19:155-62.

Orme M, Kerrigan J, Tyas D, Russell N, Nixon R. The effect of disease, functional status, and relapses on the utility of people with multiple sclerosis in the UK. Value in health : the journal of the International Society for Pharmacoeconomics and Outcomes Research. 2007;10:54-60.

Ortiz-Gutierrez R, Cano-de-la-Cuerda R, Galan-del-Rio F, Alguacil-Diego IM, Palacios-Cena D, Miangolarra-Page JC. A telerehabilitation program improves postural control in multiple sclerosis patients: a Spanish preliminary study. International journal of environmental research and public health. 2013;10:5697-710.

Owens GM. Managed care aspects of managing multiple sclerosis. The American journal of managed care. 2013;19(16 Suppl):s307-12.

Ozcan ME, Ince B, Bingol A, Erturk S, Altinoz MA, Karadeli HH, et al. Association between smoking and cognitive impairment in multiple sclerosis. Neuropsychiatric disease and treatment. 2014;10:1715-19.

Palmer AJ, Colman S, O'Leary B, Taylor BV, Simmons RD. The economic impact of multiple sclerosis in Australia in 2010. Multiple sclerosis (Houndmills, Basingstoke, England). 2013;19:1640-6.

Panitch H, Miller A, Paty D, Weinshenker B. Interferon beta- $1 \mathrm{~b}$ in secondary progressive MS: results from a 3-year controlled study. Neurology. 2004;63:1788-95. 
This is an author's draft of an accepted article submitted and published in Multiple Sclerosis and Related Disorders

DOI : http://www.sciencedirect.com/science/article/pii/S221103481630102X

Parkin D, Jacoby A, McNamee P, Miller P, Thomas S, Bates D. Treatment of multiple sclerosis with interferon beta: an appraisal of cost-effectiveness and quality of life. Journal of neurology, neurosurgery, and psychiatry. 2000;68:144-9.

Phillips AL, Edwards NC, Sutherland S. A descriptive analysis of time to first treatment with diseasemodifying drugs in newly diagnosed patients with multiple sclerosis. Annual Meeting of the Consortium of Multiple Sclerosis Centers, Indianapolis, IN, USA, 2015 [accessed 5 June 2015, at $<$ https://cmscactrims.confex.com/cmscactrims/2015/webprogram/Paper3425.html>].

Pinter D, Sumowski J, DeLuca J, Fazekas F, Pichler A, Khalil M, et al. Higher education moderates the effect of T2 lesion load and third ventricle width on cognition in multiple sclerosis. PloS one. 2014;9:e87567.

Pittas F, Ponsonby AL, van der Mei IA, Taylor BV, Blizzard L, Groom P, et al. Smoking is associated with progressive disease course and increased progression in clinical disability in a prospective cohort of people with multiple sclerosis. Journal of neurology. 2009;256:577-85.

Ploughman M, Austin MW, Murdoch M, Kearney A, Godwin M, Stefanelli M. The path to selfmanagement: a qualitative study involving older people with multiple sclerosis. Physiotherapy Canada Physiotherapie Canada. 2012;64:6-17.

Polman $\mathrm{CH}$, O'Connor PW, Havrdova E, Hutchinson M, Kappos L, Miller DH, et al. A randomized, placebo-controlled trial of natalizumab for relapsing multiple sclerosis. The New England journal of medicine. 2006;354:899-910.

Polman CH, Reingold SC, Banwell B, Clanet M, Cohen JA, Filippi M, et al. Diagnostic criteria for multiple sclerosis: 2010 revisions to the McDonald criteria. Ann Neurol. 2011;69:292-302.

Polman CH, Reingold SC, Edan G, Filippi M, Hartung HP, Kappos L, et al. Diagnostic criteria for multiple sclerosis: 2005 revisions to the "McDonald Criteria". Ann Neurol. 2005;58:840-6.

Popescu V, Agosta F, Hulst HE, Sluimer IC, Knol DL, Sormani MP, et al. Brain atrophy and lesion load predict long term disability in multiple sclerosis. Journal of neurology, neurosurgery, and psychiatry. 2013;84:1082-91.

Poser CM, Paty DW, Scheinberg L, McDonald WI, Davis FA, Ebers GC, et al. New diagnostic criteria for multiple sclerosis: guidelines for research protocols. Ann Neurol. 1983;13:227-31.

Prakash RS, Snook EM, Motl RW, Kramer AF. Aerobic fitness is associated with gray matter volume and white matter integrity in multiple sclerosis. Brain research. 2010;1341:41-51.

Prisms Study Group and University of British Columbia MS/MRI Analysis Group. PRISMS-4: longterm efficacy of interferon-beta-1a in relapsing MS. Neurology. 2001;56:1628-36.

Prosperini L, Capobianco M, Giannì C. Identifying responders and nonresponders to interferon therapy in multiple sclerosis. Degener Neuro Neuromuscul Dis. 2014;4:75-84.

Prosperini L, Gianni C, Leonardi L, De Giglio L, Borriello G, Galgani S, et al. Escalation to natalizumab or switching among immunomodulators in relapsing multiple sclerosis. Multiple sclerosis (Houndmills, Basingstoke, England). 2012;18:64-71.

Pugliatti M, Eskic D, Mikolcic T, Pitschnau-Michel D, Myhr KM, Sastre-Garriga J, et al. Assess, compare and enhance the status of persons with multiple sclerosis (MS) in Europe: a European register for MS. Acta neurologica Scandinavica Supplementum. 2012;S195:24-30.

Radue EW, Barkhof F, Kappos L, Sprenger T, Haring DA, de Vera A, et al. Correlation between brain volume loss and clinical and MRI outcomes in multiple sclerosis. Neurology. 2015;84:784-93. 
This is an author's draft of an accepted article submitted and

published in Multiple Sclerosis and Related Disorders

DOI : http://www.sciencedirect.com/science/article/pii/S221103481630102X

Rao SM, Leo GJ, Ellington L, Nauertz T, Bernardin L, Unverzagt F. Cognitive dysfunction in multiple sclerosis. II. Impact on employment and social functioning. Neurology. 1991;41:692-6.

Remington G, Rodriguez Y, Logan D, Williamson C, Treadaway K. Facilitating medication adherence in patients with multiple sclerosis. Int J MS Care. 2013;15:36-45.

Reynolds MD, Johnston JM, Dodge HH, DeKosky ST, Ganguli M. Small head size is related to low Mini-Mental State Examination scores in a community sample of nondemented older adults. Neurology. 1999;53:228-9.

Robertson NP, Clayton D, Fraser M, Deans J, Compston DA. Clinical concordance in sibling pairs with multiple sclerosis. Neurology. 1996;47:347-52.

Robinson AG, Booth CM, Eisenhauer EA. Disease-free survival as an end-point in the treatment of solid tumours - perspectives from clinical trials and clinical practice. European journal of cancer (Oxford, England : 1990). 2014a;50:2298-302.

Robinson AG, Booth CM, Eisenhauer EA. Progression-free survival as an end-point in solid tumours perspectives from clinical trials and clinical practice. European journal of cancer (Oxford, England : 1990). 2014b;50:2303-8.

Rocca MA, Filippi M. Functional MRI in multiple sclerosis. J Neuroimaging. 2007;17 Suppl 1:s36-41.

Rocca MA, Mezzapesa DM, Falini A, Ghezzi A, Martinelli V, Scotti G, et al. Evidence for axonal pathology and adaptive cortical reorganization in patients at presentation with clinically isolated syndromes suggestive of multiple sclerosis. Neurolmage. 2003;18:847-55.

Rogers EM. Diffusion of innovation. 5 ed. New York, NY, USA: Simon and Schuster; 2003.

Rolak LA, Fleming JO. The differential diagnosis of multiple sclerosis. Neurologist. 2007;13:57-72.

Romeo M, Martinelli-Boneschi F, Rodegher M, Esposito F, Martinelli V, Comi G. Clinical and MRI predictors of response to interferon-beta and glatiramer acetate in relapsing-remitting multiple sclerosis patients. Eur J Neurol. 2013;20:1060-7.

Romeo M, Martinelli V, Rodegher M, Perego E, Maida S, Sormani MP, et al. Validation of 1-year predictive score of long-term response to interferon-beta in everyday clinical practice multiple sclerosis patients. Eur J Neurol. 2015;22:973-80.

Rommer PS, Zettl UK, Kieseier B, Hartung HP, Menge T, Frohman E, et al. Requirement for safety monitoring for approved multiple sclerosis therapies: an overview. Clinical and experimental immunology. 2014;175:397-407.

Rotstein DL, Healy BC, Malik MT, Chitnis T, Weiner HL. Evaluation of no evidence of disease activity in a 7-year longitudinal multiple sclerosis cohort. JAMA neurology. 2015;72:152-58.

Rovaris M, Comi G, Rocca MA, Valsasina P, Ladkani D, Pieri E, et al. Long-term follow-up of patients treated with glatiramer acetate: a multicentre, multinational extension of the European/Canadian double-blind, placebo-controlled, MRI-monitored trial. Multiple sclerosis (Houndmills, Basingstoke, England). 2007;13:502-8.

Rudick RA, Polman $\mathrm{CH}$. Current approaches to the identification and management of breakthrough disease in patients with multiple sclerosis. The Lancet Neurology. 2009;8:545-59.

Rudick RA, Stuart WH, Calabresi PA, Confavreux C, Galetta SL, Radue EW, et al. Natalizumab plus interferon beta-1a for relapsing multiple sclerosis. The New England journal of medicine.

2006;354:911-23. 
This is an author's draft of an accepted article submitted and published in Multiple Sclerosis and Related Disorders

DOI : http://www.sciencedirect.com/science/article/pii/S221103481630102X

Ruet A, Deloire M, Hamel D, Ouallet JC, Petry K, Brochet B. Cognitive impairment, health-related quality of life and vocational status at early stages of multiple sclerosis: a 7-year longitudinal study. Journal of neurology. 2013;260:776-84.

Runia TF, Jafari N, Hintzen RQ. Application of the 2010 revised criteria for the diagnosis of multiple sclerosis to patients with clinically isolated syndromes. Eur J Neurol. 2013;20:1510-16.

Russo P, Capone A, Paolillo A, Macchia F, Ranzato F, Costantino G, et al. Cost-analysis of relapsingremitting multiple sclerosis in Italy after the introduction of new disease-modifying agents. Clin Drug Investig. 2004;24:409-20.

Sanofi-aventis Groupe. Aubagio: EPAR - product information (EMEA/H/C/002514 -PSUV/0005). Paris, France: Sanofi-aventis Groupe; Revised: 28 November 2014 [accessed 16 February 2015, at $<$ http://www.ema.europa.eu/docs/en_GB/document_library/EPAR__Product_Information/human/002514/WC500148682.pdf>].

Sbardella E, Tona F, Petsas N, Pantano P. DTI measurements in multiple sclerosis: evaluation of brain damage and clinical implications. Multiple sclerosis international. 2013;2013:671730.

Scalfari A, Neuhaus A, Daumer M, Muraro PA, Ebers GC. Onset of secondary progressive phase and long-term evolution of multiple sclerosis. Journal of neurology, neurosurgery, and psychiatry. 2014;85:67-75.

Scalfari A, Neuhaus A, Degenhardt A, Rice GP, Muraro PA, Daumer M, et al. The natural history of multiple sclerosis: a geographically based study 10: relapses and long-term disability. Brain : a journal of neurology. 2010;133:1914-29.

Schirmer L, Albert M, Buss A, Schulz-Schaeffer WJ, Antel JP, Bruck W, et al. Substantial early, but nonprogressive neuronal loss in multiple sclerosis (MS) spinal cord. Ann Neurol. 2009;66:698-704.

Schmierer K, Marta M, Turner BP, Giovannoni G. The use of magnetic resonance imaging (MRI) in the management of multiple sclerosis in the UK. Journal of neurology, neurosurgery, and psychiatry. 2014;85:e4.

Schumacher GA, Beebe G, Kibler RF, Kurland LT, Kurtzke JF, McDowell F, et al. Problems of experimental trials of therapy in multiple sclerosis: report by the panel on the evaluation of experimental trials of therapy in multiple sclerosis. Annals of the New York Academy of Sciences. 1965;122:552-68.

Schwartz CE, Quaranto BR, Healy BC, Benedict RH, Vollmer TL. Cognitive reserve and symptom experience in multiple sclerosis: a buffer to disability progression over time? Archives of physical medicine and rehabilitation. 2013;94:1971-81.

Scolding N, Barnes D, Cader S, Chataway J, Chaudhuri A, Coles A, et al. Association of British Neurologists: revised (2015) guidelines for prescribing disease-modifying treatments in multiple sclerosis. Pract Neurol. 2015;15:273-9.

Secondary progressive efficacy clinical trial of recombinant interferon-beta-1a in MS study group. Randomized controlled trial of interferon- beta-1a in secondary progressive MS: clinical results. Neurology. 2001;56:1496-504.

Sethi V, Yousry TA, Muhlert N, Ron M, Golay X, Wheeler-Kingshott C, et al. Improved detection of cortical MS lesions with phase-sensitive inversion recovery MRI. Journal of neurology, neurosurgery, and psychiatry. 2012;83:877-82.

Shirani A, Zhao Y, Karim ME, Evans C, Kingwell E, van der Kop ML, et al. Association between use of interferon beta and progression of disability in patients with relapsing-remitting multiple sclerosis. JAMA. 2012;308:247-56. 
This is an author's draft of an accepted article submitted and published in Multiple Sclerosis and Related Disorders

DOI : http://www.sciencedirect.com/science/article/pii/S221103481630102X

Signori A, Schiavetti I, Gallo F, Sormani MP. Subgroups of multiple sclerosis patients with larger treatment benefits: a meta-analysis of randomized trials. Eur J Neurol. 2015;22:960-6.

Simpson S, Jr., Blizzard L, Otahal P, Van der Mei I, Taylor B. Latitude is significantly associated with the prevalence of multiple sclerosis: a meta-analysis. Journal of neurology, neurosurgery, and psychiatry. 2011;82:1132-41.

Sinay V, Perez Akly M, Zanga G, Ciardi C, Racosta JM. School performance as a marker of cognitive decline prior to diagnosis of multiple sclerosis. Multiple sclerosis (Houndmills, Basingstoke, England). 2015;21:945-52.

Smolen JS, Aletaha D, Bijlsma JW, Breedveld FC, Boumpas D, Burmester G, et al. Treating rheumatoid arthritis to target: recommendations of an international task force. Annals of the rheumatic diseases. 2010;69:631-7.

Smolen JS, Braun J, Dougados M, Emery P, Fitzgerald O, Helliwell P, et al. Treating spondyloarthritis, including ankylosing spondylitis and psoriatic arthritis, to target: recommendations of an international task force. Annals of the rheumatic diseases. 2014;73:6-16.

Solomon AJ, Whitham RH. Multiple sclerosis and vitamin D: a review and recommendations. Current neurology and neuroscience reports. 2010;10:389-96.

Sormani MP, Arnold DL, De Stefano N. Treatment effect on brain atrophy correlates with treatment effect on disability in multiple sclerosis. Ann Neurol. 2014;75:43-9.

Sormani MP, Bonzano L, Roccatagliata L, Cutter GR, Mancardi GL, Bruzzi P. Magnetic resonance imaging as a potential surrogate for relapses in multiple sclerosis: a meta-analytic approach. Ann Neurol. 2009;65:268-75.

Sormani MP, Bonzano L, Roccatagliata L, De Stefano N. Magnetic resonance imaging as surrogate for clinical endpoints in multiple sclerosis: data on novel oral drugs. Multiple sclerosis (Houndmills, Basingstoke, England). 2011;17:630-3.

Sormani MP, Bonzano L, Roccatagliata L, Mancardi GL, Uccelli A, Bruzzi P. Surrogate endpoints for EDSS worsening in multiple sclerosis. A meta-analytic approach. Neurology. 2010;75:302-9.

Sormani MP, Bruzzi P. MRI lesions as a surrogate for relapses in multiple sclerosis: a meta-analysis of randomised trials. The Lancet Neurology. 2013;12:669-76.

Sormani MP, Rio J, Tintore M, Signori A, Li D, Cornelisse P, et al. Scoring treatment response in patients with relapsing multiple sclerosis. Multiple sclerosis (Houndmills, Basingstoke, England). 2013;19:605-12.

Spelman T, Bergvall N, Tomic D, Trojano M, Izquierdo G, Lugaresi A, et al. Real-world comparative effectiveness of fingolimod and interferon/glatiramer therapies in a switch population using propensitymatched data from MSBase. ECTRIMS, Copenhagen, Denmark, 2-5 October 2013, 2013 [accessed 17 February 2015, at $<$ http://registration.akm.ch/einsicht.php?XNABSTRACT_ID=178930\&XNSPRACHE_ID=2\&XNKONG RESS_ID=195\&XNMASKEN_ID=900>].

Spelman T, Gray O, Trojano M, Petersen T, Izquierdo G, Lugaresi A, et al. Seasonal variation of relapse rate in multiple sclerosis is latitude dependent. Ann Neurol. 2014;76:880-90.

Spelman T, Kalincik T, Zhang A, Pellegrini F, Wiendl H, Kappos L, et al. Comparative efficacy of switching to natalizumab in active multiple sclerosis. Annals of clinical and translational neurology. 2015;2:373-87. 
This is an author's draft of an accepted article submitted and published in Multiple Sclerosis and Related Disorders

DOI : http://www.sciencedirect.com/science/article/pii/S221103481630102X

Stangel M, Penner IK, Kallmann BA, Lukas C, Kieseier BC. Towards the implementation of 'no evidence of disease activity' in multiple sclerosis treatment: the multiple sclerosis decision model. Therapeutic advances in neurological disorders. 2015;8:3-13.

Stern $Y$. What is cognitive reserve? Theory and research application of the reserve concept. Journal of the International Neuropsychological Society : JINS. 2002;8:448-60.

Sumowski JF, Chiaravalloti N, Wylie G, Deluca J. Cognitive reserve moderates the negative effect of brain atrophy on cognitive efficiency in multiple sclerosis. Journal of the International Neuropsychological Society : JINS. 2009;15:606-12.

Sumowski JF, Rocca MA, Leavitt VM, Dackovic J, Mesaros S, Drulovic J, et al. Brain reserve and cognitive reserve protect against cognitive decline over 4.5 years in MS. Neurology. 2014;82:177683.

Sumowski JF, Rocca MA, Leavitt VM, Riccitelli G, Comi G, DeLuca J, et al. Brain reserve and cognitive reserve in multiple sclerosis: what you've got and how you use it. Neurology. 2013;80:218693.

Sumowski JF, Wylie GR, Chiaravalloti N, DeLuca J. Intellectual enrichment lessens the effect of brain atrophy on learning and memory in multiple sclerosis. Neurology. 2010;74:1942-5.

Svenningsson A, Falk E, Celius EG, Fuchs S, Schreiber K, Berko S, et al. Natalizumab treatment reduces fatigue in multiple sclerosis. Results from the TYNERGY trial; a study in the real life setting. PloS one. 2013;8:e58643.

Swanton JK, Rovira A, Tintore M, Altmann DR, Barkhof F, Filippi M, et al. MRI criteria for multiple sclerosis in patients presenting with clinically isolated syndromes: a multicentre retrospective study. The Lancet Neurology. 2007;6:677-86.

Swiss Multiple Sclerosis Society. From disability to ability at work: successful case management approaches in multiple sclerosis. Swiss Multiple Sclerosis Society; 2011 [accessed 24 April 2015, at $<$ https://www.multiplesklerose.ch/sites/default/files/shop/documents/casemanagement_en.pdf>].

Tedeholm H, Lycke J, Skoog B, Lisovskaja V, Hillert J, Dahle C, et al. Time to secondary progression in patients with multiple sclerosis who were treated with first generation immunomodulating drugs. Multiple sclerosis (Houndmills, Basingstoke, England). 2013;19:765-74.

Tettey P, Simpson S, Jr., Taylor BV, van der Mei IA. Vascular comorbidities in the onset and progression of multiple sclerosis. Journal of the neurological sciences. 2014;347:23-33.

Tintore M, Rovira A, Rio J, Nos C, Grive E, Sastre-Garriga J, et al. New diagnostic criteria for multiple sclerosis: application in first demyelinating episode. Neurology. 2003;60:27-30.

Tisserand DJ, Bosma H, Van Boxtel MP, Jolles J. Head size and cognitive ability in nondemented older adults are related. Neurology. 2001;56:969-71.

Torkildsen O, Aarseth J, Benjaminsen E, Celius E, Holmoy T, Kampman MT, et al. Month of birth and risk of multiple sclerosis: confounding and adjustments. Annals of clinical and translational neurology. 2014;1:141-4.

Torkildsen O, Grytten N, Aarseth J, Myhr KM, Kampman MT. Month of birth as a risk factor for multiple sclerosis: an update. Acta neurologica Scandinavica Supplementum. 2012;126 Suppl 195:58-62.

Tornatore C, Phillips JT, Khan O, Miller AE, Barnes CJ. Practice patterns of US neurologists in patients with CIS, RRMS, or RIS: a consensus study. Neurology Clinical practice. 2012;2:48-57. 
This is an author's draft of an accepted article submitted and

published in Multiple Sclerosis and Related Disorders

DOI : http://www.sciencedirect.com/science/article/pii/S221103481630102X

Traboulsee A, Letourneau-Guillon L, Freedman MS, O'Connor PW, Bharatha A, Chakraborty S, et al. Canadian expert panel recommendations for MRI use in MS diagnosis and monitoring. Can J Neurol Sci. 2015;42:159-67.

Tramo MJ, Loftus WC, Stukel TA, Green RL, Weaver JB, Gazzaniga MS. Brain size, head size, and intelligence quotient in monozygotic twins. Neurology. 1998;50:1246-52.

Trapp BD, Ransohoff R, Rudick R. Axonal pathology in multiple sclerosis: relationship to neurologic disability. Current opinion in neurology. 1999;12:295-302.

Trojano M, Pellegrini F, Fuiani A, Paolicelli D, Zipoli V, Zimatore GB, et al. New natural history of interferon-beta-treated relapsing multiple sclerosis. Ann Neurol. 2007;61:300-6.

Trojano M, Pellegrini F, Paolicelli D, Fuiani A, Zimatore GB, Tortorella C, et al. Real-life impact of early interferon beta therapy in relapsing multiple sclerosis. Ann Neurol. 2009;66:513-20.

Turner AP, Sloan AP, Kivlahan DR, Haselkorn JK. Telephone counseling and home telehealth monitoring to improve medication adherence: results of a pilot trial among individuals with multiple sclerosis. Rehabilitation psychology. 2014;59:136-46.

Uher T, Horakova D, Bergsland N, Tyblova M, Ramasamy DP, Seidl Z, et al. MRI correlates of disability progression in patients with CIS over 48 months. Neurolmage Clinical. 2014;6:312-19.

Utz KS, Hoog J, Wentrup A, Berg S, Lammer A, Jainsch B, et al. Patient preferences for diseasemodifying drugs in multiple sclerosis therapy: a choice-based conjoint analysis. Therapeutic advances in neurological disorders. 2014;7:263-75.

Visser LH, van der Zande A. Reasons patients give to use or not to use immunomodulating agents for multiple sclerosis. Eur J Neurol. 2011;18:1343-9.

Walling AD, Dickson G. Guillain-Barre syndrome. American family physician. 2013;87:191-7.

Weiner HL. The challenge of multiple sclerosis: how do we cure a chronic heterogeneous disease? Ann Neurol. 2009;65:239-48.

Weinstein MC, Torrance G, McGuire A. QALYs: the basics. Value in health : the journal of the International Society for Pharmacoeconomics and Outcomes Research. 2009;12 Suppl 1:S5-9.

While A, Forbes A, Ullman R, Mathes L. The role of specialist and general nurses working with people with multiple sclerosis. J Clin Nurs. 2009;18:2635-48.

Willer CJ, Dyment DA, Risch NJ, Sadovnick AD, Ebers GC. Twin concordance and sibling recurrence rates in multiple sclerosis. Proc Natl Acad Sci U S A. 2003;100:12877-82.

Willis H, Webster J, Larkin AM, Parkes L. An observational, retrospective, UK and Ireland audit of patient adherence to subcutaneous interferon beta-1a injections using the RebiSmart((R)) injection device. Patient preference and adherence. 2014;8:843-51.

Wilsdon T, Barron A, Mitchell-Heggs A, Ginoza S. Access to medicines for multiple sclerosis: challenges and opportunities. Charles River Associates; 2013 [accessed 20 January 2015, at $<$ http://crai.com/sites/default/files/publications/CRA-Biogen-Access-to-MS-Treatment-FinalReport.pdf>].

Wilson L, Loucks A, Bui C, Gipson G, Zhong L, Schwartzburg A, et al. Patient centered decision making: use of conjoint analysis to determine risk-benefit trade-offs for preference sensitive treatment choices. Journal of the neurological sciences. 2014;344:80-7. 
This is an author's draft of an accepted article submitted and published in Multiple Sclerosis and Related Disorders

DOI : http://www.sciencedirect.com/science/article/pii/S221103481630102X

Winslow A. MS Nurse PROfessional. European Multiple Sclerosis Platform Conference, Warsaw, Poland, 15-16 May 20152015 [accessed 3 June 2015, at <http://www.emsp.org/attachments/article/304/MS\%20Nurse\%20PRO\%20Summary,\%20Anne\%20Wi nslow.pdf $>$ ].

Wood J, Wallin M, Finkelstein J. Can a low-cost webcam be used for a remote neurological exam? Studies in health technology and informatics. 2013;190:30-2.

World Bank. Country and lending groups. World Bank; 2015a [accessed 31 March 2015, at $<$ http://data.worldbank.org/about/country-and-lending-groups>].

World Bank. Data: population, total. World Bank; 2015b [accessed 9 February 2015, at $<$ http://data.worldbank.org/indicator/SP.POP.TOTL>].

World Federation of Neurology. World Brain Alliance.2015 [accessed 3 June 2015, at <http://www.wfneurology.org/world-brain-alliance>].

World Health Organization. Atlas multiple sclerosis resources in the world 2008. World Health Organization; 2008 [accessed 19 January 2015, at <http://www.who.int/mental_health/neurology/Atlas_MS_WEB.pdf>].

World Health Organization. Health expenditure per capita, data by country. World Health Organization; 2015 [accessed 23 January 2015, at <http://apps.who.int/gho/athena/data/download.xsl?format=xml\&target=GHO/WHS7_156,WHS7_105, WHS7_104,WHS7_108\&profile=excel\&filter=COUNTRY:*;REGION:*>].

Wu M, Sirota M, Butte AJ, Chen B. Characteristics of drug combination therapy in oncology by analyzing clinical trial data on ClinicalTrials.gov. Pacific Symposium on Biocomputing Pacific Symposium on Biocomputing. 2015:68-79.

Yamout B, Alroughani R, Al-Jumah M, Goueider R, Dahdaleh M, Inshasi J, et al. Consensus recommendations for the diagnosis and treatment of multiple sclerosis: the Middle East North Africa Committee for Treatment and Research In Multiple Sclerosis (MENACTRIMS). Curr Med Res Opin. 2015;31:1349-61.

Zhang T, Shirani A, Zhao Y, Karim ME, Gustafson P, Petkau J, et al. Beta-interferon exposure and onset of secondary progressive multiple sclerosis. Eur J Neurol. 2015;22:990-1000.

Zipoli V, Portaccio E, Siracusa G, Pracucci G, Sorbi S, Amato MP. Interobserver agreement on Poser's and the new McDonald's diagnostic criteria for multiple sclerosis. Multiple sclerosis (Houndmills, Basingstoke, England). 2003;9:481-5.

Zissman K, Lejbkowicz I, Miller A. Telemedicine for multiple sclerosis patients: assessment using Health Value Compass. Multiple sclerosis (Houndmills, Basingstoke, England). 2012;18:472-80.

Zivadinov R, Yella V, Dwyer MG, Hussein S, J.L. C. Evidence for cortical atrophy in patients with clinically isolated syndrome. Multiple sclerosis (Houndmills, Basingstoke, England). 2006;12 (Suppl 1):s1-228.

Zwibel HL, Smrtka J. Improving quality of life in multiple sclerosis: an unmet need. The American journal of managed care. 2011;17 Suppl 5:s139-45. 